This is a preprint of a manuscript that has been accepted for publication, after peer review, at Geochimica et Cosmochimica Acta.

The final published version of this manuscript may have slightly different content, and is also available via DOI:XXXX.

February 7, 2021 


\title{
Differences in carbon isotope discrimination between angiosperm and gymnosperm woody plants, and their geological significance
}

\author{
Vincent J. Hare ${ }^{\mathrm{a}, \mathrm{b}, *}$, Aliénor Lavergne ${ }^{\mathrm{b}}$ \\ ${ }^{a}$ Stable Light Isotope Laboratory, Department of Archaeology, University of Cape Town, South Africa \\ ${ }^{b}$ Carbon Cycle Research Group, Department of Physics, Imperial College London, UK
}

\section{Abstract}

For most of the Phanerozoic Eon, Earth's woody vegetation has been dominated by $\mathrm{C}_{3}$ plants - predominantly gymnosperms - with angiosperms only emerging as the dominant plant group as $\mathrm{CO}_{2}$ declined during the Cenozoic (66 Ma onward). At present, differences in carbon isotope discrimination $\left(\Delta^{13} \mathrm{C}\right)$ between angiosperm and gymnosperm plants are relatively small (2-3\%), but an increasing body of evidence points to larger differences across geological times (up to 6-7\%), potentially associated with varying environmental conditions and atmospheres (i.e. concentrations of atmospheric carbon dioxide, $\left[\mathrm{CO}_{2}\right]$, and oxygen, $\left[\mathrm{O}_{2}\right]$ could have ranged from $\sim 180$ to $1100 \mathrm{ppm}$, and $\sim 15$ to $25 \%$, respectively, across the past $250 \mathrm{Ma}$ ). Yet, differences in $\Delta^{13} \mathrm{C}$ between the two plant groups, and their potential link to climatic and environmental changes, have not yet been fully explored and understood. Here, we combine a comprehensive $a b$ initio model of discrimination, with a recent model of plant eco-physiology based on least-cost optimality theory, to show how differences in $\Delta^{13} \mathrm{C}$ between angiosperms and gymnosperms arise. We train the comprehensive model using a very large $(n>7000)$ database of leaf and tree ring data spanning the past 110 years. We find that averaged differences in $\Delta^{13} \mathrm{C}$ between angiosperm and gymnosperms decrease modestly with atmospheric $\left[\mathrm{O}_{2}\right]:\left[\mathrm{CO}_{2}\right]$ ratios, and increase strongly with vapor pressure deficit $(D)$. These relationships can be explained by three key physiological differences: (1) the ratio of cost factors for transpiration to carboxylation (higher in angiosperms); (2) the ratio of mesophyll to stomatal conductances of $\mathrm{CO}_{2}$ (lower in gymnosperms); and (3) differences in photorespiration. In particular, the amount of $\mathrm{CO}_{2}$ released from photorespiration per oxygenation reaction, $\lambda$, is generally lower in gymnosperms than in angiosperms. As a result of these factors, $\Delta^{13} \mathrm{C}$ is more sensitive to $\left[\mathrm{CO}_{2}\right]$ in angiosperms, and to $D$ in gymnosperms. We propose a simplified empirical model to account for this behaviour, and test it against isotopic data from leaves, tree rings and previously-published plant chamber experiments, along with geological data from the Cenozoic. Overall, these data agree with our model over a range of $\left[\mathrm{O}_{2}\right]:\left[\mathrm{CO}_{2}\right]$ ratios from 100 to $650 \mathrm{~mol} \mathrm{~mol}^{-1}$ (equivalent to a $\mathrm{CO}_{2}$ range around $323-525 \mathrm{ppm}$ at $\left.21 \% \mathrm{O}_{2}\right)$, and $D$ levels between 0.45 and $1.1 \mathrm{kPa}\left(\mathrm{R}^{2}=0.51\right.$, $\left.\mathrm{RMSE}=1.49 \%\right)$. Our simplified empirical model offers a new explanation for secular trends in the geological record, and suggests a way forward to improve paleo- $\left[\mathrm{CO}_{2}\right]$ proxies based on terrestrial discrimination models by incorporating the effects of

\footnotetext{
* Corresponding author

Email address: vincent.john.hare@gmail.com (Vincent J. Hare)
} 
$\left[\mathrm{O}_{2}\right]$, phylogeny, and photorespiration. Lastly, the framework predicts that the average difference in $\Delta^{13} \mathrm{C}$ between woody $\mathrm{C}_{3}$ plant groups will increase in the future if both $\left[\mathrm{CO}_{2}\right]$ and global $D$ continue to rise as suggested by projections.

Keywords: carbon isotope discrimination - $\mathrm{C}_{3}$ photosynthesis - gymnosperms - angiosperms - atmospheric $\mathrm{CO}_{2}$ atmospheric $\mathrm{O}_{2}$ - paleo-proxies

\section{Introduction}

During photosynthesis, terrestrial plants fix atmospheric carbon dioxide $\left(\mathrm{CO}_{2}\right)$ into the simple sugars they need to grow, a process which sustains almost all life on Earth. In all vascular $\mathrm{C}_{3}$ plants, $\mathrm{CO}_{2}$ first enters the leaf through the stomata, before diffusing to the sites of carboxylation in the chloroplast. At each step along the pathway of carbon from the atmosphere to the leaf sugars, plants discriminate strongly against the heaviest stable carbon isotope $\left({ }^{13} \mathrm{C}\right)$, leading to a substantial difference between the stable carbon isotope compositions $\left(\delta^{13} \mathrm{C}\right)$ of the source atmospheric $\mathrm{CO}_{2}\left(\delta^{13} \mathrm{CO}_{2}\right)$, and of the carbon fixed within the leaf $\left(\delta^{13} \mathrm{C}_{\text {leaf }}\right)$. This difference is commonly defined as the leaf-level carbon isotopic discrimination (referred to $\Delta^{13} \mathrm{C}$ ) and expressed in per mil (\%o) as:

$$
\Delta^{13} \mathrm{C}=\frac{\delta^{13} \mathrm{CO}_{2}-\delta^{13} \mathrm{C}_{\text {leaf }}}{1+\delta^{13} \mathrm{C}_{\text {leaf }} / 1000}
$$

The two dominant groups of woody $\mathrm{C}_{3}$ plants, i.e. angiosperms and gymnosperms, have different physiological traits, including distinct vascular structures and reproductive habits (e.g. exposed seeds versus seeds enclosed in fruit). There are also subtle, yet significant, differences in $\Delta^{13} \mathrm{C}$ between the two plant groups. Globally, modern leaf isotope data (e.g. Diefendorf et al. (2010)) show that angiosperms are 2-3\%o more depleted in ${ }^{13} \mathrm{C}$ than gymnosperms (see Fig. 1). This isotopic offset is observed in pre-industrial wood cellulose (Stuiver and Braziunas, 1987) and in modern tree rings of the same age growing in the same location and thus under the same conditions of evaporative demand and soil water availability (Leavitt and Newberry, 1992), which suggests that differences in $\Delta^{13} \mathrm{C}$ levels are primarily driven by physiology, as opposed to environment. However, this is clearly not always the case as the $\Delta^{13} \mathrm{C}$ offset tends to decrease with latitude/temperature gradients (Leavitt and Newberry, 1992; Stuiver and Braziunas, 1987; Pedentchouk et al., 2008). No single clear physiological or environmental factor is therefore responsible for differences in $\Delta^{13} \mathrm{C}$ between angiosperm and gymnosperm plants, and the reasons for the observed isotopic offsets between the two plant groups are yet to be fully explored and understood.

In addition to these factors, $\Delta^{13} \mathrm{C}$ values in gymnosperm and angiosperm plants are sensitive to changing atmospheric composition. Several emerging lines of evidence from $\delta^{13} \mathrm{C}$ data derived from tree rings (Voelker et al., 2016), cellulose and faunal collagen (Hare et al., 2018), species-specific lipid biomarkers (Schouten et al., 2007), and speleothems (Breecker, 2017), suggest that $\Delta^{13} \mathrm{C}$ in angiosperms and gymnosperms has responded differently to past changes in atmospheric $\mathrm{CO}_{2}$ concentration (hereafter $\left[\mathrm{CO}_{2}\right]$ ). Chamber experiments have also shown clear effects of changing $\mathrm{O}_{2}$ concentration, $\left[\mathrm{O}_{2}\right]$, on $\Delta^{13} \mathrm{C}$, depending on $\mathrm{C}_{3}$ phylogeny (Porter et al., 2017). Atmospheric $\left[\mathrm{O}_{2}\right]:\left[\mathrm{CO}_{2}\right]$ ratios have varied substantially since the radiation of gymnosperms in the Mesozoic Era (252 - $66 \mathrm{Ma})$, when $\left[\mathrm{CO}_{2}\right]$ was high $(>1000 \mathrm{ppm})$. During these times, $\left[\mathrm{O}_{2}\right]$ was generally higher than present-day 


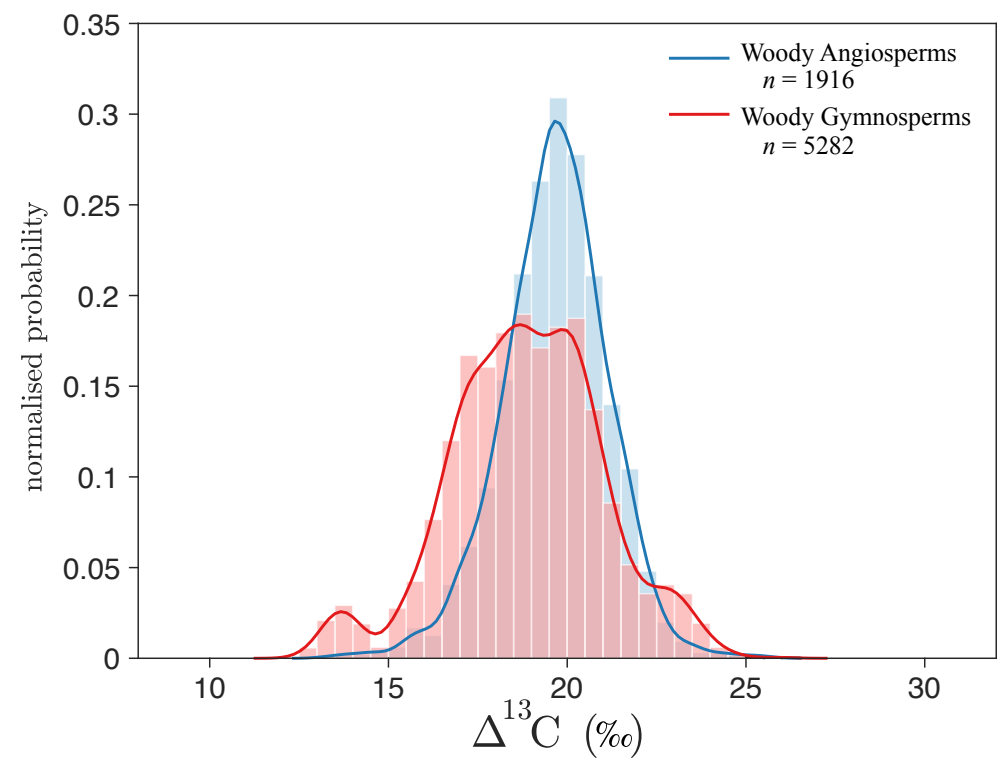

Figure 1: Distribution of carbon isotope discrimination in $\mathrm{C}_{3}$ woody angiosperm and gymnosperm plants, compiled from global bulk leaf and tree ring cellulose records (see Methods). Note: In this figure, tree ring cellulose $\delta^{13} \mathrm{C}$ values are corrected for post-photosynthetic fractionation by the subtraction of $2.1 \%$.

values of $21 \%$, perhaps as high as $29 \%$ (Mills et al., 2016). As $\left[\mathrm{CO}_{2}\right]$ declined over the Cenozoic (66 Ma onwards), angiosperms rapidly diversified to become the dominant land plant group. It is thought that the radiation of angiosperms coincided with important evolutionary adaptations to lower $\left[\mathrm{CO}_{2}\right]$ within this plant group; including a higher mesophyll conductance to $\mathrm{CO}_{2}$, denoted $g_{\mathrm{m}}$ (Yiotis and McElwain, 2019; Flexas and Carriquí, 2020), an increased vein density (De Boer et al., 2012), and more efficient stem hydraulic properties (Zanne et al., 2014). Concentrations of atmospheric $\mathrm{CO}_{2}$ regularly reached their geological minima, $\sim 180 \mathrm{ppm}$, during the Pleistocene ice ages (2.58 Ma to $11.7 \mathrm{ka}$ ) (Bereiter et al., 2015). Taken together, the full geological range of $\left[\mathrm{O}_{2}\right]:\left[\mathrm{CO}_{2}\right]$ ratios experienced by both gymnosperms and angiosperms over the Cenozoic is between approximately $150 \mathrm{~mol} \mathrm{~mol}^{-1}$ (Paleocene-Eocene Thermal Maximum, PETM; $56 \mathrm{Ma}$ ) and $1150 \mathrm{~mol} \mathrm{~mol}^{-1}$ (Last Glacial Maximum, LGM; $21 \mathrm{ka}$ ). This is a substantial range, and it is possible that these atmospheric changes led to differences in $\mathrm{C}_{3}$ plant discrimination, although the exact magnitudes of group-specific responses remain uncertain.

In geological contexts, it is generally assumed that isotope discrimination in $\mathrm{C}_{3}$ plants is independent of phylogeny. This implies that the offset in $\Delta^{13} \mathrm{C}$ between angiosperms and gymnosperms is more or less constant over time. As a result, offsets of 2-3\% between ancient tissues from each plant group are sometimes regarded as indications of fossil integrity, i.e. resistance to diagenesis (Diefendorf et al., 2015; Schlanser et al., 2020). However, emerging evidence suggests that isotope discrimination might vary between different $C_{3}$ plant groups (Sheldon et al., 2020), and substantial changes in the difference of $\Delta^{13} \mathrm{C}$ values between angiosperms and gymnosperms are occasionally observed in the geological record. For instance, this offset ranged from less than $-3 \%$ (Diefendorf et al., 2015) to greater than $+4 \%$ (Schouten et al., 2007; Schlanser et al., 2020) before, during, and after the extreme climate states of the PETM. Some of these changes have been explained by differences in plant water-use efficiency (WUE), i.e. the ratio of carbon assimilated to water transpired, which is intrinsically coupled to leaf-level discrimination 
(Soh et al., 2019; Lavergne et al., 2019). On the other hand, they could also be explained by diagenesis, or variability in post-photosynthetic fractionations, particularly in the case of plant lipids (Diefendorf et al., 2019). Underlying all these explanations, it is also plausible that a substantial proportion of these changes was driven by fundamental physiological differences between the two plant groups, modulated by atmospheric $\left[\mathrm{O}_{2}\right]:\left[\mathrm{CO}_{2}\right]$ ratios. Thus, no satisfactory unifying framework yet exists to explain the variability observed in the geological record; a full understanding of the drivers responsible for the different plant responses between $\mathrm{C}_{3}$ groups is still needed.

The aim of this study is to propose a model for isotope discrimination in $\mathrm{C}_{3}$ plants that can account for differences in phylogeny, and that can reasonably explain variations in the geological record. First, we examine the impact of plant physiology on $\Delta^{13} \mathrm{C}$ among the two groups by combining a comprehensive ab initio model of leaf discrimination, with a stomatal model based on the least-cost optimality hypothesis (Prentice et al., 2014). The optimal model has been used for exploring stomatal responses to the environment as recorded in modern isotopic samples derived from $\mathrm{C}_{3}$ plants (Wang et al., 2017; Lavergne et al., 2020a), but its application to geological timescales is novel. We then train the coupled stomatal-discrimination model against a large literature compilation of $\Delta^{13} \mathrm{C}$ measures derived from tree ring and leaf samples spanning the $20^{\text {th }}$ century to identify the key parameters that give rise to the different physiological responses between angiosperms and gymnosperms. We then investigate how the difference in $\Delta^{13} \mathrm{C}$ values between the two plant groups can be explained and predicted from environmental factors such as vapor pressure deficit $(D)$, and from changes in atmospheric $\left[\mathrm{O}_{2}\right]:\left[\mathrm{CO}_{2}\right]$ ratios. We then compare our predictions with isotopic data derived from leaves, tree-rings, plant chamber experiments, and ultimately geological data.

Finally, we discuss the implications of our findings for the interpretation of the geological record and for the reconstruction of paleo- $\left[\mathrm{CO}_{2}\right]$. Models of $\mathrm{C}_{3}$ carbon isotope discrimination are routinely used to estimate paleo$\left[\mathrm{CO}_{2}\right]$ (Schubert and Jahren, 2012; Cui et al., 2020; Franks et al., 2014), but seldom account for differences between plant groups, changes in $D$, or $\left[\mathrm{O}_{2}\right]$ levels over time. Yet, all three effects might influence terrestrial paleo-proxies (Porter et al., 2019; Hollis et al., 2019) and thereby affect estimates of the (paleo)climate sensitivity - the amount of warming experienced after a doubling of $\left[\mathrm{CO}_{2}\right]$ during geological times. Thus, our findings may ultimately contribute to ongoing efforts to better constrain paleo- $\left[\mathrm{CO}_{2}\right]$ reconstructions and thus predict more accurately the (paleo)climate sensitivity.

\section{Theory}

Farquhar et al. (1982) proposed a mathematical description of the discrimination against ${ }^{13} \mathrm{C}$, based on a model used to describe the biochemistry of $\mathrm{CO}_{2}$ assimilation in $\mathrm{C}_{3}$ leaves - the 'FvCB' model (Farquhar et al., 1980). Both the FvCB model and the corresponding discrimination model are foundational to our understanding of $\mathrm{C}_{3}$ photosynthesis, having been applied to a wide range of scientific questions in plant eco-physiology, paleoecology and geochemistry. In addition, the FvCB model has been widely used in Earth System modeling to predict the rate of carbon assimilation (A) by plants, and thus to study the carbon cycle. A comprehensive ab initio description of 
bulk leaf discrimination derived from Farquhar et al. (1982) can be written following Busch et al. (2020):

$$
\begin{aligned}
\Delta^{13} \mathrm{C}= & \frac{1}{1-t}\left[a_{\mathrm{b}} \frac{C_{\mathrm{a}}-C_{\mathrm{s}}}{C_{\mathrm{a}}}+a_{\mathrm{s}} \frac{C_{\mathrm{a}}-C_{\mathrm{s}}}{C_{\mathrm{a}}}\right] \\
& +\frac{1+t}{1-t}\left[a_{\mathrm{m}} \frac{C_{\mathrm{i}}-C_{\mathrm{c}}}{C_{\mathrm{a}}}+b \frac{C_{\mathrm{c}}}{C_{\mathrm{a}}}-\frac{R_{\mathrm{d}}}{A} \frac{\alpha_{\mathrm{b}}}{\alpha_{\mathrm{e}} \alpha_{\mathrm{R}}} e \frac{C_{\mathrm{c}}}{C_{\mathrm{a}}}-\frac{\alpha_{\mathrm{b}}}{\alpha_{\mathrm{f}} \alpha_{\mathrm{R}}} \frac{\Gamma^{*}}{C_{\mathrm{a}}}(f-w h)\right]
\end{aligned}
$$

$C_{\mathrm{a}}, C_{\mathrm{s}}, C_{\mathrm{i}}$, and $C_{\mathrm{c}}$ are the concentrations of $\mathrm{CO}_{2}$ along the $\mathrm{CO}_{2}$ diffusion pathway, i.e., in the atmosphere, the leaf surface, the intercellular space and the chloroplast, respectively, while $a_{\mathrm{b}}, a_{\mathrm{s}}, a_{\mathrm{m}}$, and $b$, are the fractionations associated with the $\mathrm{CO}_{2}$ diffusion though the boundary layer (2.9\%), stomata (4.4\%), and mesophyll (1.8\%), and carboxylation by the enzyme Rubisco (30\%), respectively. The values for the fractionations are relatively wellconstrained from theory (Craig, 1954) as well as in vitro experiments and molecular dynamics simulations (see discussion in Ubierna and Farquhar (2014)). By comparison, the fractionations due to mitochondrial respiration, $e$, and photorespiration, $f$, are relatively poorly constrained. $e$ is often regarded as negligible (e.g. Ghashghaie et al. (2003)), and literature values of $f$ range from 7 to $19.2 \%$ (Schubert and Jahren, 2018), with a theoretical value of around 11\% (Tcherkez, 2006).

$h$ is the apparent fractionation associated with several processes such as starch formation, and the export of 3phosphoglyceraldehyde (3-PG) and is currently difficult to constrain (Busch et al., 2020). $w$ is a factor given by $\left(6 C_{\mathrm{c}}+9 \Gamma^{*}\right) /\left(5 C_{\mathrm{c}}+10 \Gamma^{*}\right)$, which is approximately 1.1 , at typical values of $C_{\mathrm{c}}$ and $\Gamma^{*} . t$ is the ternary correction factor depending on the rate of transpiration and the conductance to $\mathrm{CO}_{2}$ diffusion in air (Farquhar and Cernusak (2012)), and $\alpha_{i}$ values ( $i=\mathrm{a}, \mathrm{b}, \mathrm{f}$, and e) are the formal fractionation factors associated with the respective processes (i.e., diffusion, carboxylation, mitochondrial respiration and photorespiration, respectively). $R_{\mathrm{d}}$ is the rate of mitochondrial respiration and $\Gamma^{*}$ is the photorespiratory compensation point in absence of mitochondrial respiration, i.e., the value of $C_{\mathrm{i}}$ at which the rate of photosynthetic $\mathrm{CO}_{2}$ uptake equals that of photorespiratory $\mathrm{CO}_{2}$ evolution. A full list of variables, and their respective definitions, can be found in Table 1.

In its full form, Eqn. (2) is not easily applied to the geological record because of uncertainties in the values of some terms in the equation. Assuming that both ternary and respiration effects are negligible $(t \approx 0$ and $e \approx 0)$ and that $\alpha_{i} \approx 1$, Ubierna and Farquhar (2014) proposed the following approximation that is applicable in a broad range of environmental conditions:

$$
\Delta^{13} \mathrm{C}=a_{\mathrm{s}}(1-\chi)+a_{\mathrm{m}}\left(\chi-\chi_{\mathrm{c}}\right)+b \chi_{\mathrm{c}}-(f-w h) \frac{\Gamma^{*}}{C_{\mathrm{a}}}
$$

where we adopt the notation $\chi=C_{\mathrm{i}} / C_{\mathrm{a}}$, and $\chi_{\mathrm{c}}=C_{\mathrm{c}} / C_{\mathrm{a}}$. Note that we have slightly modified the original equation to retain the $w$ and $h$ terms proposed by Busch et al. (2020). This equation is more mathematically tractable than Eqn. (2), and accurate for a first order understanding of plant $\Delta^{13} \mathrm{C}$, because it includes fractionations associated with photorespiration and $\mathrm{CO}_{2}$ diffusion in the mesophyll which are critical for reproducing the observed global trends in atmospheric $\delta^{13} \mathrm{C}$ during the $20^{\text {th }}$ century (Keeling et al., 2017). The non-negligible photorespiratory effect on the discrimination is also increasingly acknowledged in plant chamber studies (Schubert and Jahren, 2018; Zhang et al., 2019; Porter et al., 2019). At current $\mathrm{CO}_{2}$ levels ( 410 ppm), the photorespiration term in Eqn. (3) contributes only slightly to isotope discrimination, e.g. $<1 \%$ at a typical $\Gamma^{*}$ of $\sim 3.2 \mathrm{~Pa}$, at $20^{\circ} \mathrm{C}$ (value from 
Bernacchi et al. (2002)), assuming $h$ is negligible. However, its contribution increases at lower $\mathrm{CO}_{2}$ concentrations, and/or higher $\Gamma^{*}$ (higher leaf temperature). Because Rubisco has an affinity for both $\mathrm{O}_{2}$ and $\mathrm{CO}_{2}, \Gamma^{*}$ also depends on the oxygen concentration in the chloroplast, $\mathrm{O}_{\mathrm{c}}$, and on the amount of $\mathrm{CO}_{2}$ released from photorespiration per oxygenation reaction - a variable defined by Busch (2020) as $\lambda$. The relationship between these variables can be written as:

$$
\Gamma^{*}=\frac{\lambda \mathrm{O}_{\mathrm{c}}}{S_{\mathrm{c} / \mathrm{o}}}
$$

where $S_{\mathrm{c} / \mathrm{o}}$ is the Rubisco specificity factor. Emerging studies (e.g. Busch et al. (2018)) have shown that $\lambda$ depends on the relative proportions of glycine and 5,10-methylene tetrahydrofolate $\left(\mathrm{CH}_{2}-\mathrm{THF}\right)$ exported from the photorespiratory pathway. Glycine is an important building block of compounds manufactured by plants under stress, and $\mathrm{CH}_{2}$-THF is the chemical precursor of lignin and many other secondary products. Typically, $\lambda$ is around 0.5 (corresponding to $25 \%$ of the 2-phosphoglycerate carbon lost as $\mathrm{CO}_{2}$ ), but as the relative proportion of these components change, so too does $\lambda$ - and the discimination against ${ }^{13} \mathrm{C}$ due to photorespiration.

Incorporating mesophyll effects, and retaining the photorespiration terms (see full derivation in Electronic Annexure), Eq. (3) can be rewritten more succinctly as:

$$
\Delta^{13} \mathrm{C}=\bar{a}+[b-\bar{a}] \chi_{\mathrm{c}}-(f-w h) \frac{\Gamma_{\mathrm{c}}^{*}}{C_{\mathrm{a}}}
$$

where $\bar{a}=\left(a_{\mathrm{s}} \theta_{\mathrm{m}}+a_{\mathrm{m}}\right) /\left(1+\theta_{\mathrm{m}}\right)$ and $\theta_{\mathrm{m}}$ is the ratio of mesophyll conductance to stomatal conductance $\left(g_{\mathrm{m}} / g_{\mathrm{s}}\right)$. $\bar{a}$ thus represents all the fractionation processes during the $\mathrm{CO}_{2}$ diffusion along the pathway from the atmosphere to the site of photosynthesis (chloroplast). Note that if the photorespiration is assumed negligible, and the mesophyll conductance is assumed infinite (i.e. $\chi_{\mathrm{c}}=\chi$ ), Eqn. (5) can be rewritten as: $\Delta^{13} \mathrm{C} \approx a_{\mathrm{s}}+\left(b-a_{\mathrm{s}}\right) \chi$. This simple formulation has been widely used in the literature for modern and paleo studies (see also Lavergne et al. (2019), and Hare et al. (2018)).

Eqn. (5) offers a more complete formalism than its simplest version, but lacks an expression for the $\chi_{\mathrm{c}}$ term. A theoretical model for $\chi_{c}$ was recently derived by Wang et al. (2017) using an evolutionary optimality approach that assumes that $\mathrm{C}_{3}$ land plants minimise the summed unit costs of transpiration and carboxylation. In this framework, $\chi_{\mathrm{c}}$ depends on $C_{\mathrm{a}}$, the daytime leaf temperature $\left(T_{\mathrm{d}},{ }^{\circ} \mathrm{C}\right)$, the leaf-to-air vapour pressure deficit $(D, \mathrm{kPa})$, and the ratio of cost factors for carboxylation to transpiration at $25^{\circ} \mathrm{C}\left(\beta_{\mathrm{c}}\right.$, unitless), as:

$$
\chi_{\mathrm{c}}=\frac{\Gamma_{\mathrm{c}}^{*}}{C_{\mathrm{a}}}+\left(1-\frac{\Gamma_{\mathrm{c}}^{*}}{C_{\mathrm{a}}}\right) \frac{\xi_{\mathrm{c}}}{\xi_{\mathrm{c}}+\sqrt{D}}
$$

where

$$
\xi_{\mathrm{c}}^{2}=\left[\beta_{\mathrm{c}}\left(K+\Gamma_{\mathrm{c}}^{*}\right)\right] /\left[1.6 \eta^{*}\left(1+1 / \theta_{\mathrm{m}}\right)\right]
$$

$\eta^{*}$ (unitless) is the viscosity of water relative to its value at $25^{\circ} \mathrm{C}$ and $K(\mathrm{~Pa})$ is the effective Michaelis constant for Rubisco-limited photosynthesis at ambient partial pressure of $\mathrm{O}_{2}(\mathrm{~Pa})$. Note that Eqn. (6) implicitly links both $D$ 
Table 1: List of symbols used in this study, and their definitions.

\begin{tabular}{|c|c|c|}
\hline Variables (units) & Description & Refs. \\
\hline$\Delta^{13} \mathrm{C}(\%)$ & leaf-level carbon isotope discrimination & $1,2,3$ \\
\hline$\Delta^{13} \mathrm{C}_{\mathrm{a}-\mathrm{g}}^{*}(\%)$ & difference between average co-located angiosperm and gymnosperm $\Delta^{13} \mathrm{C}$ at constant $T_{\mathrm{d}}, P_{\text {atm }}, \& D$ & this study \\
\hline$\varepsilon_{\text {lipid }}(\%)$ & post-photosynthetic fractionation during biosynthesis of leaf lipids & 4,5 \\
\hline$\varepsilon_{\text {cellulose }}(\%)$ & post-photosynthetic fractionation during biosynthesis of cellulose & 6,7 \\
\hline$t$ & ternary correction factor & $1,2,3$ \\
\hline$a_{\mathrm{s}}, a_{\mathrm{m}}(\%)$ & fractionations for $\mathrm{CO}_{2}$ diffusion in air, $4.4 \%$, and water, $1.8 \%$ & 8,1 \\
\hline$b(\%)$ & fractionation during Rubisco carboxylation, $30 \%$ & 1 \\
\hline$f(\%)$ & fractionation during photorespiration, 7-19.2\% (theoretical: 11\%) & 9 \\
\hline$h(\%)$ & $\begin{array}{l}\text { apparent fractionation resulting from starch formation, and/or the kinetic fractionation associated with the } \\
\text { export of triose phosphates (TP) from the chloroplast, and/or enzymes such as aldolase, transaldolase, } \\
\text { transketolase and TP isomerase }\end{array}$ & 3 \\
\hline$w$ (unitless) & coefficient of $h$ in $f-w h$ & 3 \\
\hline $\begin{array}{l}\alpha_{b} ; \alpha_{e} ; \alpha_{f} \text { (unit- } \\
\text { less) }\end{array}$ & $\begin{array}{l}\text { fractionation factors for }{ }^{13} \mathrm{C} /{ }^{12} \mathrm{C} \text { during carboxylation } \alpha_{b}=1+b \text {; respiration } \alpha_{e}=1+e ; \text { photorespiration } \\
\alpha_{f}=1+f\end{array}$ & 1 \\
\hline$\alpha_{h}$ (unitless) & as above, for $h$ & 3 \\
\hline$\lambda$ (unitless) & $\begin{array}{l}\text { amount of } \mathrm{CO}_{2} \text { released from photorespiration per oxygenation reaction, relative to that of } N \text {. tabacum at } \\
25^{\circ} \mathrm{C}\left(\lambda_{\text {ref }}\right)\end{array}$ & 10 \\
\hline$\lambda_{\mathrm{a}}, \lambda_{\mathrm{g}}$ (unitless) & average $\lambda$, woody angiosperms, woody gymnosperms & this study \\
\hline$\varepsilon_{f}$ (unitless) & gradient of the slope of $\Delta^{13} \mathrm{C}_{\mathrm{a}-\mathrm{g}}^{*}$ vs $\left[\mathrm{O}_{2}\right] /\left[\mathrm{CO}_{2}\right]$ at constant $T_{\mathrm{d}}$ & this study \\
\hline$\varepsilon_{a b}$ (unitless) & gradient of the slope of $\Delta^{13} \mathrm{C}_{\mathrm{a}-\mathrm{g}}^{*}$ vs $D$ at constant $T_{\mathrm{d}}$ & this study \\
\hline$\alpha_{\mathrm{G}} ; \alpha_{\mathrm{T}}$ (unitless) & $\begin{array}{l}\text { proportion of glycine removed from the photorespiratory pathway; proportion of 2-Phosphoglycolate carbon } \\
\text { exported as } \mathrm{CH}_{2} \text {-THF from the photorespiratory pathway }\end{array}$ & 11,10 \\
\hline$C_{\mathrm{a}}(\mathrm{Pa})$ & atmospheric $\mathrm{pCO}_{2}(\mathrm{~Pa})$, or as concentration $\left(\mu \mathrm{mol} \mathrm{mol}^{-1}\right)$ & \\
\hline$C_{\mathrm{S}}(\mathrm{Pa})$ & leaf-surface $\mathrm{pCO}_{2}(\mathrm{~Pa})$, or as concentration $\left(\mu \mathrm{mol} \mathrm{mol}^{-1}\right)$ & \\
\hline$C_{\mathrm{i}}(\mathrm{Pa})$ & leaf intercellular $\mathrm{pCO}_{2}(\mathrm{~Pa})$, or as concentration $\left(\mu \mathrm{mol} \mathrm{mol}^{-1}\right)$ & \\
\hline$C_{\mathrm{c}}(\mathrm{Pa})$ & chloroplastic $\mathrm{pCO}_{2}(\mathrm{~Pa})$, or as concentration $\left(\mu \mathrm{mol} \mathrm{mol}^{-1}\right)$ & \\
\hline $\mathrm{O}_{\mathrm{c}}\left(\mathrm{mol} \cdot \mathrm{mol}^{-1}\right)$ & chloroplastic oxygen concentration & \\
\hline$g_{s}\left(\mathrm{~mol} \mathrm{~m}{ }^{-2} \mathrm{~s}^{-1}\right)$ & stomatal conductance & 12,13 \\
\hline$g_{m}\left(\mathrm{~mol} \mathrm{~m}^{-2} \mathrm{~s}^{-1}\right)$ & mesophyll conductance & 12,13 \\
\hline$\beta_{\mathrm{c}}$ (unitless) & ratio of carboxylation to transpiration cost factors at $25^{\circ} \mathrm{C}$ & 14 \\
\hline$K_{\mathrm{c}}(\mathrm{Pa})$ & Michaelis-Menten coefficient of Rubisco carboxylation & 15 \\
\hline$K_{\mathrm{O}}(\mathrm{Pa})$ & Michaelis-Menten coefficient of Rubisco oxygenation & 15 \\
\hline$K(\mathrm{~Pa})$ & effective Michaelis-Menten coefficient of Rubisco & 15 \\
\hline$\Gamma_{\mathrm{c}}(\mathrm{Pa})$ & chloroplastic $\mathrm{CO}_{2}$ compensation point in the absence of mitochondrial respiration, when $A=0$ & 2 \\
\hline$\Gamma^{*}(\mathrm{~Pa})$ & chloroplastic $\mathrm{CO}_{2}$ compensation point, absence of mitochondrial respiration, when $A=-\mathcal{R}_{\mathrm{d}}$ & 2 \\
\hline$S_{\mathrm{c} / \mathrm{o}}\left(\mathrm{mol} \mathrm{mol}^{-1}\right)$ & Rubisco $\mathrm{CO}_{2} / \mathrm{O}_{2}$ specificity & 16 \\
\hline$T_{\mathrm{d}}\left({ }^{\circ} \mathrm{K}\right)$ & daytime leaf temperature & \\
\hline$D(\mathrm{kPa})$ & daytime vapour pressure deficit & \\
\hline$\left[\mathrm{O}_{2}\right]\left(\mathrm{mol} \mathrm{mol}^{-1}\right)$ & atmospheric oxygen concentration & \\
\hline$\left[\mathrm{CO}_{2}\right]\left(\mathrm{mol} \mathrm{mol}^{-1}\right)$ & atmospheric carbon dioxide concentration & \\
\hline
\end{tabular}

1. Ubierna and Farquhar (2014) 2. Ubierna et al. (2019) 3. Busch et al. (2020) 4.Diefendorf et al. (2012) 5. Diefendorf et al. (2019) 6. Frank et al. (2015) 7. Lavergne et al. (2020a) 8. Craig (1954) 9. Tcherkez (2006) 10. Busch (2020) 11. Busch et al. (2018) 12. Flexas and Carriquí (2020) 13. Yiotis and McElwain (2019) 14. Wang et al. (2017) 15. Bernacchi et al. (2002) 16. Galmés et al. (2016) 
and $C_{\mathrm{a}}$ to plant WUE, via the relationship between $\chi_{\mathrm{c}}$ and intrinsic WUE, i.e. iWUE $=\theta_{\mathrm{m}} /\left(1+\theta_{\mathrm{m}}\right) C_{\mathrm{a}}\left(1-\chi_{\mathrm{c}}\right) 1.6$ (Ehleringer et al., 1993; Soh et al., 2019; Lavergne et al., 2019).

What differences in discrimination are expected between the two $\mathrm{C}_{3}$ plant groups according to this theory? The terms in Equations (5-7) can be divided into three categories: (1) constants associated with kinetic fractionation $\left(a_{\mathrm{S}}\right.$, $\left.a_{\mathrm{m}}, b, f\right),(2)$ atmospheric and environmental variables $\left(D, C_{\mathrm{a}}\right.$ and $\left.\eta^{*}\right)$, and variables associated with the kinetics of Rubisco ( $K$ and $\Gamma^{*}$, both temperature- and atmospheric pressure-dependent); and finally, (3) plant-specific parameters related to vascular/leaf morphology $\left(\beta_{\mathrm{c}}\right.$ and $\left.g_{\mathrm{m}} / g_{\mathrm{s}}\right)$, and metabolism $(\lambda)$. Because Rubisco is common to all oxygenic phototrophs, and is thought to have suffered relatively little modification through geological times, it is reasonable to assume that differences in $\Delta^{13} \mathrm{C}$ between $\mathrm{C}_{3}$ plant groups arise from $\beta_{\mathrm{c}}, g_{\mathrm{m}} / g_{\mathrm{s}}$ and $\lambda$, modulated by site-specific environmental conditions. These three plant-specific parameters are unitless, and are assumed to be constant, independent of environmental changes.

Here, we first examine the expected values for $\beta_{\mathrm{c}}, g_{\mathrm{m}} / g_{\mathrm{s}}$, and $\lambda$ using a large compilation of leaf and tree ring $\Delta^{13} \mathrm{C}$ measurements, spanning a wide range of environments. We then perform sensitivity analyses using Eqns. (5-7) to determine the impacts of $T_{d}$ and $D$ variations on changes in $\Delta^{13} \mathrm{C}$, across the full range of Cenozoic $\left[\mathrm{O}_{2}\right]:\left[\mathrm{CO}_{2}\right]$ ratios. Finally, we propose a simple empirical model for describing the dependence of the offset in $\Delta^{13} \mathrm{C}$ values between angiosperm and gymnosperms upon $\left[\mathrm{O}_{2}\right]:\left[\mathrm{CO}_{2}\right]$ ratio, at any given $T_{d}$ and $D$.

\section{Methods}

\subsection{Compilation of tree ring and leaf stable carbon isotope measurements}

We used a large global dataset (the "training dataset") of leaf and tree ring $\delta^{13} \mathrm{C}$ measurements, developed and partly used elsewhere (Lavergne et al., 2020b), spanning the whole $20^{\text {th }}$ century $\left(\left[\mathrm{CO}_{2}\right]\right.$ ranging between 297 and $401 \mathrm{ppm}$ ). The leaf isotopic dataset was derived from three published compilations (Cornwell et al., 2016; Diefendorf et al., 2010; Sheldon et al., 2020), while the tree ring isotopic dataset was provided by Lavergne et al. (2020a). After removal of duplicate values, we used the TRY database (Kattge et al., 2020) to assign leaf phenology (deciduous/evergreen), plant vascular type (angiosperm/gymnosperm) and woodiness (woody/nonwoody plants) to each plant material. We only selected data from $\mathrm{C}_{3}$ woody plants for the analyses (total of $n=7098$ measurements with $n=1916$ for angiosperms and $n=5282$ for gymnosperms). Note that because the theory for $\Delta^{13} \mathrm{C}$ is only valid for well-mixed atmospheric $\delta^{13} \mathrm{CO}_{2}$, we excluded data showing the 'canopy effect', i.e. those from tropical closed-canopy locations, and/or $\delta^{13} \mathrm{C}<-30 \%$ (i.e. we adjusted the Kohn (2010) cutoff value of $-31.5 \%$ by $\sim 1.1 \%$ to account for the Suess effect). We corrected tree ring $\delta^{13} \mathrm{C}$ data for post-photosynthetic fractionations ( $\delta^{13} \mathrm{C}$ being more depleted in leaves than in tree rings, e.g. Cernusak et al. (2009)) using two different approaches, which we labelled correction "A" and correction "B". Correction "A" assumed a constant value for post-photosynthetic fractionation of $\varepsilon_{\text {cellulose }}=-2.1 \pm 1.2 \%$ as used in earlier studies (Frank et al., 2015; Lavergne et al., 2020a). Because the factors influencing post-photosynthetic fractionation are currently uncertain (Gessler

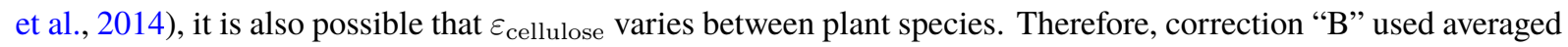
estimates of $\varepsilon_{\text {cellulose }}$ calculated from Guerrieri et al. (2016) and Guerrieri et al. (2019) data for each species (if 
available). The average correction "B" was $\varepsilon_{\text {cellulose,angio }}=-2.8 \%$ for angiosperms, and $\varepsilon_{\text {cellulose,gymno }}=-4.7$ $\%$ for gymnosperms.

\subsection{Atmospheric and environmental data}

To calculate $\Delta^{13} \mathrm{C}$ from $\delta^{13} \mathrm{C}$ values for our training dataset, we used mean annual $\delta^{13} \mathrm{CO}_{2}$ data from Graven et al. (2017). $\mathrm{CO}_{2}$ concentrations were taken from the compilation of Köhler et al. (2017), which is based on a spline interpolation of direct observations (yearly average), and ice core measurements. $\left[\mathrm{CO}_{2}\right]$ was converted from ppm to Pa using site elevation data obtained from high-resolution sources using the coordinates of the selected sites (e.g. NED1 (USGS) in North America, SRTM1 (NASA) in Europe). For each site, daytime growing season temperature, $T_{\mathrm{d}}$, and vapour pressure deficit, $D$, were calculated from monthly $0.5^{\circ}$ resolution historical climate data provided by the Climatic Research Unit (CRU TS4.03) (Harris et al., 2014). Note that the $T_{\mathrm{d}}$ values were adjusted to leaf values following Helliker and Richter (2008), i.e., sub-tropical to boreal leaf temperatures converging to $21.4 \pm 2.2$ ${ }^{\circ} \mathrm{C}$. Further details of these calculations can be found in Text S1 of Lavergne et al. (2020b), and in the Electronic Annexure.

\subsection{Estimation of plant-specific parameters}

To estimate the parameters $\beta_{\mathrm{c}}, g_{\mathrm{m}} / g_{\mathrm{s}}$ and $\lambda$, we employed a Markov chain Monte Carlo technique (MCMC) in MATLAB R2017b (Mathworks, Inc.), based on widely-used delayed rejection adaptive Metropolis (DRAM) algorithm of Haario et al. (2006). The approach was chosen because it allowed us to better incorporate prior constraints on parameters (for instance, leaf gas exchange measurements have shown that $g_{\mathrm{m}} / g_{\mathrm{s}}$ in gymnosperms range around 0.5-4.3 (Yiotis and McElwain, 2019)). Parameters for $\mathrm{C}_{3}$ woody angiosperms and gymnosperms were estimated using the training dataset (Section 3.1), but also using the tree ring and leaf data from the training dataset individually (the latter calibrated parameters are reported in the Electronic Annexure). In all cases, we considered a model of the form of Eqns. (5-7), with Gaussian errors, and constants $b=30 \%, a_{s}=4.4 \%$, $a_{m}=1.8 \%$ (Ubierna and Farquhar, 2014), $R=8.3145 \mathrm{~J} \mathrm{~mol}^{-1} \mathrm{~K}^{-1}$, and $f=11 \pm 4 \%$ (Tcherkez, 2006). In practice, we found that the best fit (lowest RMSE) was obtained using a value of $h=-1 \%$ for angiosperms, and $h=-10 \%$ for gymnosperms. Rubisco kinetic parameters measured on tobacco leaves were taken from Bernacchi et al. (2002). The estimated values of $\lambda$ for each plant vascular group were reported relative to that of

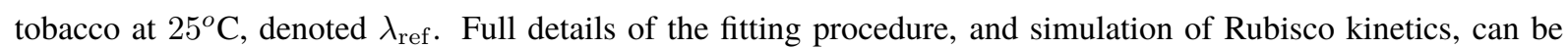
found in the Electronic Annexure.

\subsection{Simulations of plant $\Delta^{13} \mathrm{C}$ over variable $\left[\mathrm{O}_{2}\right]:\left[\mathrm{CO}_{2}\right]$ ratios, and comparison to tree ring and chamber isotopic data}

We simulated the expected responses of plant $\Delta^{13} \mathrm{C}$ to environmental changes across a range of $\left[\mathrm{O}_{2}\right]:\left[\mathrm{CO}_{2}\right]$ ratios spanning the Cenozoic era (66 Ma onwards) from $\sim 200$ (e.g. Paleogene) to $1200 \mathrm{~mol} \mathrm{~mol}^{-1}$ (e.g. LGM) using Eqns. (5-7) and our best-fit values for $\beta_{\mathrm{c}}, g_{\mathrm{m}} / g_{\mathrm{s}}$, and $\lambda / \lambda_{\text {ref. }}$. The simulations were performed at $20^{\circ} \mathrm{C}$ for two different levels of vapour pressure deficit: low $D(0.23 \mathrm{kPa})$ and high $D(1.54 \mathrm{kPa})$. Although this choice of $D$ levels may seem arbitrary, it encompasses a reasonably wide range of environments (optimal $D \sim 0.8 \mathrm{kPa}$ ). 
We then compared our results against our "testing dataset" which was comprised of averaged $\Delta^{13} \mathrm{C}$ differences calculated from the tree ring and leaf isotopic compilation, Cenozoic geological data from the available literature sources (Diefendorf et al., 2015; Bechtel et al., 2008, 2019; Schlanser et al., 2020; Schouten et al., 2007), and the chamber experiments data derived from Porter et al. (2017). The chamber experiments from the latter study were conducted on woody angiosperms and gymnosperms under conditions of variable $\left[\mathrm{O}_{2}\right]$ and $\left[\mathrm{CO}_{2}\right]$, i.e. ranging from 16 to $21 \%$ and from 428 to 1916 ppm, respectively. Note that for various reasons, we excluded these data from the training dataset to estimate the plant-specific parameters. These included potential uncertainties in chamber design (Porter et al., 2015), and estimation of chamber $\delta^{13} \mathrm{CO}_{2}$ values (Leavitt, 2001), which occasionally result in high variability of $\Delta^{13} \mathrm{C}$. In these previously-published chamber experiments, angiosperm and gymnosperm plants were grown at constant $T_{\mathrm{d}}$ and $D\left(20^{\circ} \mathrm{C}\right.$ and $0.82 \mathrm{kPa}$, respectively). In order to be comparable to our compilation, non-woody species (Z. aethiopica) from Porter et al. (2017) were excluded from our analysis, and we selected available tree ring data at the same $T_{\mathrm{d}}$ and $D$ levels. Tree ring data were averaged for $\left[\mathrm{O}_{2}\right] /\left[\mathrm{CO}_{2}\right]$ intervals of 10 mol mol ${ }^{-1}$ over the range $200-1200 \mathrm{~mol} \mathrm{~mol}^{-1}$, and for $D$ intervals of $0.5 \mathrm{kPa}$ over the range $0.4-1.0 \mathrm{kPa}$.

\section{Results}

\subsection{Plant-specific parameters for woody angiosperms and gymnosperms}

Significant differences between woody angiosperms and gymnosperms are identified in all three plant-specific parameters (see Table 2, Fig. 2). The best-fit values of $\beta_{\mathrm{c}}$ (combining leaf and tree ring datasets, correction "A") are $210 \pm 25(1 \sigma)$ for angiosperms and $147 \pm 10$ for gymnosperms. The value for angiosperms is in excellent agreement with that obtained by Lavergne et al. (2020b) using robust linear regressions (i.e. $211 \pm 1.8$ ), but that for gymnosperms is lower than the one obtained by the same study (i.e. $286 \pm 1.6$ ), and the value first estimated by Wang et al. (2017), i.e. 343.

For both corrections, $g_{\mathrm{m}} / g_{\mathrm{s}}$ is higher in angiosperms (e.g. $2.6 \pm 0.7$ ) than in gymnosperms (e.g. 0.98 \pm 0.10 ), with greater spread in the values for angiosperms. These general trends echo the findings of previous studies (Yiotis and McElwain, 2019; Flexas and Carriquí, 2020) showing higher $g_{\mathrm{m}}$ in angiosperms than in gymnosperms using leaf-gas exchange measurements. For instance, Yiotis and McElwain (2019) found $g_{\mathrm{m}} / g_{\mathrm{s}}$ values in the range $1.8 \pm 1.1$ for angiosperms and $0.9 \pm 0.1$ for gymnosperms, in good agreement with our values. Flexas and Carriquí (2020) found a slightly lower range of 0.8-1.7 for angiosperms (95\% CI), but their range of 0.5-1.3 for gymnosperms is also in good agreement with our findings.

The most pronounced differences between the two plant groups are observed for $\lambda / \lambda_{\text {ref }}$ (Fig. 2c), with values around 5.2 for angiosperms and 0.1 for gymnosperms. Using species-specific $\varepsilon_{\text {cellulose }}$ (correction "B"), $\lambda / \lambda_{\text {ref }}$ is slightly higher than using correction " $\mathrm{A}$ " for gymnosperms $(0.2)$, but still significantly lower than the comparable value for angiosperms (4.0).

\subsection{Simulations of plant $\Delta^{13} \mathrm{C}$ over variable $\left[\mathrm{O}_{2}\right]:\left[\mathrm{CO}_{2}\right]$ ratios}

Using our best-fit values for $\beta_{\mathrm{c}}, g_{\mathrm{m}} / g_{\mathrm{s}}$, and $\lambda / \lambda_{\text {ref }}$, we simulated the expected responses of angiosperm and gymnosperm $\Delta^{13} \mathrm{C}$ to $\left[\mathrm{CO}_{2}\right]$ from 200 to $1200 \mu \mathrm{mol} \mathrm{mol}^{-1}$ (Fig. 3a), and $\left[\mathrm{O}_{2}\right]:\left[\mathrm{CO}_{2}\right]$ ratios from 200 to 1200 
Table 2: Best fit plant-specific parameters for Eqns. (5-7) fitted to global $\Delta^{13} \mathrm{C}$ data from leaves and tree rings. Parameters are: $\beta_{\mathrm{c}}$, the ratio of carboxylation to transpiration cost factors at $25^{\circ} \mathrm{C} ; g_{\mathrm{m}} / g_{\mathrm{s}}$, the ratio of mesophyll to stomatal conductance; and $\lambda / \lambda_{\text {ref }}$, the amount of $\mathrm{CO}_{2}$ released from transpiration per oxygenation reaction, relative to that of $N$. tabacum at $25^{\circ} \mathrm{C}$. All values are unitless, errors are $1 \sigma$. Correction "A" used a constant post-photosynthetic fractionation factor for tree ring cellulose, $\varepsilon_{\text {cellulose }}=-2.1 \%$, whereas correction "B" used species-specific post-photosynthetic fractionation factors (i.e., $\varepsilon_{\text {cellulose,angio }}=-2.8 \%$ for angiosperms and $\varepsilon_{\text {cellulose,gymno }}=-4.7$ $\%$ for gymnosperms). Lowest RMSE values were found with with $h=-1 \%$ for angiosperms, and $h=-10 \%$ for gymnosperms.

\begin{tabular}{cllll}
\hline & $\beta_{\mathrm{c}}$ & $g_{\mathrm{m}} / g_{\mathrm{s}}$ & $\lambda / \lambda_{\text {ref }}$ & RMSE \\
\hline \hline woody angiosperms & & & & \\
Correction "A" & $210 \pm 25$ & $2.6 \pm 0.7$ & $5.2 \pm 0.2$ & 1.436 \\
Correction "B" & $213 \pm 25$ & $2.5 \pm 0.7$ & $4.0 \pm 0.2$ & 1.463
\end{tabular}

woody gymnosperms

\begin{tabular}{lllll} 
Correction “A" & $147 \pm 10$ & $0.98 \pm 0.10$ & $0.1 \pm 0.1$ & 1.767 \\
Correction "B" & $281 \pm 18$ & $0.93 \pm 0.10$ & $0.2 \pm 0.2$ & 2.140 \\
\hline
\end{tabular}
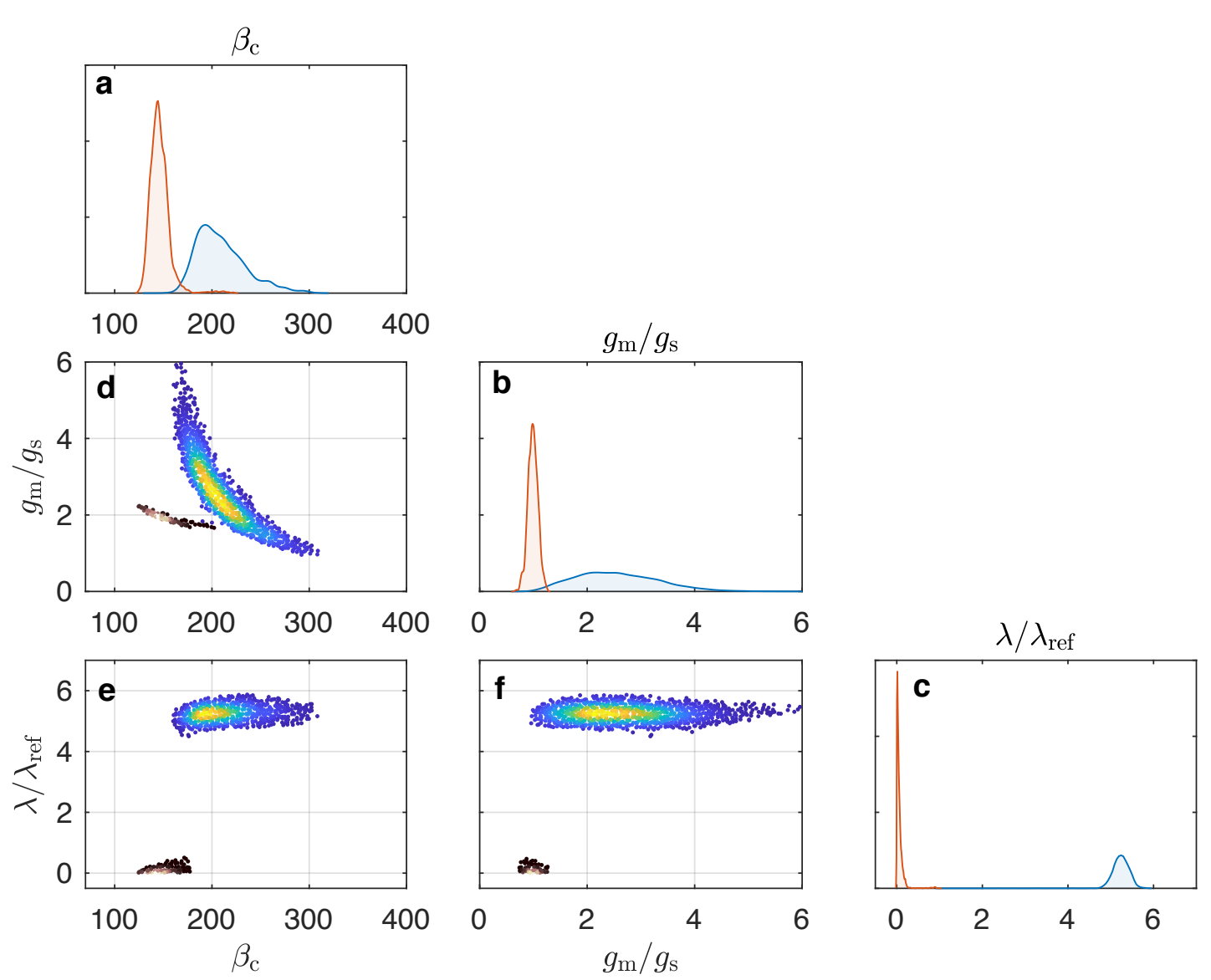

Figure 2: Probability distributions for three plant-specific parameters, estimated by MCMC for angiosperm (blue) and gymnosperm (red) species from global compilations of leaf and tree ring $\Delta^{13} \mathrm{C}$ (correction "A"). (a) shows $\beta_{\mathrm{c}}$, the ratio of carboxylation to transpiration cost factors); (b) shows $g_{\mathrm{m}} / g_{\mathrm{s}}$, the ratio of mesophyll to stomatal conductance; and (c) shows $\lambda / \lambda_{\text {ref }}$, which is the amount of $\mathrm{CO}_{2}$ released from photorespiration per oxygenation reaction, relative to that of $N$. tabacum at $25^{\circ} \mathrm{C}$. All three parameters are unitless. (d-f) Two dimensional probability distributions showing covariance between parameters, estimated by MCMC. 
mol mol ${ }^{-1}$ (Fig. 3b), both at $20^{\circ} \mathrm{C}$. The simulations show that gymnosperm $\Delta^{13} \mathrm{C}$ does not change with $\left[\mathrm{O}_{2}\right]$ or $\left[\mathrm{CO}_{2}\right]$ levels, but decreases by $\sim 6 \%$ when $D$ is increased from $0.23 \mathrm{kPa}$ (solid red lines, Fig. 3a) to $1.43 \mathrm{kPa}$ (dashed red lines). For angiosperms, $\Delta^{13} \mathrm{C}$ decreases strongly with lower $\left[\mathrm{CO}_{2}\right]$ at low $D$ (solid blue lines), but decreases slightly with lower $\left[\mathrm{CO}_{2}\right]$ at high $D$ (dashed blue lines). The $\Delta^{13} \mathrm{C}$ offset between gymnosperms and angiosperms varies across $\left[\mathrm{CO}_{2}\right]$ levels.

For simplicity, we define the offset in discrimination between co-located (i.e same $T_{\mathrm{d}}$ and $D$ ) angiosperm and gymnosperm plants as $\Delta_{\mathrm{a}-\mathrm{g}}^{*}=\Delta_{\mathrm{a}}-\Delta_{\mathrm{g}}$, where the subscripts "a" and "g" are adopted to indicate each plant group, respectively. The asterisk $\left(^{*}\right)$ denotes an average isotopic offset between two tissues, rather than a fractionation in the strict sense. Figures $3 b, c$ show that $\Delta_{a-\mathrm{g}}^{*}$ decreases linearly with increasing $\left[\mathrm{O}_{2}\right]:\left[\mathrm{CO}_{2}\right]$ ratio, when $T_{\mathrm{d}}$ and $D$ are held constant. In addition, $\Delta_{\mathrm{a}-\mathrm{g}}^{*}$ values are greater at higher $D$ (dashed purple lines, Fig. 3c) and high $T_{\mathrm{d}}($ Fig. S3, see Electronic Annexure).
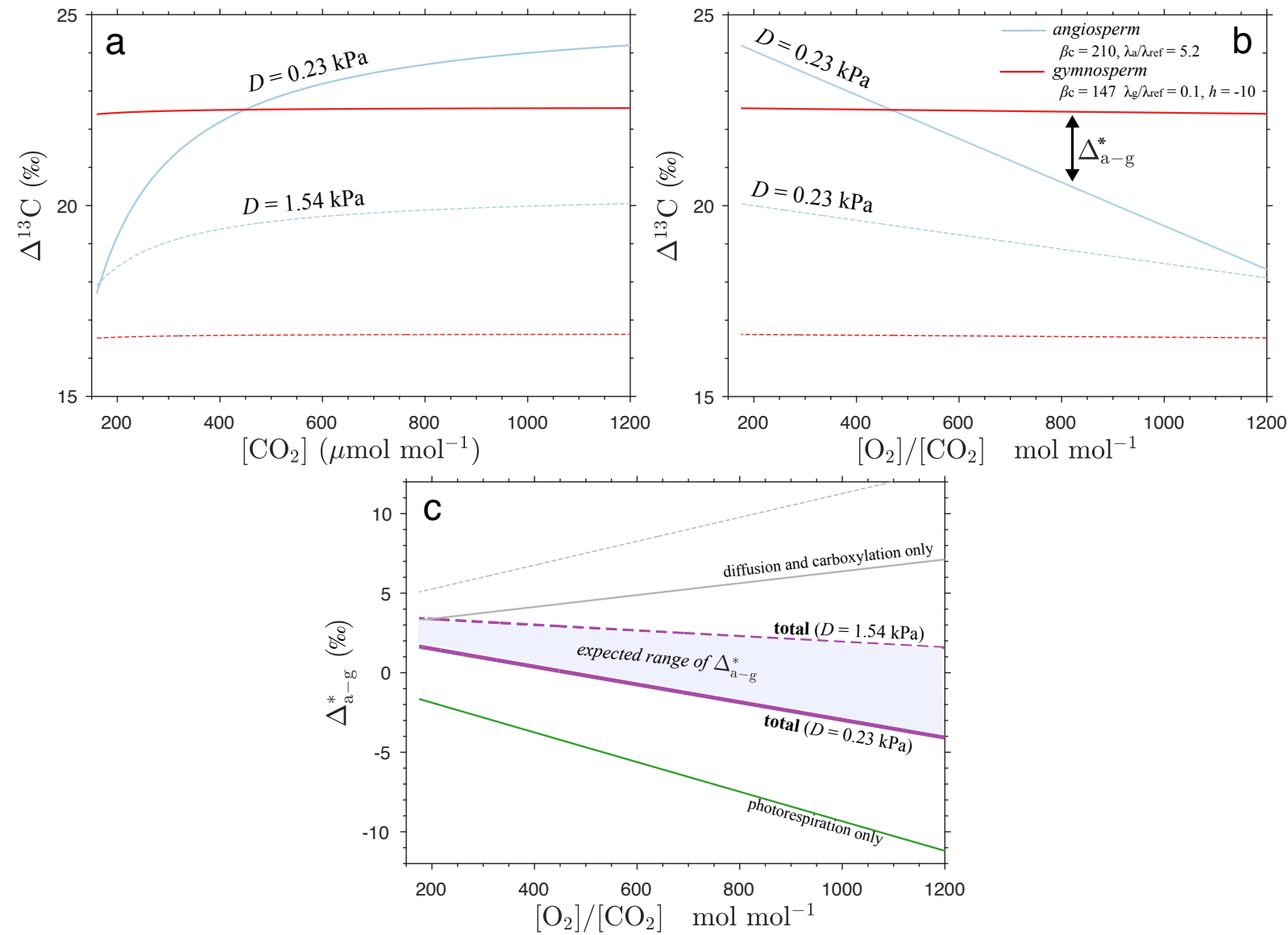

Figure 3: Simulations of the effects of $\left[\mathrm{O}_{2}\right]:\left[\mathrm{CO}_{2}\right]$ ratio on plant $\Delta^{13} \mathrm{C}$ for different environmental conditions. We used the best-fit values for plant specific traits $\left(\beta_{\mathrm{c}}\right.$, ratio of carboxylation to transpiration cost factors; $g_{\mathrm{m}} / g_{\mathrm{s}}$, ratio of mesophyll to stomatal conductances; and $\lambda$, the amount of $\mathrm{CO}_{2}$ released by photorespiration per oxygenation reaction) as estimated from the MCMC approach applied to Eqns. (5-7). Parameters are listed in Table (2). (a) shows the effect of atmospheric $\mathrm{CO}_{2}$ concentrations on $\Delta^{13} \mathrm{C}$ for angiosperms (blue curves) and gymnosperms (red), both at vapour pressure deficits of $D=1.54 \mathrm{kPa}$ (dashed lines) and $D=0.23 \mathrm{kPa}$ (solid lines); (b) shows the corresponding curves plotted against $\left[\mathrm{O}_{2}\right]:\left[\mathrm{CO}_{2}\right]$ ratio, and (c) $\Delta_{\mathrm{a}-\mathrm{g}}^{*}=\Delta_{\mathrm{a}}-\Delta_{\mathrm{g}}$ against $\left[\mathrm{O}_{2}\right] /\left[\mathrm{CO}_{2}\right]$ (purple curves), along with contributions from each term separately (green and grey lines). 
Because most $(>70 \%)$ of the plants in our training dataset grew between $D=0.23$ and $1.54 \mathrm{kPa}$, Figure 3c shows that $\Delta_{\mathrm{a}-\mathrm{g}}^{*}$ is expected to fall in a large range between +3.5 and $-4.0 \%$ at $20{ }^{\circ} \mathrm{C}$, over $\left[\mathrm{O}_{2}\right]:\left[\mathrm{CO}_{2}\right]$ levels likely experienced over the Cenozoic (shaded purple region). The dependence of $\Delta_{\mathrm{a}-\mathrm{g}}^{*}$ on $T_{\mathrm{d}}$ is weaker, and does not significantly affect this range, given the $T_{\mathrm{d}}$ values in our dataset ( $>80 \%$ between 17 and $23{ }^{\circ} \mathrm{C}$ ). The simulations show that the linear relationship between $\Delta_{\mathrm{a}-\mathrm{g}}^{*}$ and $\left[\mathrm{O}_{2}\right]:\left[\mathrm{CO}_{2}\right]$ ratio is predominantly affected by the photorespiration term, rather than by the diffusion and carboxylation terms (Fig. 3c). Overall, at low $D=0.23$ $\mathrm{kPa}$, the photorespiration term contributes to up to $-9 \%$ of the difference in $\Delta^{13} \mathrm{C}$ between the two groups over the entire range of $\left[\mathrm{O}_{2}\right]:\left[\mathrm{CO}_{2}\right]$ ratio, while the terms related to diffusion and Rubisco carboxylation account for $+4 \%$ of $\Delta_{\mathrm{a}-\mathrm{g}}^{*}$ over this range.

\subsection{Dependence of $\Delta_{\mathrm{a}-\mathrm{g}}^{*}$ on $\mathrm{D}$ and atmospheric $\left[\mathrm{O}_{2}\right]:\left[\mathrm{CO}_{2}\right]$ ratio: a semi-empirical linear model}

A semi-empirical expression can be derived for describing $\Delta_{\mathrm{a}-\mathrm{g}}^{*}$ in terms of both $D$ and $\left[\mathrm{O}_{2}\right]:\left[\mathrm{CO}_{2}\right]$ ratios when plants from the two vascular groups are growing under the same environmental conditions:

$$
\Delta_{\mathrm{a}-\mathrm{g}}^{*} \approx \varepsilon_{f} \frac{\left[\mathrm{O}_{2}\right]}{\left[\mathrm{CO}_{2}\right]}+\varepsilon_{a b} D+\varepsilon_{0}
$$

where $\varepsilon_{f}$ is a coefficient related to the difference in fractionation between angiosperms and gymnosperms due to photorespiration terms, and $\varepsilon_{a b}$ is a coefficient related to differences attributed to $\mathrm{CO}_{2}$ diffusion and carboxylation. At this stage the meaning of the third term, $\varepsilon_{0}$ is not fully clear, but is included to describe all other remaining contributions (including differences in respiration, random effects, etc.), which we assume to be constant. Because the $\mathrm{CO}_{2}$ compensation point is related to $\lambda$, the chloroplastic oxygen concentration $O_{\mathrm{c}}$ (in turn related to [O $\left.\mathrm{O}_{2}\right]$ ) and the Rubisco specificity, $S_{\mathrm{c} / \mathrm{o}}$ (Busch, 2020), the first term can be approximated (using Eqns. 4-5) as:

$$
\varepsilon_{f} \approx S_{\mathrm{c} / \mathrm{o}}^{-1}\left[\lambda_{g}\left(f-w h_{\mathrm{g}}\right)-\lambda_{a}\left(f-w h_{\mathrm{a}}\right)\right]
$$

where the subscripts a and g denote angiosperm and gymnosperm-specific $\lambda$ values, respectively. Eqns. (8-9) provide a simple, but powerful framework for interpreting co-located plant isotope records. Eqn. 8 predicts that $\Delta_{\mathrm{a}-\mathrm{g}}^{*}$ will vary linearly with both $D$ and $\left[\mathrm{O}_{2}\right] /\left[\mathrm{CO}_{2}\right]$, if $\varepsilon_{a b}$ and $\varepsilon_{f}$ are constant. Eqn. 9 predicts that the slope of $\Delta_{\mathrm{a}-\mathrm{g}}^{*}$ versus $\left[\mathrm{O}_{2}\right] /\left[\mathrm{CO}_{2}\right]$ will be negative if $\lambda_{\mathrm{a}}>\lambda_{\mathrm{g}}$, and will be steeper if differences in $\lambda$ increase. It is possible that $\lambda$ may vary in a subtle way from species to species within each plant group, although this is yet to be determined. Such variations might lead to slightly different $\varepsilon_{f}$ when comparing a single species of gymnosperm to another species of angiosperm at any given location. However, when several species are compared, we expect this variation will be averaged out, because according to our analysis, differences in $\lambda$ appear to be fairly robust across each plant group.

Our proposed model (Eqn. 8) is simple enough to be tested against stable carbon isotope data from plant chamber experiments, as well as tree rings and leaves (see Fig. 4a,c caption, and details of "testing dataset" in Methods). Overall, $\Delta_{\mathrm{a}-\mathrm{g}}^{*}$ shows significant variation with both $D$ (Fig. 4b) and $\left[\mathrm{O}_{2}\right] /\left[\mathrm{CO}_{2}\right]$ (Fig. 4a). $\Delta_{\mathrm{a}-\mathrm{g}}^{*}$ decreases with $\left[\mathrm{O}_{2}\right] /\left[\mathrm{CO}_{2}\right]$ modestly, from approximately 100 to $650 \mathrm{~mol} \mathrm{~mol}^{-1}$ (Fig. 4a), as would be expected from our linear 

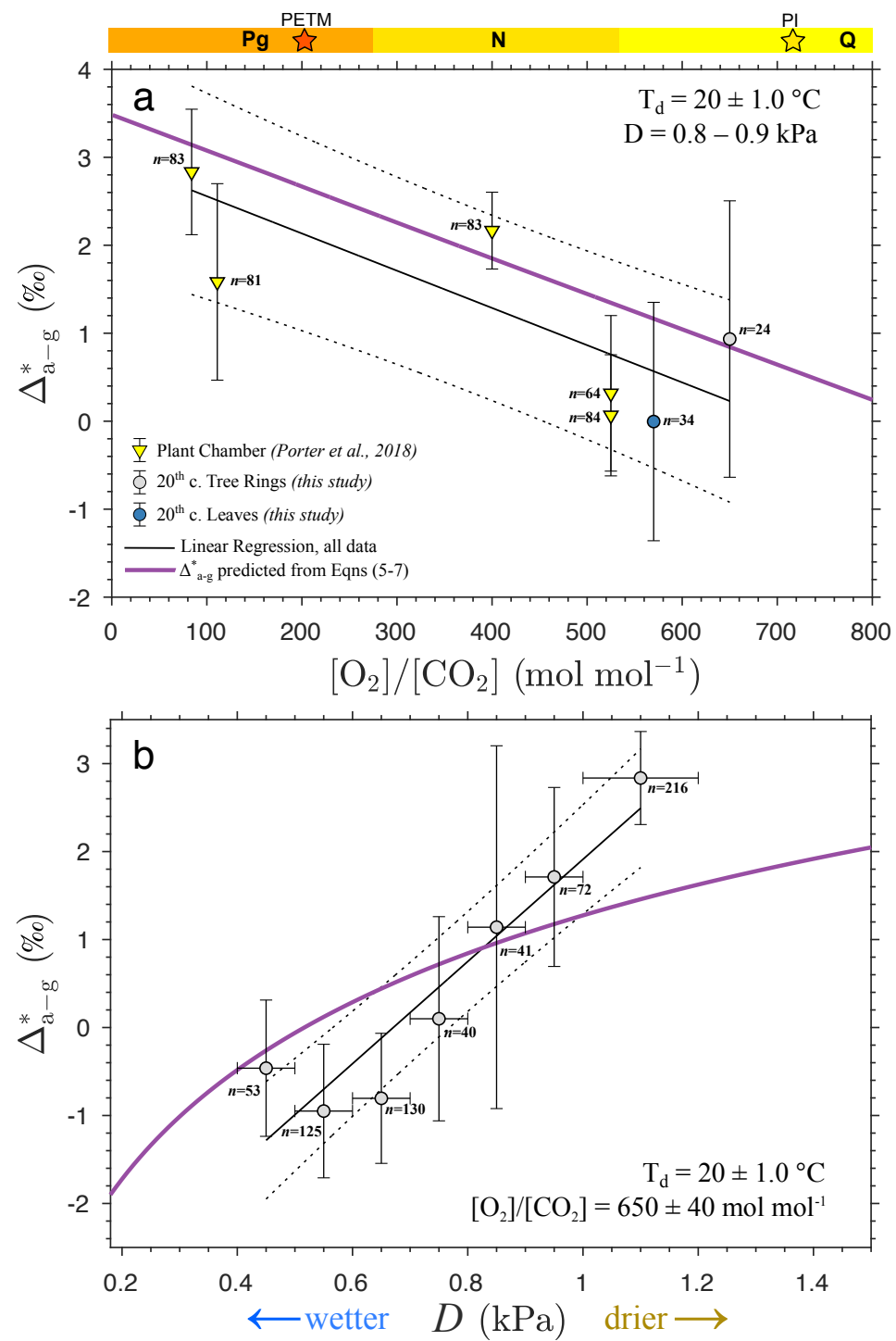

Figure 4: Differences between average angiosperm and gymnosperm carbon isotope discrimination, $\Delta_{\mathrm{a}-\mathrm{g}}^{*}$, inferred from plant chamber, leaves and tree ring data at $20^{\circ} \mathrm{C}$, (a) plotted against $\left[\mathrm{O}_{2}\right] /\left[\mathrm{CO}_{2}\right]$ at vapor pressure deficit $(D)$ of $0.85 \mathrm{kPa}$, and (b) against vapor pressure deficit at $\left[\mathrm{O}_{2}\right] /\left[\mathrm{CO}_{2}\right]=650 \mathrm{~mol} \mathrm{~mol}^{-1}$. The bars represent the $95 \%$ confidence intervals of the $\Delta_{\mathrm{a}-\mathrm{g}}^{*}$ values. (a) shows linear partial least-squares fit in black over a range of $\left[\mathrm{O}_{2}\right] /\left[\mathrm{CO}_{2}\right]$ from $400-650 \mathrm{~mol} \mathrm{~mol}^{-1}$, with $1 \sigma$ prediction bounds. Errors in $\left[\mathrm{O}_{2}\right] /\left[\mathrm{CO}_{2}\right]$ are approximately the size of each datapoint. In (b), a partial linear least-squares fit is shown in black over 0.45 to $1.1 \mathrm{kPa}$, error bars indicating the bin width, with the total number $(n)$ of angiosperm and gymnosperm data within each bin indicated next to each datapoint.The fitted coefficients are $\varepsilon_{f}=-0.004 \pm 0.002$ $\%$ mol mol ${ }^{-1}, \varepsilon_{a b}=5.9 \pm 1.3 \% \mathrm{~mol} \mathrm{~mol}^{-1}(1 \sigma)$, and $\varepsilon_{0}=-0.9 \%$ (Eqn. 8). The relationship predicted according to the comprehensive ab initio model (Eqns 5-7) is also shown in heavy purple lines. For comparison, a rough timescale for the Cenozoic is shown at the top of the figure (note: it is likely that there was considerable overlap in the $\left[\mathrm{O}_{2}\right]:\left[\mathrm{CO}_{2}\right]$ range of the Palaeogene and Neogene). PI = pre-industrial value, $\mathrm{Q}=$ Quaternary, $\mathrm{N}=$ Neogene, $\mathrm{Pg}=$ Paleogene, PETM = Paleocene-Eocene Thermal Maximum.

model (Eqn. 8). The linear fit to the data over the $100-650 \mathrm{~mol} \mathrm{~mol}^{-1}$ range of $\left[\mathrm{O}_{2}\right] /\left[\mathrm{CO}_{2}\right]$ values yields a slope of $\varepsilon_{f}=-0.004 \pm 0.002 \% \mathrm{~mol} \mathrm{~mol}^{-1}(1 \sigma)$, with an intercept of $3.0 \pm 1.0 \%$. Although there is more scatter in this relationship (adjusted $\mathrm{R}^{2}=0.51$ ) and the trend is modest, it is in agreement with the slope predicted by Eqns. (5-7) to within $1 \sigma$ prediction bounds. Note that to ensure robust binning, a minimum number of 6 angiosperms and 6 gymnosperm $\Delta^{13} \mathrm{C}$ values were used in the calculation of $\Delta_{\mathrm{a}-\mathrm{g}}^{*}$. Fits are found to be somewhat insensitive to the 
binning procedure when a different bin width (i.e., $30 \mathrm{~mol} \mathrm{~mol}^{-1}$ ) is chosen; the resulting regressed coefficients are not significantly different $\left(\varepsilon_{f}=-0.0037 \pm 0.0014 \%\right.$ mol mol$\left.{ }^{-1}\right)$. All binned data can be found in the Electronic Annexure.

The slope of $\Delta_{\mathrm{a}-\mathrm{g}}^{*}$ versus $D$ is higher than that of $\Delta_{\mathrm{a}-\mathrm{g}}^{*}$ versus $\left[\mathrm{O}_{2}\right] /\left[\mathrm{CO}_{2}\right]$, and in the opposite direction (Fig. $\left.4 \mathrm{~b}\right)$. A linear fit to the binned data in Figure $4 \mathrm{~b}$ yielded a positive slope of $\varepsilon_{a b}=5.9 \pm 1.3 \% \mathrm{~mol} \mathrm{~mol}^{-1}(1 \sigma)$, with an intercept of $-3.9 \pm 1.0$ (adjusted $R^{2}=0.86$ ). This result is in general agreement with the predictions (purple lines, Fig. 4b) at moderate $D$ levels (i.e. between 0.7 and $1 \mathrm{kPa}$ ). However, the slope of $\Delta_{\mathrm{a}-\mathrm{g}}^{*}$ versus $D$ as implied by the data, is greater than that predicted by Eqns. (5-7). Figure $4 \mathrm{~b}$ shows that the predictions using Eqns. (5-7) diverge slightly from the trend in the data at $0.5<D<0.7 \mathrm{kPa}$ and at $D>1 \mathrm{kPa}$.

Finally, using our fitted value for $\varepsilon_{f}$, it is possible to calculate the Rubisco specificity $\left(S_{\mathrm{c} / \mathrm{o}}\right)$ using Eqn. 9. We estimated that $S_{\mathrm{c} / \mathrm{o}}=290 \mathrm{~mol} \mathrm{~mol}^{-1}$, assuming $f=11 \%, h_{\mathrm{a}}=-1 \% \mathrm{o}, h_{\mathrm{g}}=-10 \%$, $\lambda_{\mathrm{ref}}=0.6$, and using the previously-estimated values for $\lambda_{\mathrm{a}} / \lambda_{\text {ref }}$, and $\lambda_{\mathrm{g}} / \lambda_{\text {ref }}$ (i.e., 5.2 and 0.1 , respectively, Section 4.1), as well as the solubility conversion factors (liquid to gas phase) from Galmés et al. (2016).

\section{Discussion}

\subsection{Basis for the relationships between $\Delta_{\mathrm{a}-\mathrm{g}}^{*}, \mathrm{D}$, and $\left[\mathrm{O}_{2}\right] /\left[\mathrm{CO}_{2}\right]$}

The relationships between $\Delta_{\mathrm{a}-\mathrm{g}}^{*}$ and vapor pressure deficit $(D)$, and between $\Delta_{\mathrm{a}-\mathrm{g}}^{*}$ and $\left[\mathrm{O}_{2}\right] /\left[\mathrm{CO}_{2}\right]$, at least over 100 to $650 \mathrm{~mol} \mathrm{~mol}^{-1}$, are both noteworthy. To the best of our knowledge, neither relationship has been described before - but both follow from the comprehensive ab initio model of discrimination (see Sections 2 and 4.2), and from key differences in plant-specific traits. These traits are: $\beta_{\mathrm{c}}$, the ratio of cost factors for carboxylation and transpiration $; g_{\mathrm{m}} / g_{\mathrm{s}}$, the ratio of mesophyll to stomatal conductances for $\mathrm{CO}_{2} ;$ and $\lambda / \lambda_{\text {ref }}$, the parameter related to photorespiration (Section 4.1). Gymnosperm $\Delta^{13} \mathrm{C}$ is more sensitive to $D$ than angiosperms. This is because lower values of $g_{\mathrm{m}} / g_{\mathrm{s}}$ in gymnosperms amplify the response of $\chi_{\mathrm{c}}$ to $D$, via Eqn. (6). In addition, gymnosperms are less responsive to $\left[\mathrm{CO}_{2}\right]$ because $\lambda / \lambda_{\text {ref }}$ is generally much lower in this plant group than in angiosperms, reducing the photorespiratory compensation point (Eqn. 4). Our findings therefore support the recent study of Sheldon et al. (2020), who found that gymnosperm $\Delta^{13} \mathrm{C}$ values obtained from herbarium records were largely insensitive to rising levels of $\left[\mathrm{CO}_{2}\right]$ from $1850 \mathrm{CE}$ to present - and provide a mechanistic explanation for these authors' observations.

Rubisco specificity is fairly well constrained in $\mathrm{C}_{3}$ plants, with a range of around $85-110 \mathrm{~mol} \mathrm{~mol}{ }^{-1}$ at $25^{\circ} \mathrm{C}$, with little variation according to $\mathrm{C}_{3}$ phylogenetic group (Orr et al., 2016). Using a compilation of in vitro data, as well as leaf data, Galmés et al. (2016) obtained an average value of $108 \mathrm{~mol} \mathrm{~mol}^{-1}$ at $20^{\circ} \mathrm{C}$. Our value of $290 \mathrm{~mol} \mathrm{~mol}^{-1}$ is thus higher than the range of values obtained in the literature, although relatively of the same order of magnitude. It is worth noting that a rough estimate of the Rubisco specificity - a fundamental parameter in the biochemistry of photosynthesis - can be obtained independently from carbon isotopic measurements at known $\left[\mathrm{O}_{2}\right] /\left[\mathrm{CO}_{2}\right]$ levels using a simple linear fit. It gives us confidence in the generality of our findings. One possible explanation for our higher than average estimate might be inaccuracies in the (assumed) values of $\lambda_{\text {ref }}$ and $h$. For instance, a value of 
0.2 for $\lambda_{\text {ref }}$ would decrease our estimate of $S_{\mathrm{c} / \mathrm{o}}$ to $97 \mathrm{~mol} \mathrm{~mol}^{-1}$, which would be more consistent with values from the literature. We expect that it will be possible to better constrain $S_{\mathrm{c} / \mathrm{o}}$ once further information about $\lambda_{\text {ref }}$ and $h$ become available.

How can the variation in $\lambda / \lambda_{\text {ref }}$ be interpreted? There is currently no published study investigating the values for $\lambda$, but we can get insights from the theory. Busch (2020) define the variable as $\lambda=0.5\left(1-\alpha_{\mathrm{G}}\right)+\alpha_{\mathrm{T}}$, where $\alpha_{\mathrm{G}}$ is the proportion of glycine removed from the photorespiratory pathway, and $\alpha_{\mathrm{T}}$ is proportion of 2-phosphoglycolate carbon exported as $\mathrm{CH}_{2}$-THF. Glycine is produced via the photorespiratory pathway, and forms a key precursor of compounds (e.g. dehydrins, glycine betaine) which are accumulated in higher plants in response to environmental stresses such as dessication and damage by reactive oxygen radicals, e.g. Sakamoto and Murata (2002). We suggest that higher $\alpha_{\mathrm{G}}$ values in gymnosperms (hence lower $\lambda$ ) is consistent both with ecology (e.g. conifer tolerance to drought), as well as gymnosperm evolutionary history (evolution under high $\left[\mathrm{O}_{2}\right]$ atmospheres). The effects of $\lambda / \lambda_{\text {ref }}$ on $\Delta^{13} \mathrm{C}$ also underscore the importance of incorporating photorespiration into models of $\mathrm{C}_{3}$ plant discrimination, which has been suggested by other studies (Schubert and Jahren, 2018; Zhang et al., 2019; Lavergne et al., 2019). We note that the value of $h=-10 \%$, found in our study for gymnosperms, is consistent with the analysis of Schubert and Jahren (2018). According to our analysis, and Eqn. (3), the term $f-w h$ behaves as an apparent fractionation with large combined magnitude of $\sim 21 \%$, which is close to the best-fit value of $f$ proposed by Schubert and Jahren (2018) of $19.2 \%$, without considering $h$.

Our results also imply that our values for $\lambda$ are higher than tobacco $\left(\lambda_{\text {ref }}\right)$. This could be interpreted as higher proportion of $\mathrm{CH}_{2}$-THF exported for lignin production, because our compilation is almost entirely from trees (as opposed to lab-grown herbaceous plants). Walker et al. (2017) suggested $\lambda_{\text {ref }}=0.6$ at $25^{\circ} \mathrm{C}$ for tobacco, and identified a positive relationship between $\lambda$ and temperature. However, these relationships are still speculative, and so robust quantification of the true value of $\lambda$ is not currently possible using our dataset. Regardless of the true values of $\lambda$ or $\lambda_{\text {ref }}$, differences between $\lambda / \lambda_{\text {ref }}$ for our gymnosperm and angiosperm records appear to be robust, and offer a convincing explanation for group-specific responses to changes in atmospheric $\left[\mathrm{CO}_{2}\right]$ in tree ring studies (e.g. Voelker et al. (2016)) and faunal collagen (Hare et al., 2018), and to changes in $\left[\mathrm{O}_{2}\right]$ levels (Porter et al., 2017).

\subsection{Implications for Cenozoic records of stable carbon isotopes}

Although previous geological studies (e.g. Diefendorf et al. (2015); Bechtel et al. (2019); Schlanser et al. (2020)) have assumed a constant offset of 2-3\% between co-located angiosperm and gymnosperm $\Delta^{13} \mathrm{C}$ plants, our results suggest that this offset (i.e., $\Delta_{a-g}^{*}$ ) is variable over geological timescales. Our empirical linear model for $\Delta_{\mathrm{a}-\mathrm{g}}^{*}$ (Eqns. 8-9) is directly applicable to the terrestrial geological record, assuming that the fossil plant materials considered for gymnosperms and angiosperms came from the same area, and plants originally grew under similar environmental conditions. In these cases, $\Delta_{\mathrm{a}-\mathrm{g}}^{*}$ should increase at higher $D$ and atmospheric $\left[\mathrm{CO}_{2}\right]($ assuming constant $\left[\mathrm{O}_{2}\right]$ ). According to our fits (Fig. 4), these relationships should hold for many levels of $D$, $\left[\mathrm{O}_{2}\right]$ and $\left[\mathrm{CO}_{2}\right]$ over the Cenozoic, although more data are needed to evaluate whether it holds at much higher $\left[\mathrm{O}_{2}\right] /\left[\mathrm{CO}_{2}\right]$, i.e. LGM to pre-Industrial conditions of $>700 \mathrm{~mol} \mathrm{~mol}^{-1}$. No published data are yet available for testing this 
hypothesis, but it would be a good test of the framework, because $\Delta_{\mathrm{a}-\mathrm{g}}^{*}$ should be negative during the LGM, when $\left[\mathrm{O}_{2}\right] /\left[\mathrm{CO}_{2}\right]$ was very high, and $D$ was generally low.

$\Delta_{\mathrm{a}-\mathrm{g}}^{*}$ values calculated from Cenozoic paleo-data generally support our novel interpretation. Figure 5 shows that $\Delta_{\mathrm{a}-\mathrm{g}}^{*}$ values were very high (around $+4 \%$ and higher) during the Palaeocene-Eocene $(\sim 63-52 \mathrm{Ma})$, when $\left[\mathrm{CO}_{2}\right]$ was high, but decreased to around $+2.5 \%$ in the Miocene (Bechtel et al., 2019, 2008), when $\left[\mathrm{CO}_{2}\right]$ was lower. The lowest $\Delta_{\mathrm{a}-\mathrm{g}}^{*}$ values $(-2 \%)$ are observed in the $20^{\text {th }}$ century from leaves and tree rings records when $\left[\mathrm{CO}_{2}\right]$ and/or $D$ levels were lower. In this figure, the observed $\Delta_{\mathrm{a}-\mathrm{g}}^{*}$ values are plotted against those predicted from the comprehensive model (Eqn. 5-7), using the palaeo- $\left[\mathrm{CO}_{2}\right]$ curve of Foster et al. (2017), and assuming $\left[\mathrm{CO}_{2}\right]$ equal to $\sim 1010 \mu \mathrm{mol} \mathrm{mol}^{-1}$ over the PETM according to Gehler et al. (2016). Note that it is difficult to estimate the corresponding growing-season $D$ and $T_{\mathrm{d}}$ values for paleo-data, but for simplicity, we have chosen nominal values of $0.8 \mathrm{kPa}$ and $20^{\circ} \mathrm{C}$. These values describing a relatively moist atmosphere are consistent with moderate to high levels of moisture availability as reconstructed from paleobotanical data for the Paleocene-Eocene (Eberle and Greenwood, 2012; Greenwood et al., 2010; West et al., 2015) and Miocene (Bechtel et al., 2019) sites.

Figure 5 also shows trends in modern tree ring data. In an extensive survey, Leavitt and Newberry (1992) found that average differences in identical-age rings from Wisconsin formed in $1992 \mathrm{CE}$ (green squares) decreased with site latitude across a gradient from $41^{\circ} \mathrm{N}$ (average $D=1.3 \mathrm{kPa}$ ) to $45.5^{\circ} \mathrm{N}$ (average $D=0.8 \mathrm{kPa}$ ). These trends are also consistent with our model, which predicts that $\Delta_{\mathrm{a}-\mathrm{g}}^{*}$ must decrease with increasing site latitude, because atmospheric pressure and temperature (and thus $D$ ) decreases.

Our results show a slight deviation from the 1:1 line. The ab initio model based on Eqns. (5-7) generally underestimates the high $\Delta_{\mathrm{a}-\mathrm{g}}^{*}$ values and overestimates the low values - but the observed and predicted $\Delta_{\mathrm{a}-\mathrm{g}}^{*}$ values are in relatively good agreement across different tissues (tree rings cellulose/lipid), time periods, and angiosperm and gymnosperm species $\left(\mathrm{R}^{2}=0.509, \mathrm{RMSE}=1.493 \%\right.$, $p$-value $\left.<0.001\right)$. The slight deviation of predicted values from the observations might be due to systematic biases in the paleo-data, or issues with some of the model assumptions (or both). One possible deficiency in the ab initio model is that it assumes that $\chi_{\mathrm{c}}$ (and thus $\Delta^{13} \mathrm{C}$ ), is affected by atmospheric $D$, but not affected by other complex variables such as soil moisture. Because atmospheric $D$ is generally expected to co-vary with soil moisture, not accounting for such additional variables might result in a potential underestimation of $\Delta^{13} \mathrm{C}$ values, and thus affect the predicted $\Delta_{\mathrm{a}-\mathrm{g}}^{*}$ values. Such co-variance might partly explain why there is an offset between the observed data and the ab initio model in Figure 4b. A recent study (Lavergne et al., 2020b) has shown that $\beta_{\mathrm{c}}$, which was assumed constant here, should decrease with a reduction of soil moisture. This effect was not taken into account in our predictions mainly because we do not currently have a good understanding of how soil moisture should affect $\beta_{\mathrm{c}}$ values based on first principles - but this is grounds for future research. Soil $\mathrm{pH}$ was also suggested to influence $\beta_{\mathrm{c}}$ in several studies (Wang et al., 2017; Paillassa et al., 2020), further influencing the predicted $\Delta_{\mathrm{a}-\mathrm{g}}^{*}$ values. These factors would be worth investigating in the future, although they present a challenge in paleo-contexts, where variables such as soil moisture and $\mathrm{pH}$ are often unconstrained. Further work using refined models, together with a larger observational dataset, particularly derived from plant chamber experiments, is likely to help improve the predictive skills of the ab initio model. 


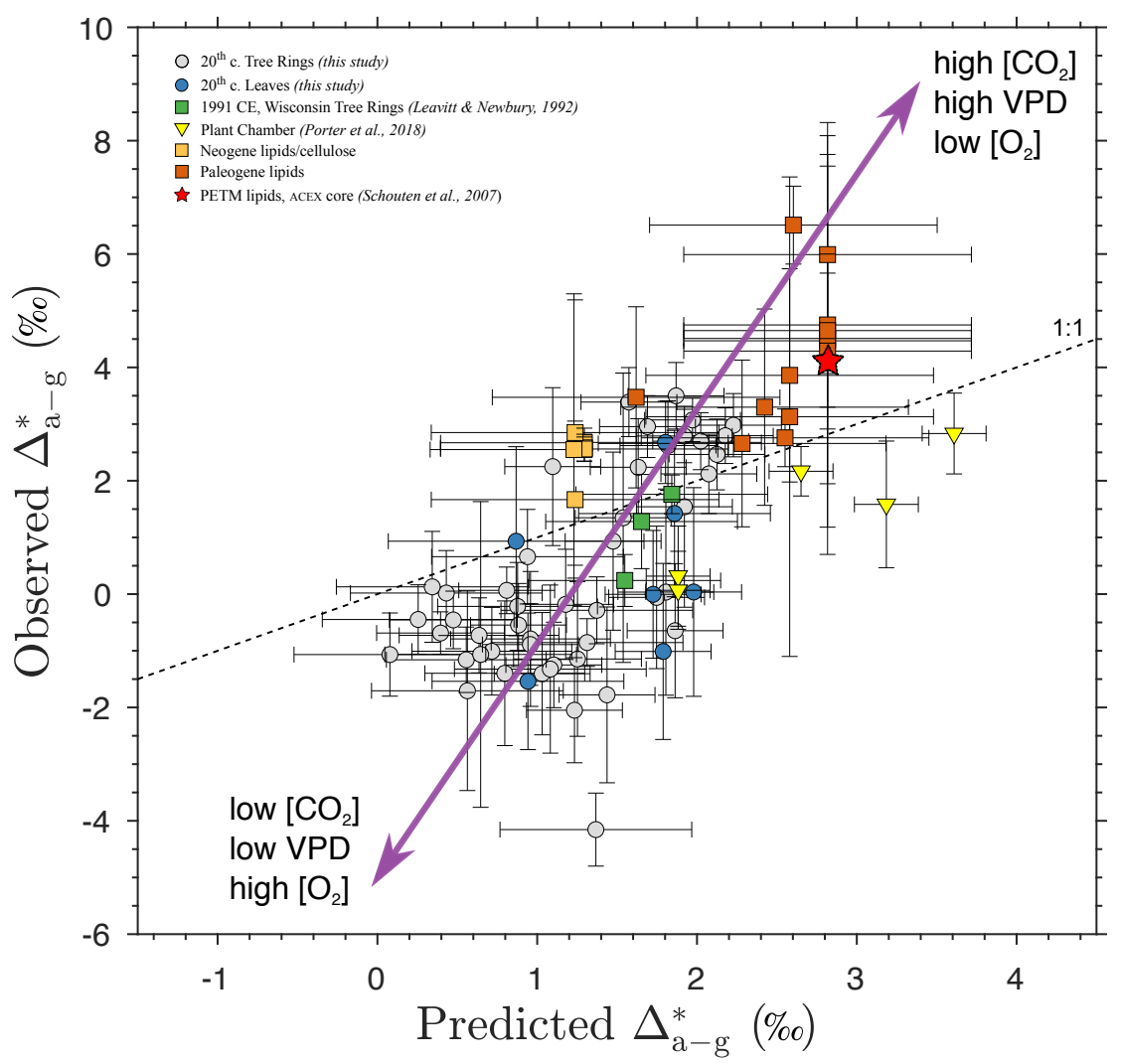

Figure 5: Changes in $\Delta_{\mathrm{a}-\mathrm{g}}^{*}$ across the Cenozoic, predicted from Eqns. (5-7), versus observed values, including $20^{t h}$ century tree ring and leaf data (grey and blue circles), tree ring data from Leavitt and Newberry (1992) (green squares), and plant chamber experiments (Porter et al., 2017) (yellow triangles). Errorbars are 95\% CI. Paleogene lipid data: Bighorn Basin, Wyoming (Diefendorf et al., 2015), Canadian Arctic, and Driftwood Canyon, British Colombia (Schlanser et al., 2020), ACEX core, Arctic Schouten et al. (2007). Neogene lipid and cellulose data: Poland and Austria Bechtel et al. (2008, 2019). Lipid data are corrected for variations in post-photosynthetic fractionations between angiosperms and gymnosperms (e.g. $\varepsilon_{\text {lipid }}=-0.4 \%$ and $\varepsilon_{\text {lipid }}=-0.6 \%$ for angiosperm and gymnosperm terpenoids (Diefendorf et al., 2012), respectively). PETM: Paleocene-Eocene Thermal Maximum.

It is worth noting that other factors not accounted for in our framework could potentially modulate $\Delta_{\mathrm{a}-\mathrm{g}}^{*}$ variations in the geological record. For instance, it is possible that some of the range in $\Delta_{\mathrm{a}-\mathrm{g}}^{*}$ values, particularly in the case of lipid data, could be explained by group-specific post-photosynthetic fractionations. In Figure 5 we corrected fossil $\delta^{13} \mathrm{C}$ data for post-photosynthetic fractionations following Diefendorf et al. (2012), i.e., using constant values of $\varepsilon_{\text {lipid }}=-0.4 \%$ and $\varepsilon_{\text {lipid }}=-0.6 \%$ for angiosperm and gymnosperm terpenoids, respectively. However, a recent study has shown that $\varepsilon_{\text {lipid }}$ values vary substantially between different gymnosperm clades (Diefendorf et al., 2019). This variation is expected to be averaged if several species of gymnosperms grew together, but it is difficult to know the size of the effect on $\Delta_{\mathrm{a}-\mathrm{g}}^{*}$ if the isotopic record considered is biased towards one particular species. There are other potentially confounding effects on geological $\Delta_{\mathrm{a}-\mathrm{g}}^{*}$ values. Older leaves tend to be more depleted in ${ }^{13} \mathrm{C}$ than younger leaves, by up to $2.1 \%$ (Vogado et al., 2020), because ${ }^{13} \mathrm{C}$-depleted photosynthetic carbon is used along with carbon imported from outside the leaf as the leaf develops. This might lead to age-related difference in $\Delta^{13} \mathrm{C}$ between plant species that retain their leaves for long times (e.g. evergreens) and deciduous plants. Further research is needed to better understand and quantify these effects on $\Delta_{\mathrm{a}-\mathrm{g}}^{*}$. However, it should be 
emphasised that although many confounding effects may potentially exist, our framework still explains over half of the variations observed in the geological record; and is thus a step-change from previous studies, which have assumed that $\Delta_{\mathrm{a}-\mathrm{g}}^{*}$ is invariant with $D,\left[\mathrm{CO}_{2}\right]$, and $\left[\mathrm{O}_{2}\right]$.

\subsection{Implications for paleo-[CO $\left.\mathrm{CO}_{2}\right]$ proxies based on $\mathrm{C}_{3}$ plant discrimination}

Two models of carbon isotope discrimination are currently used to estimate paleo- $\left[\mathrm{CO}_{2}\right]$ from fossil $\mathrm{C}_{3}$ plant matter (Schubert and Jahren, 2012; Franks et al., 2014), and both models have been extensively applied to Cenozoic records (Cui and Schubert, 2018; Cui et al., 2020; Reichgelt et al., 2020; Royer et al., 2019). Both formulations are related to the FvCB model (Schubert and Jahren, 2018; Hollis et al., 2019) but differ according to their parameterisation and assumptions. In the Franks et al. (2014) model, phylogenic dependencies are incorporated via a term for the maximum total conductance of $\mathrm{CO}_{2}\left(g_{\mathrm{s}, \mathrm{max}} / 1.6\right)$ obtained from measurements of stomatal size and density, and photorespiration is assumed negligible. In the Schubert and Jahren (2018) model (see also Schubert and Jahren (2012)), discrimination is assumed to be largely independent of phylogeny (with constant $\Delta_{\mathrm{a}-\mathrm{g}}^{*}$ ), but photorespiration terms are effectively included (i.e. the hyperbolic relationship in this model is functionally equivalent to Eqn. (5) but assuming constant $\Gamma^{*}$ ). Presently, there is no easy way to include a term for atmospheric humidity (i.e. $D$, indirectly related to soil moisture availability), $\left[\mathrm{O}_{2}\right]$, or variable $\Gamma^{*}$, explicitly in either model. All of these effects could lead to biases in palaeo- $\left[\mathrm{CO}_{2}\right]$ estimated from fossil $\mathrm{C}_{3}$ plant matter, if unaccounted for (Hollis et al., 2019). Porter et al. (2019) recently suggested that these paleo- $\left[\mathrm{CO}_{2}\right]$ proxies could be further improved by correcting for the effects of $\left[\mathrm{O}_{2}\right]$ and phylogeny, while Steinthorsdottir et al. (2020) recently showed that better precision and accuracy can sometimes be achieved if several angiosperm and gymnosperm species from one location are used, rather than individual species. These suggestions are consistent with our approach and give us confidence about the relevance of our findings.

Overall, our results suggest that all the above-mentioned factors - photorespiration, $\left[\mathrm{O}_{2}\right]$, phylogenetic dependence, and variable $\Gamma^{*}$ - are important to include in paleo- $\left[\mathrm{CO}_{2}\right]$ proxies based on discrimination in terrestrial $\mathrm{C}_{3}$ plants. Although further investigations are necessary (but are beyond the scope of this study), the framework presented here should provide a way forward to correct paleo- $\left[\mathrm{CO}_{2}\right]$ proxies for these effects. To illustrate this point, we consider the recent record of palaeo- $\left[\mathrm{CO}_{2}\right]$ from Cui et al. (2020) dominated by angiosperm plants growing in sites with relatively high atmospheric humidity (low $D$ ). In Figure 6 we compare the respective paleo- $\left[\mathrm{CO}_{2}\right]$ data points with those predicted from Eqns (5-7) (numerical solution estimated using the MATLAB 'solve' function) using the Cui et al. (2020) dataset and the best-fit values from our Table 2 for angiosperms. The resulting paleo- $\left[\mathrm{CO}_{2}\right]$ predicted by this method (dashed curves in Fig. 6) agrees with the curve of Cui et al. (2020) at low $D$ levels $(D=0.4 \mathrm{kPa}$, dashed heavy teal line), to within uncertainties. In this figure, we also plot palaeo- $\left[\mathrm{CO}_{2}\right]$ data derived from the compilation of Foster et al. (2017). Our curve at $D=0.4 \mathrm{kPa}$ also agrees with the spline of Foster et al. (2017) (for clarity, not shown) to within uncertainties. We note that the agreement with Cui et al. (2020) at low $D$ is perhaps unsurprising, considering that terrestrial organic matter records are generally biased towards wet sites (preservation bias), and because the Schubert and Jahren (2018) model is predominantly based on chamber data, obtained under low $D$ levels. 


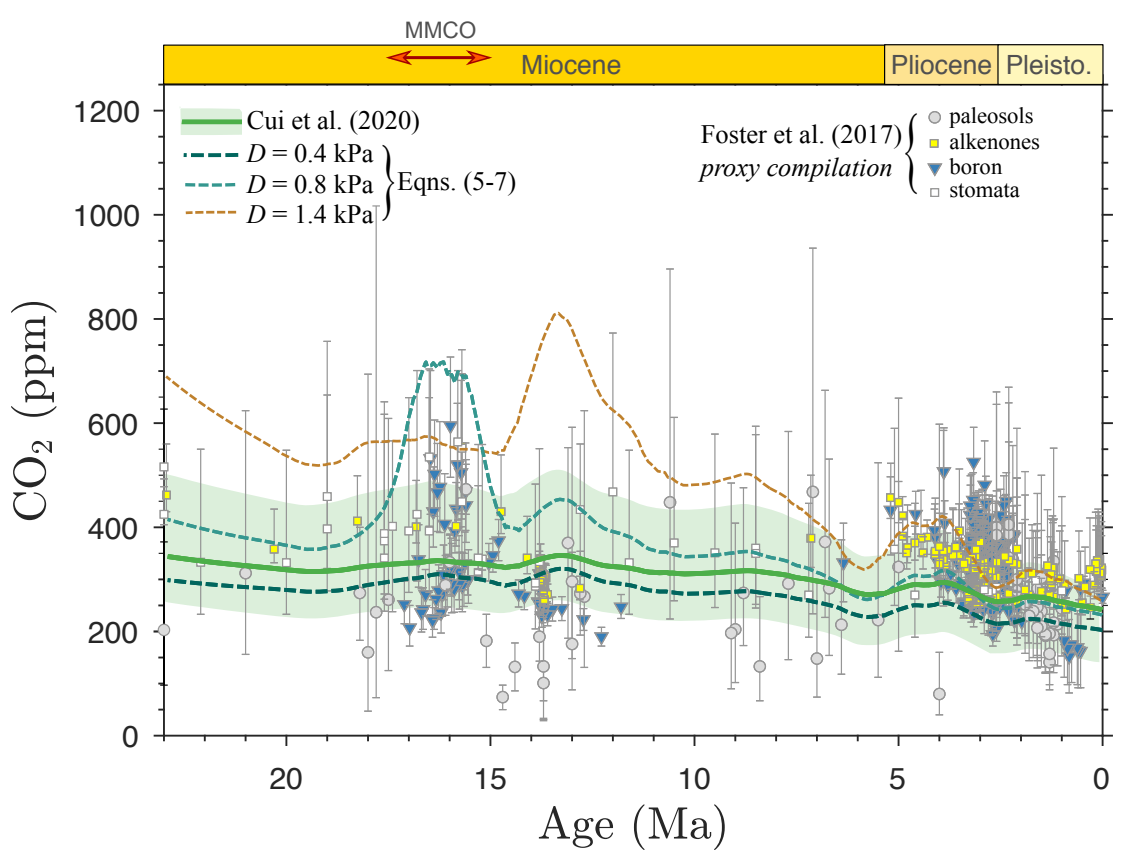

Figure 6: Paleo- $\left[\mathrm{CO}_{2}\right]$ proxies across the Cenozoic, showing the recent curve of Cui et al. (2020), based on the model of $\mathrm{C}_{3}$ land plant discrimination of Schubert and Jahren $(2012$, 2018) (heavy green line, with shaded green area representing $84 \%$ confidence intervals from Cui et al. (2020)). Dashed green lines represent paleo- $\left[\mathrm{CO}_{2}\right]$ estimated by numerical solution of Eqns. (5-7), this study, applied to the same data compilation of Cui et al. (2020), with locally weighted (LOWESS, $\alpha=0.15$ ) fits through $n=461$ data points (not shown), at three different levels of vapor pressure deficit ( $D=0.4,0.8,1.4 \mathrm{kPa}$ ). For numerical modeling, best-fit parameters for angiosperms (Section 4.1 , this study) were used. For comparison, raw paleo- $\left[\mathrm{CO}_{2}\right]$ proxy data from the compilation of Foster et al. (2017) is also shown (see references therein for paleosol, alkenone, boron, and stomatal datasets). Pleisto: Pleistocene; MMCO: Mid-Miocene Climatic Optimum.

However, our $\left[\mathrm{CO}_{2}\right]$ curves at higher $D$ levels (i.e., $D=0.8$ and $D=1.4 \mathrm{kPa}$, dashed blue and brown lines) are significantly higher than the curve of Cui et al. (2020). Considering that fewer than $10 \%$ of trees in our modern global compilation grew at $D<0.4 \mathrm{kPa}$, and over $50 \%$ of angiosperms grew at $D>1.0 \mathrm{kPa}$, higher $D$ levels are possible in the fossil record. If $\mathrm{C}_{3}$ plants originally grew under somewhat higher $D$ levels, then our estimates at $D=0.8$ and $D=1.4 \mathrm{kPa}$ would result in a likely range of mean $\left[\mathrm{CO}_{2}\right]$ values between 550 and $700 \mathrm{ppm}$ at the Mid-Miocene Climatic Optimum (MMCO, 17 to $15 \mathrm{Ma}$ ago). It should be noted that this range is presented as a rough estimate of the sensitivity of the terrestrial $\Delta^{13} \mathrm{C}$-based $\left[\mathrm{CO}_{2}\right]$ proxy to different $D$ levels - incorporating potential errors in smoothing methods - and is not a formal confidence interval. Obtaining statistically robust confidence intervals for this $\left[\mathrm{CO}_{2}\right]$ proxy method is a highly technical task that will likely improve with future research, and greater data coverage.

Steinthorsdottir et al. (2020) recently estimated paleo- $\left[\mathrm{CO}_{2}\right]$ from MMCO Lagerstätte deposits using different approaches and found relatively similar estimates; i.e., 402 - 614 ppm using stomatal methods, 364 - 609 ppm using the Franks et al. (2014) method, and 471 - 624 ppm using the $\mathrm{C}_{3}$ proxy method of Schubert and Jahren (2012). Their estimates are higher than previously inferred from carbonate and $\delta^{11} \mathrm{~B}$ (400 - 450 ppm; Foster et al. (2017)). $\left[\mathrm{CO}_{2}\right]$ values around $400-450 \mathrm{ppm}$ as suggested by the last study imply extremely high equilibrium climate sensitivity (ECS), i.e. warming of $5{ }^{\circ} \mathrm{K}$ at the MCO for a doubling of $\left[\mathrm{CO}_{2}\right]$, which is out of the 2.3 - 
$4.7^{\circ} \mathrm{K}$ range proposed by a growing number of studies based on both modern and paleo-records (e.g., Sherwood et al. (2020)). The range of $\left[\mathrm{CO}_{2}\right]$ values implied by our re-modeling of the Cui et al. (2020) compilation, and by Steinthorsdottir et al. (2020) are more consistent with an ECS lower than $5^{\circ} \mathrm{K}$, suggesting that $\left[\mathrm{CO}_{2}\right]$ should be revised upwards for the MCO in paleo reconstructions.

Although incorporating greater diversity of plant physiological responses (Porter et al., 2019; Yiotis and McElwain, 2019; Steinthorsdottir et al., 2020), and/or increasing the number of parameters into models (Konrad et al., 2020) might help to improve the accuracy of paleo- $\left[\mathrm{CO}_{2}\right]$ proxies, there are nevertheless disadvantages to our approach. For instance, our proposed framework assumes constant anatomical and physiological differences across plant evolutionary history (particularly with respect to photorespiration), or even within a single plant lifetime, which might not be the case (Reich et al., 2018). Nevertheless, the differences identified here are robust across a wide variety of woody species, and environments. Further research is needed to determine whether these relationships hold over a wider range of temperatures, $\left[\mathrm{O}_{2}\right]:\left[\mathrm{CO}_{2}\right]$ ratios, water availability, and nutrient regimes.

\section{Conclusion}

In this study, we aimed to better understand the factors that influence differences in $\Delta^{13} \mathrm{C}$ between angiosperm and gymnosperm $\mathrm{C}_{3}$ woody plants. Using a comprehensive ab initio model of carbon isotope discrimination, and training it against a very large $20^{\text {th }}$ century dataset, we demonstrated that isotope discrimination is phylogenydependent. Multiple intrinsic physiological factors give rise to differences in gymnosperm and angiosperm $\Delta^{13} \mathrm{C}$ values - including $\beta_{\mathrm{c}}$ - the ratio of cost factors for carboxylation to transpiration (related to leaf physiology), $g_{\mathrm{m}} / g_{\mathrm{s}}$ - the ratio of mesophyll to stomatal conductances for $\mathrm{CO}_{2}$ (related to leaf morphology), and $\lambda$ - the fraction of $\mathrm{CO}_{2}$ released during photorespiration (related to plant carbon metabolism).

We also showed that the $\Delta^{13} \mathrm{C}$ offset between the two $\mathrm{C}_{3}$ plant groups is very likely not constant over time, but varies with environmental conditions, and changes in atmospheric $\left[\mathrm{O}_{2}\right]:\left[\mathrm{CO}_{2}\right]$ ratio. Overall, our results can be summarised as follows:

- $\Delta^{13} \mathrm{C}$ in angiosperms is more sensitive to $\left[\mathrm{CO}_{2}\right]$ than in gymnosperms;

- $\Delta^{13} \mathrm{C}$ in gymnosperms is more sensitive to $D$ than in angiosperms;

- $\Delta_{\mathrm{a}-\mathrm{g}}^{*}$ increases modestly with decreasing $\left[\mathrm{O}_{2}\right]$ : $\left[\mathrm{CO}_{2}\right]$ ratio, and/or increasing $\left[\mathrm{CO}_{2}\right]$,

- $\Delta_{\mathrm{a}-\mathrm{g}}^{*}$ increases strongly with increasing $D$.

These findings have important implications for geological studies because they suggest that the substantial variations of stable carbon isotopic composition observed in the geological record (up to $7 \%$ ) reflect not only diagenesis, or post-photosynthetic fractionation (as has been previously assumed), but also different plant responses to $D$, and changing atmospheric $\left[\mathrm{O}_{2}\right]:\left[\mathrm{CO}_{2}\right]$ ratios. On the other hand, the simple model presented here for $\Delta_{\mathrm{a}-\mathrm{g}}^{*}($ Eqn. 8) presents an opportunity to refine $\Delta^{13} \mathrm{C}$-based proxies of paleoatmospheric composition, if diagenesis can be ruled out, and $D$ levels can be independently constrained. 
Our framework reconciles previously unexplained observed patterns, such as covariation of modern tree ring $\Delta_{\mathrm{a}-\mathrm{g}}^{*}$ with latitude (and D) (Leavitt and Newberry, 1992), variable $\left[\mathrm{O}_{2}\right]$ (Porter et al., 2017), and differences during glacial maxima (Hare et al., 2018; Breecker, 2017). It also offers a testable relationship that can be evaluated and refined using plant chamber experiments and field observations. For instance, we predict that $\Delta_{\mathrm{a}-\mathrm{g}}^{*}$ will increase in future decades of the $21^{\text {st }}$ century, because $D$ is likely to rise along with anthropogenic $\left[\mathrm{CO}_{2}\right]$ emissions.

\section{Declaration of Competing Interest}

The authors declare that they have no known competing financial interests or personal relationships that could have appeared to influence the work reported in this paper.

\section{Acknowledgments}

This work was supported by a South African NRF - ERC Partnership Grant (No. 120141) to VJH for research leave to Imperial College, kindly hosted by H. Graven. A.L. was supported by a Marie Sklodowska-Curie Individual Fellowship under the European Union's Horizon 2020 Research and Innovation Programme (Grant agreement no: 838739 ECAW-ISO). We thank S. Leavitt, I. C. Prentice, and Caitlyn Witkowski, for helpful suggestions, and comments. The meticulous and constructive comments of three anonymous reviewers are appreciated.

\section{References}

Bechtel A., Gratzer R., Sachsenhofer R. F., Gusterhuber J., Lücke A. and Püttmann W. (2008) Biomarker and carbon isotope variation in coal and fossil wood of Central Europe through the Cenozoic. Palaeogeography, Palaeoclimatology, Palaeoecology 262(3-4), 166-175.

Bechtel A., Widera M. and Woszczyk M. (2019) Composition of lipids from the First Lusatian lignite seam of the Konin Basin (Poland): Relationships with vegetation, climate and carbon cycling during the mid-Miocene Climatic Optimum. Organic Geochemistry 138, 103908.

Bereiter B., Eggleston S., Schmitt J., Nehrbass-Ahles C., Stocker T. F., Fischer H., Kipfstuhl S. and Chappellaz J. (2015) Revision of the EPICA Dome C CO2 record from 800 to $600 \mathrm{kyr}$ before present. Geophysical Research Letters 42(2), 542-549.

Bernacchi C. J., Portis A. R., Nakano H., von Caemmerer S. and Long S. P. (2002) Temperature response of mesophyll conductance. Implications for the determination of Rubisco enzyme kinetics and for limitations to photosynthesis in vivo. Plant physiology 130(4), 1992-1998.

Breecker D. O. (2017) Atmospheric $\mathrm{pCO}_{2}$ control on speleothem stable carbon isotope compositions. Earth and Planetary Science Letters 458, 58-68.

Busch F. A. (2020) Photorespiration in the context of Rubisco biochemistry, CO2 diffusion, and metabolism. The Plant Journal 101, 919-939. 
Busch F. A., Holloway-Phillips M., Stuart-Williams H. and Farquhar G. D. (2020) Revisiting carbon isotope discrimination in C3 plants shows respiration rules when photosynthesis is low. Nature Plants 6(3), 245-258.

Busch F. A., Sage R. F. and Farquhar G. D. (2018) Plants increase CO2 uptake by assimilating nitrogen via the photorespiratory pathway. Nature plants $\mathbf{4}(1), 46$.

Cernusak L. A., Tcherkez G., Keitel C., Cornwell W. K., Santiago L. S., Knohl A., Barbour M. M., Williams D. G., Reich P. B., Ellsworth D. S. et al. (2009) Why are non-photosynthetic tissues generally 13C enriched compared with leaves in C3 plants? Review and synthesis of current hypotheses. Functional Plant Biology 36(3), 199-213.

Cornwell W. K., Wright I., Turner J., Maire V., Barbour M., Cernusak L., Dawson T., Ellsworth D., Farquhar G., Griffiths H. et al. (2016) A global dataset of leaf delta 13C values. Scientific Data .

Craig H. (1954) Carbon 13 in plants and the relationships between carbon 13 and carbon 14 variations in nature. The journal of geology pp. 115-149.

Cui Y. and Schubert B. A. (2018) Towards determination of the source and magnitude of atmospheric pCO2 change across the early Paleogene hyperthermals. Global and Planetary Change 170, 120-125.

Cui Y., Schubert B. A. and Jahren A. H. (2020) A 23 my record of low atmospheric CO2. Geology 48(9), 888-892.

De Boer H. J., Eppinga M. B., Wassen M. J. and Dekker S. C. (2012) A critical transition in leaf evolution facilitated the Cretaceous angiosperm revolution. Nature Communications 3(1), 1-11.

Diefendorf A. F., Freeman K. H. and Wing S. L. (2012) Distribution and carbon isotope patterns of diterpenoids and triterpenoids in modern temperate $\mathrm{C} 3$ trees and their geochemical significance. Geochimica et Cosmochimica Acta 85, 342-356.

Diefendorf A. F., Freeman K. H., Wing S. L., Currano E. D. and Mueller K. E. (2015) Paleogene plants fractionated carbon isotopes similar to modern plants. Earth and Planetary Science Letters 429, 33-44.

Diefendorf A. F., Leslie A. B. and Wing S. L. (2019) A phylogenetic analysis of conifer diterpenoids and their carbon isotopes for chemotaxonomic applications. Organic Geochemistry 127, 50-58.

Diefendorf A. F., Mueller K. E., Wing S. L., Koch P. L. and Freeman K. H. (2010) Global patterns in leaf 13C discrimination and implications for studies of past and future climate. Proceedings of the National Academy of Sciences 107(13), 5738-5743.

Eberle J. J. and Greenwood D. R. (2012) Life at the top of the greenhouse Eocene world-A review of the Eocene flora and vertebrate fauna from Canada's High Arctic. Bulletin 124(1-2), 3-23.

Ehleringer J., R, Hall A. E. and Farquhar G. D. (1993). Water use in relation to productivity, Chapter in Saugier et al (Eds.), Stable isotopes and plant carbon-water relations, Elsevier, pp. 155-172.

Farquhar G. D. and Cernusak L. A. (2012) Ternary effects on the gas exchange of isotopologues of carbon dioxide. Plant, Cell \& Environment 35(7), 1221-1231. 
Farquhar G. D., O’Leary M. H. and Berry J. A. (1982) On the relationship between carbon isotope discrimination and the intercellular carbon dioxide concentration in leaves. Functional Plant Biology 9(2), 121-137.

Farquhar G. v., von Caemmerer S. v. and Berry J. (1980) A biochemical model of photosynthetic $\mathrm{CO}_{2}$ assimilation in leaves of C3 species. Planta 149(1), 78-90.

Flexas J. and Carriquí M. (2020) Photosynthesis and photosynthetic efficiencies along the terrestrial plant's phylogeny: Lessons for improving crop photosynthesis. The Plant Journal 101(4), 964-978.

Foster G. L., Royer D. L. and Lunt D. J. (2017) Future climate forcing potentially without precedent in the last 420 million years. Nature communications $\mathbf{8}, 14845$.

Frank D., Poulter B., Saurer M., Esper J., Huntingford C., Helle G., Treydte K., Zimmermann N. E., Schleser G., Ahlström A. et al. (2015) Water-use efficiency and transpiration across European forests during the Anthropocene. Nature Climate Change 5(6), 579-583.

Franks P. J., Royer D. L., Beerling D. J., Van de Water P. K., Cantrill D. J., Barbour M. M. and Berry J. A. (2014) New constraints on atmospheric CO2 concentration for the Phanerozoic. Geophysical Research Letters 41(13), 4685-4694.

Galmés J., Hermida-Carrera C., Laanisto L. and Niinemets Ü. (2016) A compendium of temperature responses of Rubisco kinetic traits: variability among and within photosynthetic groups and impacts on photosynthesis modeling. Journal of experimental botany 67(17), 5067-5091.

Gehler A., Gingerich P. D. and Pack A. (2016) Temperature and atmospheric CO2 concentration estimates through the PETM using triple oxygen isotope analysis of mammalian bioapatite. Proceedings of the National Academy of Sciences 113(28), 7739-7744.

Gessler A., Ferrio J. P., Hommel R., Treydte K., Werner R. A. and Monson R. K. (2014) Stable isotopes in tree rings: towards a mechanistic understanding of isotope fractionation and mixing processes from the leaves to the wood. Tree physiology 34(8), 796-818.

Ghashghaie J., Badeck F.-W., Lanigan G., Nogués S., Tcherkez G., Deléens E., Cornic G. and Griffiths H. (2003) Carbon isotope fractionation during dark respiration and photorespiration in C3 plants. Phytochemistry reviews 2(1-2), 145-161.

Graven H., Allison C. E., Etheridge D. M., Hammer S., Keeling R. F., Levin I., Meijer H. A., Rubino M., Tans P. P., Trudinger C. M. et al. (2017) Compiled records of carbon isotopes in atmospheric CO2 for historical simulations in CMIP6. Geoscientific Model Development (Online) 10(12).

Greenwood D. R., Basinger J. F. and Smith R. Y. (2010) How wet was the Arctic Eocene rain forest? Estimates of precipitation from Paleogene Arctic macrofloras. Geology 38(1), 15-18. 
Guerrieri R., Belmecheri S., Ollinger S. V., Asbjornsen H., Jennings K., Xiao J., Stocker B. D., Martin M., Hollinger D. Y., Bracho-Garrillo R. et al. (2019) Disentangling the role of photosynthesis and stomatal conductance on rising forest water-use efficiency. Proceedings of the National Academy of Sciences 116(34), 16909-16914.

Guerrieri R., Lepine L., Asbjornsen H., Xiao J. and Ollinger S. V. (2016) Evapotranspiration and water use efficiency in relation to climate and canopy nitrogen in US forests. Journal of Geophysical Research: Biogeosciences 121(10), 2610-2629.

Haario H., Laine M., Mira A. and Saksman E. (2006) DRAM: efficient adaptive MCMC. Statistics and computing 16(4), 339-354.

Hare V. J., Loftus E., Jeffrey A. and Ramsey C. B. (2018) Atmospheric CO2 effect on stable carbon isotope composition of terrestrial fossil archives. Nature communications 9(1), 1-8.

Harris I., Jones P. D., Osborn T. J. and Lister D. H. (2014) Updated high-resolution grids of monthly climatic observations-the CRU TS3. 10 Dataset. International journal of climatology 34(3), 623-642.

Helliker B. R. and Richter S. L. (2008) Subtropical to boreal convergence of tree-leaf temperatures. Nature 454(7203), 511-514.

Hollis C. J., Dunkley Jones T., Anagnostou E., Bijl P. K., Cramwinckel M. J., Cui Y., Dickens G. R., Edgar K. M., Eley Y., Evans D. et al. (2019) The DeepMIP contribution to PMIP4: methodologies for selection, compilation and analysis of latest Paleocene and early Eocene climate proxy data, incorporating version 0.1 of the DeepMIP database. Geoscientific Model Development 12(7), 3149-3206.

Kattge J., Bönisch G., Díaz S., Lavorel S., Prentice I. C., Leadley P., Tautenhahn S., Werner G. D., Aakala T., Abedi M. et al. (2020) TRY plant trait database-enhanced coverage and open access. Global change biology .

Keeling R. F., Graven H. D., Welp L. R., Resplandy L., Bi J., Piper S. C., Sun Y., Bollenbacher A. and Meijer H. A. (2017) Atmospheric evidence for a global secular increase in carbon isotopic discrimination of land photosynthesis. Proceedings of the National Academy of Sciences 114(39), 10361-10366.

Köhler P., Nehrbass-Ahles C., Schmitt J., Stocker T. F. and Fischer H. (2017) A 156 kyr smoothed history of the atmospheric greenhouse gases $\mathrm{CO} 2, \mathrm{CH} 4$, and $\mathrm{N} 2 \mathrm{O}$ and their radiative forcing. Earth System Science Data 9(1), 363-387.

Kohn M. J. (2010) Carbon isotope compositions of terrestrial C3 plants as indicators of (paleo)ecology and (paleo)climate. Proceedings of the National Academy of Sciences 107(46), 19691-19695.

Konrad W., Royer D. L., Franks P. J. and Roth-Nebelsick A. (2020) Quantitative critique of leaf-based paleo-CO2 proxies: Consequences for their reliability and applicability. Geological Journal .

Lavergne A., Graven H., De Kauwe M. G., Keenan T. F., Medlyn B. E. and Prentice I. C. (2019) Observed and modelled historical trends in the water-use efficiency of plants and ecosystems. Global change biology 25(7), 2242-2257. 
Lavergne A., Sandoval D., Hare V. J., Graven H. and Prentice I. C. (2020b) Impacts of soil water stress on the acclimated stomatal limitation of photosynthesis: insights from stable carbon isotope data. Global Change Biology 26, 7158-7172.

Lavergne A., Voelker S., Csank A., Graven H., de Boer H. J., Daux V., Robertson I., Dorado-Liñán I., MartínezSancho E., Battipaglia G. et al. (2020a) Historical changes in the stomatal limitation of photosynthesis: empirical support for an optimality principle. New Phytologist 225(6), 2484-2497.

Leavitt S. (2001) Seasonal response of $\delta^{13} \mathrm{C}$ in Pinus resinosa Ait. seedling growth rings to changing environment in controlled growth experiments. Dendrochronologia 19(1), 9-22.

Leavitt S. and Newberry T. (1992) Systematics of stable-carbon isotopic differences between gymnosperm and angiosperm trees. Plant Physiol.(Life Sci. Adv.) 11, 257-262.

Mills B. J., Belcher C. M., Lenton T. M. and Newton R. J. (2016) A modeling case for high atmospheric oxygen concentrations during the Mesozoic and Cenozoic. Geology 44(12), 1023-1026.

Orr D. J., Alcântara A., Kapralov M. V., Andralojc P. J., Carmo-Silva E. and Parry M. A. (2016) Surveying Rubisco diversity and temperature response to improve crop photosynthetic efficiency. Plant Physiology 172(2), 707-717.

Paillassa J., Wright I. J., Prentice I. C., Pepin S., Smith N. G., Ethier G., Westerband A. C., Lamarque L. J., Wang H., Cornwell W. K. et al. (2020) When and where soil is important to modify the carbon and water economy of leaves. New Phytologist 228(1), 121-135.

Pedentchouk N., Sumner W., Tipple B. and Pagani M. (2008) $\delta 13 \mathrm{C}$ and $\delta$ D compositions of n-alkanes from modern angiosperms and conifers: an experimental set up in central Washington State, USA. Organic Geochemistry 39(8), 1066-1071.

Porter A. S., Gerald C. E.-F., McElwain J. C., Yiotis C. and Elliott-Kingston C. (2015) How well do you know your growth chambers? Testing for chamber effect using plant traits. Plant Methods 11(1), 1-10.

Porter A. S., Gerald C. E.-F., Yiotis C., Montanez I. P. and McElwain J. C. (2019) Testing the accuracy of new paleoatmospheric $\mathrm{CO} 2$ proxies based on plant stable carbon isotopic composition and stomatal traits in a range of simulated paleoatmospheric O2:CO2 ratios. Geochimica et Cosmochimica Acta 259, 69-90.

Porter A. S., Yiotis C., Montañez I. P. and McElwain J. C. (2017) Evolutionary differences in $\Delta^{13}$ C detected between spore and seed bearing plants following exposure to a range of atmospheric $\mathrm{O}_{2}: \mathrm{CO}_{2}$ ratios; implications for paleoatmosphere reconstruction. Geochimica et Cosmochimica Acta 213, 517-533.

Prentice I. C., Dong N., Gleason S. M., Maire V. and Wright I. J. (2014) Balancing the costs of carbon gain and water transport: testing a new theoretical framework for plant functional ecology. Ecology Letters 17(1), 82-91.

Reich P. B., Hobbie S. E., Lee T. D. and Pastore M. A. (2018) Unexpected reversal of C3 versus C4 grass response to elevated $\mathrm{CO}_{2}$ during a 20-year field experiment. Science 360(6386), 317-320. 
Reichgelt T., D’Andrea W. J., Valdivia-McCarthy A. d. C., Fox B. R., Bannister J. M., Conran J. G., Lee W. G. and Lee D. E. (2020) Elevated $\mathrm{CO}_{2}$, increased leaf-level productivity, and water-use efficiency during the early Miocene. Climate of the Past 16(4), 1509-1521.

Royer D. L., Moynihan K. M., McKee M. L., Londoño L. and Franks P. J. (2019) Sensitivity of a leaf gas-exchange model for estimating paleoatmospheric $\mathrm{CO}_{2}$ concentration. Climate of the Past 15(2).

Sakamoto A. and Murata N. (2002) The role of glycine betaine in the protection of plants from stress: clues from transgenic plants. Plant, Cell \& Environment 25(2), 163-171.

Schlanser K. M., Diefendorf A. F., West C. K., Greenwood D. R., Basinger J. F., Meyer H. W., Lowe A. J. and Naake H. H. (2020) Conifers are a major source of sedimentary leaf wax n-alkanes when dominant in the landscape: Case studies from the Paleogene. Organic Geochemistry 147, 104069.

Schouten S., Woltering M., Rijpstra W. I. C., Sluijs A., Brinkhuis H. and Damsté J. S. S. (2007) The PaleoceneEocene carbon isotope excursion in higher plant organic matter: Differential fractionation of angiosperms and conifers in the Arctic. Earth and Planetary Science Letters 258(3-4), 581-592.

Schubert B. A. and Jahren A. H. (2012) The effect of atmospheric $\mathrm{CO}_{2}$ concentration on carbon isotope fractionation in C3 land plants. Geochimica et Cosmochimica Acta 96, 29-43.

Schubert B. A. and Jahren A. H. (2018) Incorporating the effects of photorespiration into terrestrial paleoclimate reconstruction. Earth-Science Reviews 177, 637-642.

Sheldon N. D., Smith S. Y., Stein R. and Ng M. (2020) Carbon isotope ecology of gymnosperms and implications for paleoclimatic and paleoecological studies. Global and Planetary Change 184, 103060.

Sherwood S., Webb M. J., Annan J. D., Armour K. C., Forster P. M., Hargreaves J. C., Hegerl G., Klein S. A., Marvel K. D., Rohling E. J., Watanabe M., Andrews T., Braconnot P., Bretherton C. S., Foster G. L., Hausfather Z., Heydt A. S. v. d., Knutti R., Mauritsen T., Norris J. R., Proistosescu C., Rugenstein M., Schmidt G. A., Tokarska K. B. and Zelinka M. D. (2020) An assessment of Earth's climate sensitivity using multiple lines of evidence. Reviews of Geophysics n/a(n/a), e2019RG000678. e2019RG000678 2019RG000678.

URL: https://agupubs.onlinelibrary.wiley.com/doi/abs/10.1029/2019RG000678

Soh W. K., Yiotis C., Murray M., Parnell A., Wright I. J., Spicer R. A., Lawson T., Caballero R. and McElwain J. C. (2019) Rising $\mathrm{CO}_{2}$ drives divergence in water use efficiency of evergreen and deciduous plants. Science Advances 5(12), eaax7906.

Steinthorsdottir M., Jardine P. and Rember W. (2020) Near-Future $\mathrm{pCO}_{2}$ during the hot Mid Miocene Climatic Optimum. Paleoceanography and Paleoclimatology p. e2020PA003900.

Stuiver M. and Braziunas T. F. (1987) Tree cellulose $13 \mathrm{C} / 12 \mathrm{C}$ isotope ratios and climatic change. Nature 328(6125), 58-60. 
Tcherkez G. (2006) How large is the carbon isotope fractionation of the photorespiratory enzyme glycine decarboxylase? Functional Plant Biology 33(10), 911-920.

Ubierna N., Cernusak L. A., Holloway-Phillips M., Busch F. A., Cousins A. B. and Farquhar G. D. (2019) Critical review: incorporating the arrangement of mitochondria and chloroplasts into models of photosynthesis and carbon isotope discrimination. Photosynthesis research 141(1), 5-31.

Ubierna N. and Farquhar G. D. (2014) Advances in measurements and models of photosynthetic carbon isotope discrimination in C3 plants. Plant, cell \& environment 37(7), 1494-1498.

Voelker S. L., Brooks J. R., Meinzer F. C., Anderson R., Bader M. K.-F., Battipaglia G., Becklin K. M., Beerling D., Bert D., Betancourt J. L. et al. (2016) A dynamic leaf gas-exchange strategy is conserved in woody plants under changing ambient $\mathrm{CO} 2$ : Evidence from carbon isotope discrimination in paleo and $\mathrm{CO}_{2}$ enrichment studies. Global change biology 22(2), 889-902.

Vogado N. O., Winter K., Ubierna N., Farquhar G. D. and Cernusak L. A. (2020) Directional change in leaf dry matter $\delta^{13} \mathrm{C}$ during leaf development is widespread in $\mathrm{C}_{3}$ plants. Annals of Botany .

Walker B. J., Orr D. J., Carmo-Silva E., Parry M. A., Bernacchi C. J. and Ort D. R. (2017) Uncertainty in measurements of the photorespiratory $\mathrm{CO} 2$ compensation point and its impact on models of leaf photosynthesis. Photosynthesis research 132(3), 245-255.

Wang H., Prentice I. C., Keenan T. F., Davis T. W., Wright I. J., Cornwell W. K., Evans B. J. and Peng C. (2017) Towards a universal model for carbon dioxide uptake by plants. Nature plants 3(9), 734.

West C. K., Greenwood D. R. and Basinger J. F. (2015) Was the Arctic Eocene 'rainforest' monsoonal? Estimates of seasonal precipitation from early Eocene megafloras from Ellesmere Island, Nunavut. Earth and Planetary Science Letters 427, 18-30.

Yiotis C. and McElwain J. C. (2019) A novel hypothesis for the role of photosynthetic physiology in shaping macroevolutionary patterns. Plant physiology 181(3), 1148-1162.

Zanne A. E., Tank D. C., Cornwell W. K., Eastman J. M., Smith S. A., FitzJohn R. G., McGlinn D. J., O’Meara B. C., Moles A. T., Reich P. B. et al. (2014) Three keys to the radiation of angiosperms into freezing environments. Nature 506(7486), 89-92.

Zhang H.-Y., Hartmann H., Gleixner G., Thoma M. and Schwab V. F. (2019) Carbon isotope fractionation including photosynthetic and post-photosynthetic processes in $\mathrm{C} 3$ plants: Low [CO2] matters. Geochimica et Cosmochimica Acta 245, 1-15. 


\title{
Differences in carbon isotope discrimination between angiosperm and
} gymnosperm woody plants, and their geological significance

\author{
(ELECTRONIC ANNEX)
}

Vincent J. Hare 1

Stable Light Isotope Laboratory, Department of Archaeology, University of Cape Town Carbon Cycle Research Group, Department of Physics, Imperial College London

Aliénor Lavergne

Carbon Cycle Research Group, Department of Physics, Imperial College London

(Dated: February 12, 2021)

${ }^{1}$ Email: vincent.john.hare@ gmail.com 


\section{Locations of $\Delta^{13} \mathrm{C}$ dataset}

Figure $\mathrm{S} 1$ shows the location of the tree ring and leaf data sites for angiosperm and gymnosperm plants used in the study. The isotopic data are derived from diverse species and plant functional types growing in a wide range of environments characterised by different soil water content and evaporative demand (vapour pressure deficit, $D$, ranging around 0.1 and $2 \mathrm{kPa}$ ).

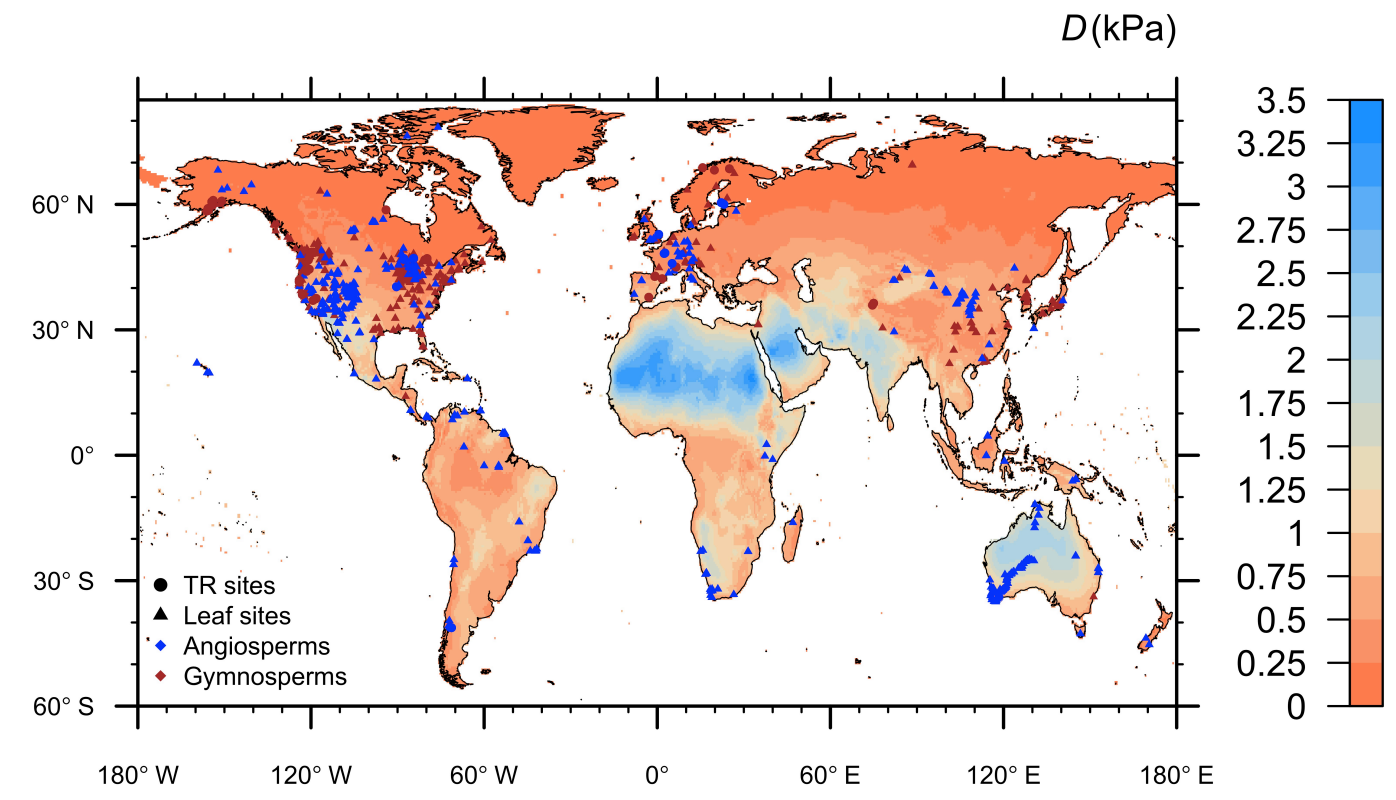

Figure S1: Global locations of tree ring (TR) and leaf stable carbon isotopic data. Blue points correspond to angiosperms, while red points are for gymnosperms. Yearly-averaged daytime vapour pressure deficit $(D)$ is given in $\mathrm{kPa}$.

\section{Derivation of expression for $\Delta^{13} \mathrm{C}$ in $C_{c}$-basis (Eq. 4, main text)}

An comprehensive expression for leaf carbon isotope discrimination, assuming finite mesophyll conductance, and including photorespiration terms (but excluding fractionation during respiration), was proposed by [14] as:

$$
\Delta^{13} \mathrm{C}=a_{\mathrm{s}}(1-\chi)+a_{\mathrm{m}}\left(\chi-\chi_{\mathrm{c}}\right)+b \chi_{\mathrm{c}}-(f-w h) \frac{\Gamma^{*}}{C_{\mathrm{a}}}
$$

where for convenience we adopt the notation suggested by ref. [16] of $\chi=C_{\mathrm{i}} / C_{\mathrm{a}}$, and $\chi_{\mathrm{c}}=C_{\mathrm{c}} / C_{\mathrm{a}}$. Assuming that the $\mathrm{CO}_{2}$ flux from the outside of the leaf to the intercellular spaces is equal to the flux from the intercelullar spaces to the chloroplast, Fick's law yields:

$$
A=g_{\mathrm{s}}\left(C_{\mathrm{a}}-C_{\mathrm{i}}\right)=g_{\mathrm{m}}\left(C_{\mathrm{i}}-C_{\mathrm{c}}\right)
$$

which can be rewritten as:

$$
g_{\mathrm{s}}(1-\chi)=\theta_{\mathrm{m}} g_{\mathrm{s}}\left(\chi-\chi_{\mathrm{c}}\right)
$$

where $\theta_{\mathrm{m}}$ is the ratio of mesophyll $\left(g_{\mathrm{m}}\right)$ to stomatal conductance $\left(g_{\mathrm{s}}\right)$. Rearranging this expression yields

$$
(1-\chi)=\frac{\theta_{\mathrm{m}}\left(1-\chi_{\mathrm{c}}\right)}{1+\theta_{\mathrm{m}}}, \text { and }
$$




$$
\left(\chi-\chi_{\mathrm{c}}\right)=\frac{1-\chi_{\mathrm{c}}}{1+\theta_{\mathrm{m}}}
$$

Inserting Eqns 1.4-1.5 into Eq. 1.1 yields the expression for $\Delta^{13} \mathrm{C}$ in terms of $\chi_{\mathrm{c}}$ :

$$
\Delta^{13} \mathrm{C}=\bar{a}+[b-\bar{a}] \chi_{\mathrm{c}}-f \frac{\Gamma_{\mathrm{c}}}{C_{\mathrm{a}}}
$$

where $\bar{a}=\left(a_{\mathrm{s}} \theta_{\mathrm{m}}+a_{\mathrm{m}}\right) /\left(1+\theta_{\mathrm{m}}\right)$.

\section{Rubisco kinetics}

Parameters associated with Rubisco kinetics include the Michaelis-Menten coefficients for $\mathrm{CO}_{2}, K_{\mathrm{c}}$ $(\mathrm{Pa})$, and $\mathrm{O}_{2}, K_{\mathrm{o}}(\mathrm{Pa})$, as well as $\Gamma_{\mathrm{c}}(\mathrm{Pa})$. The former two parameters are combined into the effective Michaelis-Menten coefficient for Rubisco, $K(\mathrm{~Pa})$, as follows:

$$
K=K_{\mathrm{c}}\left(1+\frac{p \mathrm{O}_{2}}{K_{\mathrm{o}}}\right)
$$

Both $K_{\mathrm{c}}$ and $K_{\mathrm{o}}$ exhibit an Arrhenius temperature response which depends on their respective activation energies $\left(E_{\mathrm{a}, \mathrm{Kc}}\right.$ and $\left.E_{\mathrm{a}, \mathrm{Ko}}\right)$. At any given temperature $\mathrm{T}(\mathrm{K})$, these variables in $(\mathrm{Pa})$ were computed as follows:

$$
\begin{aligned}
& K_{\mathrm{c}}(\mathrm{T})=K_{\mathrm{c}, 25} \times 10^{-6} P_{\mathrm{atm}} \exp \left[\frac{E_{\mathrm{a}, \mathrm{Kc}}}{R}\left(\frac{1}{298.15}-\frac{1}{T}\right)\right] \\
& K_{\mathrm{o}}(\mathrm{T})=K_{\mathrm{o}, 25} \times 10^{-3} P_{\mathrm{atm}} \exp \left[\frac{E_{\mathrm{a}, \mathrm{Ko}}}{R}\left(\frac{1}{298.15}-\frac{1}{T}\right)\right]
\end{aligned}
$$

Values for $K_{\mathrm{c}, 25}, E_{\mathrm{a}, \mathrm{Kc}}, K_{\mathrm{o}, 25}$, and $E_{\mathrm{a}, \mathrm{Ko}}$ were taken from study [1] as $272.38 \mu \mathrm{mol} \mathrm{mol}^{-1}, 80.99 \mathrm{~kJ}$ $\mathrm{mol}^{-1}, 165.82 \mathrm{mmol} \mathrm{mol}^{-1}$, and $23.72 \mathrm{~kJ} \mathrm{~mol}^{-1}$ respectively. For leaf and tree ring data, $p \mathrm{O}_{2}$ was estimated from altitude ( $z$, in meters) via a standard barometric formula:

$$
p \mathrm{O}_{2}[\mathrm{~Pa}]=101325 \times\left(1-\left(2.25577 \times 10^{-5}\right) z\right)^{5.25588}
$$

Finally, the photorespiratory $\mathrm{CO}_{2}$ compensation point $(\mathrm{Pa})$ was calculated as:

$$
\Gamma_{\mathrm{c}}(T)=\Gamma_{\mathrm{c}, 25} \times 10^{-6} P_{\mathrm{atm}}\left(\lambda / \lambda_{\mathrm{ref}}\right) \exp \left[\frac{E_{\mathrm{a}, \Gamma_{\mathrm{c}}}}{R}\left(\frac{1}{298.15}-\frac{1}{T}\right)\right]
$$

Likewise, $\Gamma_{\mathrm{c}, 25}$ and $E_{\mathrm{a}, \Gamma_{\mathrm{c}}}$ were taken from [1] as $37.43 \mu \mathrm{mol} \mathrm{mol}^{-1}$ and $24.46 \mathrm{~kJ} \mathrm{~mol}^{-1}$. Since these values were estimated for tobacco at $25^{\circ} \mathrm{C}$, we use the $\lambda_{\text {ref }}$ value inferred from [15] as 0.6.

\section{Estimation of daytime growing leaf temperature, $T_{\mathrm{d}}$}

Latitude and longitude were used to extract minimum and maximum temperatures $\left(T_{\min }\right.$ and $\left.T_{\min },{ }^{\circ} \mathrm{C}\right)$, and actual vapor pressure $\left(e_{\mathrm{a}}\right)$ for each site from monthly $0.5^{\circ}$ resolution data provided by the Climatic 
Research Unit (CRU Ts4.03; Ref. [9]). We calculated the raw monthly mean daytime air $T\left(T_{\mathrm{d}, \text { raw }}\right)$ to consider only the part of the day when photosynthesis occurs, as:

$$
T_{\mathrm{d}, \text { raw }}=T_{\max }\left[\frac{1}{2}+\frac{\sqrt{1-x^{2}}}{2 \arccos x}\right]+T_{\min }\left[\frac{1}{2}-\frac{\sqrt{1-x^{2}}}{2 \arccos x}\right]
$$

where $x=-\tan \phi \tan \delta$, with $\phi$ the latitude, and $\delta$ the average solar declination for the month.

We then convert raw monthly mean daytime air temperature to rough estimation of leaf temperature, $T_{\mathrm{d}}$, using the relationship identified between mean daytime air temperature (growing season) and leaf temperature in [10] (illustrated in Figure S2, S3). A regression was perfomed on the [10] data, excluding outlier values for the high Arctic (shown in red). The regression yielded a slope of 0.2998, and an intercept of $15.287^{\circ} \mathrm{C}\left(\mathrm{R}^{2}=0.3\right)$. This attenuates the variation in the raw values, to a range between 12 and $23{ }^{\circ} \mathrm{C}$ (e.g. for gymnosperms, shown below).

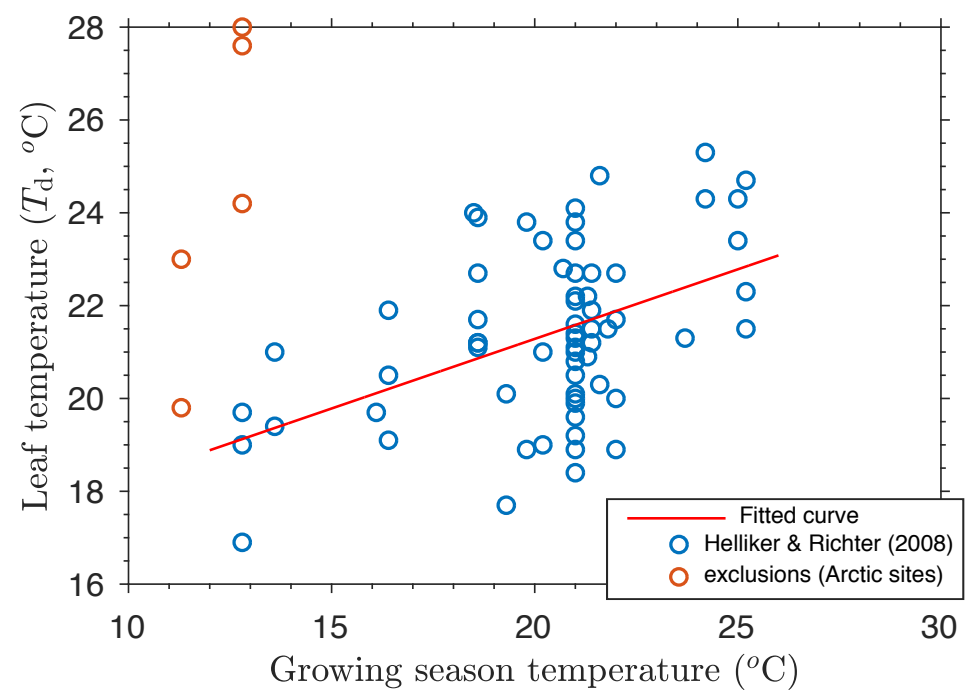

Figure S2: Mean daytime air temperature during the growing season versus leaf temperature estimated by leaf $\delta^{18} \mathrm{O}$. Data are from [10]. Outliers from the high Arctic (red) are excluded.

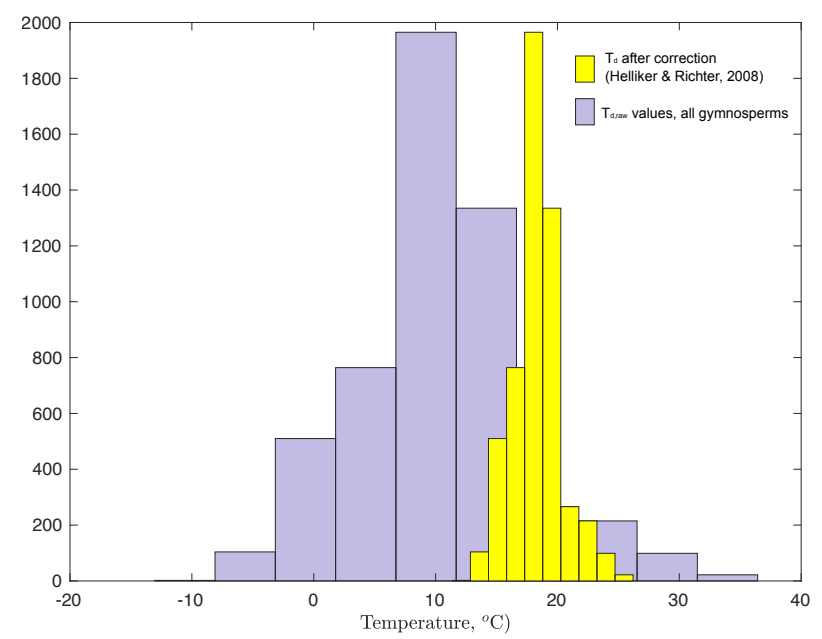

Figure S3: Comparison of raw (purple) and corrected (yellow) daytime leaf growing temperatures, after correction using the regressed relationship in Figure S2) 


\section{Full list of symbols used}

\begin{tabular}{|c|c|c|}
\hline Variable (units) & Description & Reference \\
\hline$\Delta^{13} \mathrm{C}(\%)$ & leaf-level carbon isotope discrimination & 14,133 \\
\hline$\Delta^{13} \mathrm{C}_{\mathrm{a}}(\%)$ & leaf-level carbon isotope discrimination, average angiosperm & this study \\
\hline$\Delta^{13} \mathrm{C}_{\mathrm{g}}(\%)$ & leaf-level carbon isotope discrimination, average gymnosperm & this study \\
\hline$\Delta^{13} \mathrm{C}_{\mathrm{a}-\mathrm{g}}^{*}(\%)$ & $\begin{array}{l}\text { difference between average co-located angiosperm and gymnosperm } \Delta^{13} \mathrm{C} \\
\text { at constant } T_{\mathrm{d}}, P_{\mathrm{atm}}, \& D\end{array}$ & this study \\
\hline$\varepsilon_{\text {lipid }}(\%)$ & post-photosynthetic fractionation during biosynthesis of leaf lipids & \\
\hline$\varepsilon_{\text {cellulose }}(\%)$ & post-photosynthetic fractionation during biosynthesis of cellulose & \\
\hline$t$ & ternary correction factor & [14, 13 3 \\
\hline$a_{\mathrm{s}}(\%)$ & fractionation for $\mathrm{CO}_{2}$ diffusion in air, $4.4 \%$ & 5 \\
\hline$a_{\mathrm{m}}(\%)$ & fractionation for $\mathrm{CO}_{2}$ diffusion in water, $1.8 \%$ & [14] \\
\hline$b(\%)$ & fractionation during Rubisco carboxylation, $30 \%$ & [14] \\
\hline$f(\%)$ & fractionation during photorespiration, $8-18 \%$ (theoretical: $11 \%$ ) & [12] \\
\hline$h(\%)$ & $\begin{array}{l}\text { apparent fractionation resulting from starch formation, and/or the kinetic } \\
\text { fractionation associated with the export of triose phosphates (TP) from the } \\
\text { chloroplast, and/or enzymes such as aldolase, transaldolase, transketolase } \\
\text { and TP isomerase }\end{array}$ & 3 \\
\hline$w$ (unitless) & coefficient of $h$ in $f-w h$ & [3] \\
\hline$\alpha_{b}$ (unitless) & fractionation factor for ${ }^{13} \mathrm{C} /{ }^{12} \mathrm{C}$ during carboxylation, $\alpha_{b}=1+b$ & [14] \\
\hline$\alpha_{e}$ (unitless) & fractionation factor for ${ }^{13} \mathrm{C} /{ }^{12} \mathrm{C}$ during respiration, $\alpha_{b}=1+e$ & 14 \\
\hline$\alpha_{f}$ (unitless) & fractionation factor for ${ }^{13} \mathrm{C} /{ }^{12} \mathrm{C}$ during photorespiration, $\alpha_{b}=1+f$ & [14] \\
\hline$\alpha_{h}$ (unitless) & as above, for $h$ & 3 \\
\hline$\lambda$ (unitless) & $\begin{array}{l}\text { amount of } \mathrm{CO}_{2} \text { released from photorespiration per oxygenation reaction, } \\
\text { relative to that of } N \text {. tabacum at } 25^{\circ} \mathrm{C}\end{array}$ & 2 \\
\hline$\lambda_{\mathrm{a}}$ (unitless) & average $\lambda$, woody angiosperms & this study \\
\hline$\lambda_{\mathrm{g}}$ (unitless) & average $\lambda$, woody gymnosperms & this study \\
\hline$\varepsilon_{f}$ (unitless) & gradient of the slope of $\Delta^{13} \mathrm{C}_{\mathrm{a}-\mathrm{g}}^{*}$ vs $\left[\mathrm{O}_{2}\right] /\left[\mathrm{CO}_{2}\right]$ at constant $T_{\mathrm{d}}, D$. & this study \\
\hline$\varepsilon_{a b}$ (unitless) & intercept of the slope of $\Delta^{13} \mathrm{C}_{\mathrm{a}-\mathrm{g}}^{*}$ vs $\left[\mathrm{O}_{2}\right] /\left[\mathrm{CO}_{2}\right]$ at constant $T_{\mathrm{d}}, D$. & this study \\
\hline$\alpha_{\mathrm{G}}$ (unitless) & proportion of glycine removed from the photorespiratory pathway & 42 \\
\hline$\alpha_{\mathrm{T}}$ (unitless) & $\begin{array}{l}\text { proportion of 2-Phosphoglycolate carbon exported as } \mathrm{CH}_{2}-\mathrm{THF} \text { from the } \\
\text { photorespiratory pathway }\end{array}$ & 2 \\
\hline$C_{\mathrm{a}}(\mathrm{Pa})$ & atmospheric $\mathrm{pCO}_{2}(\mathrm{~Pa})$, or as concentration $\left(\mu \mathrm{mol} \mathrm{mol}^{-1}\right)$ & \\
\hline$C_{\mathrm{s}}(\mathrm{Pa})$ & leaf-surface $\mathrm{pCO}_{2}(\mathrm{~Pa})$, or as concentration $\left(\mu \mathrm{mol} \mathrm{mol}^{-1}\right)$ & \\
\hline$C_{\mathrm{i}}(\mathrm{Pa})$ & leaf intercellular $\mathrm{pCO}_{2}(\mathrm{~Pa})$, or as concentration $\left(\mu \mathrm{mol} \mathrm{mol}^{-1}\right)$ & \\
\hline$C_{\mathrm{c}}(\mathrm{Pa})$ & chloroplastic $\mathrm{pCO}_{2}(\mathrm{~Pa})$, or as concentration $\left(\mu \mathrm{mol} \mathrm{mol}^{-1}\right)$ & \\
\hline $\mathrm{O}_{\mathrm{c}}\left(\mathrm{mol} . \mathrm{mol}^{-1}\right)$ & chloroplastic oxygen concentration & \\
\hline$g_{s}\left(\mathrm{~mol} \mathrm{~m}^{-2} \mathrm{~s}^{-1}\right)$ & stomatal conductance & |6 17| \\
\hline$g_{m}\left(\mathrm{~mol} \mathrm{~m}^{-2} \mathrm{~s}^{-1}\right)$ & mesophyll conductance & $6|17|$ \\
\hline$\beta_{\mathrm{c}}$ (unitless) & ratio of carboxylation to transpiration cost factors at $25^{\circ} \mathrm{C}$ & [16] \\
\hline$A\left(\mathrm{~mol} \mathrm{~m}^{-2} \mathrm{~s}^{-1}\right)$ & net rate of $\mathrm{CO}_{2}$ assimilation & \\
\hline$\eta^{*}$ (unitless) & viscosity of water relative to its value at $25^{\circ} \mathrm{C}$ & [16] \\
\hline$K_{\mathrm{c}}(\mathrm{Pa})$ & Michaelis-Menten coefficient of Rubisco carboxylation & 11 \\
\hline$K_{\mathrm{o}}(\mathrm{Pa})$ & Michaelis-Menten coefficient of Rubisco oxygenation & 11 \\
\hline$K(\mathrm{~Pa})$ & effective Michaelis-Menten coefficient of Rubisco & 1 \\
\hline$S_{\mathrm{c} / \mathrm{o}}\left(\mathrm{mol} \mathrm{mol}^{-1}\right)$ & Rubisco $\mathrm{CO}_{2} / \mathrm{O}_{2}$ specificity & 7 \\
\hline$\Gamma_{\mathrm{c}}(\mathrm{Pa})$ & $\begin{array}{l}\text { chloroplastic } \mathrm{CO}_{2} \text { compensation point in the absence of mitochondrial } \\
\text { respiration, when } A=0\end{array}$ & 13] \\
\hline$\Gamma^{*}(\mathrm{~Pa})$ & $\begin{array}{l}\text { chloroplastic } \mathrm{CO}_{2} \text { compensation point in the absence of mitochondrial } \\
\text { respiration, when } A=-\mathcal{R}_{\mathrm{d}}\end{array}$ & [13] \\
\hline$z(\mathrm{~m})$ & elevation & \\
\hline$P_{\text {atm }}(\mathrm{kPa})$ & atmospheric pressure & \\
\hline$T_{\mathrm{d}}\left({ }^{\circ} \mathrm{K}\right)$ & daytime leaf temperature & \\
\hline$D(\mathrm{kPa})$ & daytime vapour pressure deficit & \\
\hline$\left[\mathrm{O}_{2}\right]\left(\mathrm{mol} \mathrm{mol}^{-1}\right)$ & atmospheric oxygen concentration & \\
\hline$\left[\mathrm{CO}_{2}\right]\left(\mathrm{mol} \mathrm{mol}^{-1}\right)$ & atmospheric carbon dioxide concentration & \\
\hline
\end{tabular}

Note: Partial pressure and concentration are equivalent in equations for $\Delta^{13} \mathrm{C}$ when used in $\chi$ or $\chi_{\mathrm{c}}$ terms, but when $C_{\mathrm{a}}$ appears as the denominator, e.g. $\Gamma^{*} / C_{\mathrm{a}}$, the units should match that of $\Gamma^{*}$. 


\section{Fitting procedure}

We employed a Markov chain Monte Carlo technique (MCMC) based on the delayed rejection adaptive Metropolis (DRAM) algorithm of ref. [8] for robust parameter estimation of $\beta_{\mathrm{c}}, g_{\mathrm{m}} / g_{\mathrm{s}}$, and $\lambda / \lambda_{\text {ref. }}$. All MATLAB code is available from the authors.

We estimated these parameters for both combined and individual leaf and tree ring datasets. In all cases, we consider a model in the form of Eqns. (5-8), with Gaussian errors, and constants $b=30 \%, a_{s}=4.4$ $\%, a_{m}=1.8 \%, R=8.3145 \mathrm{~J} \mathrm{~mol}^{-1} \mathrm{~K}^{-1}$, and $f=11 \pm 2 \%$. Rubisco kinetic parameters were taken from [1] , and computed as in Section 2. Parameters for angiosperms were modelled as:

$$
\begin{gathered}
\beta_{\mathrm{c}} \sim \operatorname{Uniform}(70,1000) \\
g_{\mathrm{m}} / g_{\mathrm{s}} \sim \operatorname{Norm}\left(\mu_{1}, s_{1}{ }^{2}\right), g_{\mathrm{m}} / g_{\mathrm{s}} \in[0.06,6.3] \\
\lambda / \lambda_{\text {ref }} \sim \operatorname{Uniform}(0,10)
\end{gathered}
$$

Whereas parameters for gymnosperms were modelled as:

$$
\begin{gathered}
\beta_{\mathrm{c}} \sim \operatorname{Uniform}(70,1000) \\
g_{\mathrm{m}} / g_{\mathrm{s}} \sim \operatorname{Norm}\left(\mu_{2}, s_{2}{ }^{2}\right), g_{\mathrm{m}} / g_{\mathrm{s}} \in[0.5,4.3] \\
\lambda / \lambda_{\text {ref }} \sim \operatorname{Uniform}(0,10)
\end{gathered}
$$

Our choice was motivated as follows. Constraints on the range of $\beta_{\mathrm{c}}$ (between 70 and 1000) were chosen in accordance to other analyses (e.g. [11, 16]), and are quite conservative. The range of $g_{\mathrm{m}} / g_{\mathrm{s}}$ was chosen to reflect the isotope-independent measurements reported in ref. [17], and initial values of $\mu_{1}, s_{1}, \mu_{2}$, and $s_{2}$ chosen from the same study as $1.8,1.1,0.9$, and 0.1 , respectively. $\lambda / \lambda_{\text {ref }}$ must be greater than 0 , and is expected to be around 1. It could also be greater than 1 if the proportion of $\mathrm{CH}_{2}-\mathrm{THF}$ exported from the photorespiratory pathway increases. Thus, we use a likely range of values between 0 and 10 .

MCMC chains were run for 15000 iterations. To assess chain quality and algorithm convergence, we considered both integrated correlation time, $\tau$ (a measure of the averaged number of iterations required to achieve independent sampling), and a Geweke test (the output of which is equivalent to a Z-test). Lower $\tau$ values, and a Geweke statistic approaching $1(p<<0.05)$ can be regarded as indications of acceptable chain convergence.

Figure S5 shows the chain outputs for the combined angiosperm datasets, as an example. All statistics can be found in Tables S1-S4. In all cases, chains converged rapidly on the stationary distribution $(\tau<48)$. 

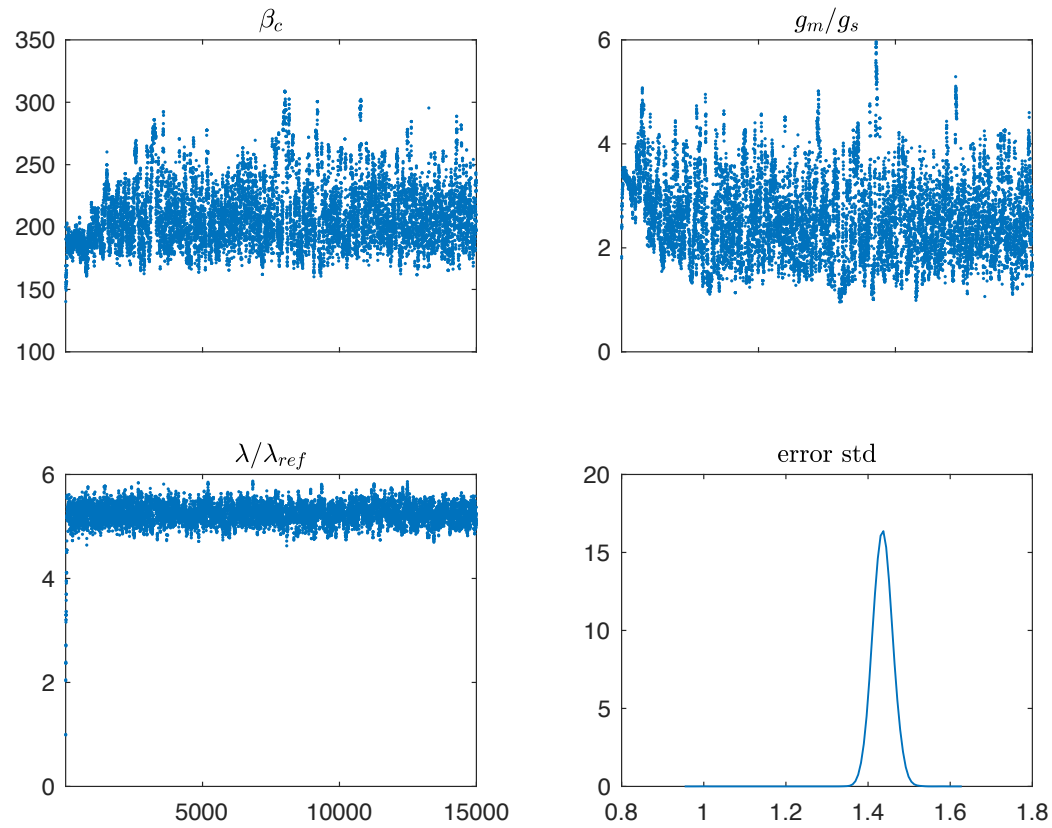

Figure S4: MCMC chains for estimation of angiosperm parameters (leaf + tree ring). 
Table S1. Fitted parameters: angiosperm leaf $\Delta^{13} \mathrm{C}$ dataset.

\begin{tabular}{llllll}
\hline Parameter & $\mu$ & $\pm 1 \sigma$ & MC error & $\tau$ & Geweke \\
\hline \hline$\beta_{\mathrm{c}}$ & 214 & 26 & 1.9 & 48 & 0.89 \\
$g_{\mathrm{m}} / g_{\mathrm{s}}$ & 2.5 & 0.77 & 0.06 & 54 & 0.70 \\
$\lambda / \lambda_{\text {ref }}$ & 5.2 & 0.31 & 0.02 & 58 & 0.95 \\
\hline
\end{tabular}

Table S2. Fitted parameters: angiosperm tree ring $\Delta^{13} \mathrm{C}$ dataset.

\begin{tabular}{llllll}
\hline Parameter & $\mu$ & $\pm 1 \sigma$ & MC error & $\tau$ & Geweke \\
\hline \hline$\beta_{\mathrm{c}}$ & 284 & 25 & 0.6 & 20 & 0.99 \\
$g_{\mathrm{m}} / g_{\mathrm{s}}$ & 3.2 & 0.74 & 0.03 & 45 & 0.86 \\
$\lambda / \lambda_{\text {ref }}$ & 4.8 & 0.3 & 0.01 & 31 & 0.96 \\
\hline
\end{tabular}

Table S3. Fitted parameters: gymnosperm leaf $\Delta^{13} \mathrm{C}$ dataset.

\begin{tabular}{llllll}
\hline Parameter & $\mu$ & $\pm 1 \sigma$ & MC error & $\tau$ & Geweke \\
\hline \hline$\beta_{\mathrm{c}}$ & 346 & 40 & 3.6 & 107 & 0.85 \\
$g_{\mathrm{m}} / g_{\mathrm{s}}$ & 0.94 & 0.09 & 0.005 & 36 & 0.94 \\
$\lambda / \lambda_{\text {ref }}$ & 7.3 & 0.75 & $9 \times 10^{-3}$ & 190 & 0.81 \\
\hline
\end{tabular}

Table S4. Fitted parameters: gymnosperm tree ring $\Delta^{13} \mathrm{C}$ dataset

\begin{tabular}{llllll}
\hline Parameter & $\mu$ & $\pm 1 \sigma$ & MC error & $\tau$ & Geweke \\
\hline \hline$\beta_{\mathrm{c}}$ & 140 & 10 & 0.5 & 28 & 0.96 \\
$g_{\mathrm{m}} / g_{\mathrm{s}}$ & 0.89 & 0.10 & 0.006 & 34 & 0.91 \\
$\lambda / \lambda_{\text {ref }}$ & 0.44 & 0.22 & $1 \times 10^{-2}$ & 27 & 0.70 \\
\hline
\end{tabular}




\section{Sensitivity analyses}

In Section 4.1 of the main manuscript, we conducted sensitivity analyses across a range of $\left[\mathrm{O}_{2}\right]:\left[\mathrm{CO}_{2}\right]$ ratios from 200 (e.g. Palaeogene) to 1200 (e.g. LGM) using Eqns. (5-7) and our best-fitted values for $\beta_{\mathrm{c}}$, $g_{\mathrm{m}} / g_{\mathrm{s}}$, and $\lambda / \lambda_{\text {ref }}$ at $20^{\circ} \mathrm{C}$, at two different levels of vapour pressure deficit. In fact, these simulations were a subset of a larger number of simulations over variable $D$ (shown in Fig S5a) and variable $T_{\mathrm{d}}$ (shown in Fig. S5b). The MATLAB code is also available from the authors.
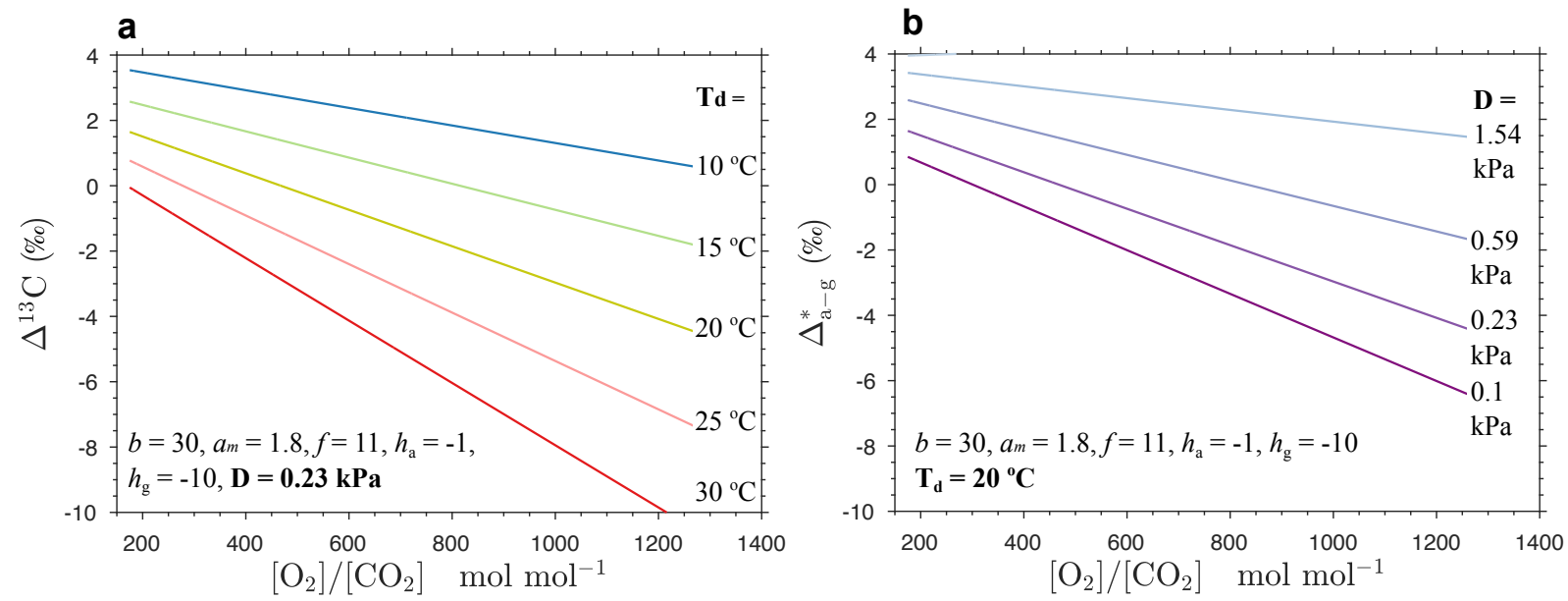

Figure S5: Simulations of the effects of $\left[\mathrm{O}_{2}\right]:\left[\mathrm{CO}_{2}\right]$ ratio on $\Delta_{\mathrm{a}-\mathrm{g}}^{*}$ for different environmental conditions, using parameters for plant specific traits $\left(\beta_{\mathrm{c}}, g_{\mathrm{m}} / g_{\mathrm{s}}\right.$, and $\left.\lambda / \lambda_{\text {ref }}\right)$. (a) shows the effect of variable $T$, at constant $D$, at two different scenarios for $\lambda / \lambda_{\text {ref }}$ (dashed and solid lines); and (b) shows the effect of variable $D$, at constant $T$, for the same scenarios of $\lambda / \lambda_{\text {ref }}$ as in (a).

These simulations show that $\Delta_{\mathrm{a}-\mathrm{g}}^{*}$ decrease with increasing $\left[\mathrm{O}_{2}\right] /\left[\mathrm{CO}_{2}\right]$ when $\lambda_{\mathrm{a}}>\lambda_{\mathrm{g}}$ (solid lines), and that the magnitude of this decrease is stronger with increasing $T$ and/or decreasing $D$ (the highest gradients are for $T=30^{\circ} \mathrm{C}$, and $D=0.1 \mathrm{kPa}$ ).

Our simulations also show that the $D$ effect is stronger than the $T$ effect, considering the range of leaf $T_{\mathrm{d}}$ estimated according to Section 4 (above). $D$ levels higher than $1.5 \mathrm{kPa}$ indicate significant water demand for transpiration. Note that because higher $D$ is usually also accompanied by higher temperatures, the two effects are expected to partly cancel each other out with respect to $\Delta_{\mathrm{a}-\mathrm{g}}^{*}$. However, the $D$ effect is much stronger, and ultimately wins!

\section{Datasets}

The following datasets are included in this paper, in excel format:

Global13Cdata.xlsx

Binned13Cdata.xlsx

(both available via link: https://doi.org/10.6084/m9.figshare.12722423.v1)

\section{References}

[1] Carl J Bernacchi, Archie R Portis, Hiromi Nakano, Susanne von Caemmerer, and Stephen P Long. Temperature response of mesophyll conductance. implications for the determination of rubisco 
enzyme kinetics and for limitations to photosynthesis in vivo. Plant physiology, 130(4):1992-1998, 2002.

[2] Florian A Busch. Photorespiration in the context of rubisco biochemistry, co2 diffusion, and metabolism. The Plant Journal, 2020.

[3] Florian A Busch, Meisha Holloway-Phillips, Hilary Stuart-Williams, and Graham D Farquhar. Revisiting carbon isotope discrimination in c 3 plants shows respiration rules when photosynthesis is low. Nature Plants, 6(3):245-258, 2020.

[4] Florian A Busch, Rowan F Sage, and Graham D Farquhar. Plants increase CO2 uptake by assimilating nitrogen via the photorespiratory pathway. Nature plants, 4(1):46, 2018.

[5] Harmon Craig. Carbon 13 in plants and the relationships between carbon 13 and carbon 14 variations in nature. The journal of geology, pages 115-149, 1954.

[6] Jaume Flexas and Marc Carriquí. Photosynthesis and photosynthetic efficiencies along the terrestrial plant's phylogeny: lessons for improving crop photosynthesis. The Plant Journal, 2019.

[7] Jeroni Galmés, Carmen Hermida-Carrera, Lauri Laanisto, and Ülo Niinemets. A compendium of temperature responses of rubisco kinetic traits: variability among and within photosynthetic groups and impacts on photosynthesis modeling. Journal of experimental botany, 67(17):5067-5091, 2016.

[8] Heikki Haario, Marko Laine, Antonietta Mira, and Eero Saksman. Dram: efficient adaptive mcmc. Statistics and computing, 16(4):339-354, 2006.

[9] IPDJ Harris, Philip D Jones, Timothy J Osborn, and David H Lister. Updated high-resolution grids of monthly climatic observations-the CRU TS3. 10 Dataset. International journal of climatology, 34(3):623-642, 2014.

[10] Brent R Helliker and Suzanna L Richter. Subtropical to boreal convergence of tree-leaf temperatures. Nature, 454(7203):511-514, 2008.

[11] Alienor Lavergne, David Sandoval, Vincent J Hare, Heather D Graven, and I Colin Prentice. Soil water stress impacts on the stomatal limitation of photosynthesis: a meta-analysis. In Review, Global Change Biology, 2020.

[12] Guillaume Tcherkez. How large is the carbon isotope fractionation of the photorespiratory enzyme glycine decarboxylase? Functional Plant Biology, 33(10):911-920, 2006.

[13] Nerea Ubierna, Lucas A Cernusak, Meisha Holloway-Phillips, Florian A Busch, Asaph B Cousins, and Graham D Farquhar. Critical review: incorporating the arrangement of mitochondria and chloroplasts into models of photosynthesis and carbon isotope discrimination. Photosynthesis research, 141(1):5-31, 2019.

[14] Nerea Ubierna and Graham D Farquhar. Advances in measurements and models of photosynthetic carbon isotope discrimination in c 3 plants. Plant, cell \& environment, 37(7):1494-1498, 2014.

[15] Berkley J Walker, Douglas J Orr, Elizabete Carmo-Silva, Martin AJ Parry, Carl J Bernacchi, and Donald R Ort. Uncertainty in measurements of the photorespiratory co 2 compensation point and its impact on models of leaf photosynthesis. Photosynthesis research, 132(3):245-255, 2017.

[16] Han Wang, I Colin Prentice, Trevor F Keenan, Tyler W Davis, Ian J Wright, William K Cornwell, Bradley J Evans, and Changhui Peng. Towards a universal model for carbon dioxide uptake by plants. Nature plants, 3(9):734, 2017. 
[17] Charilaos Yiotis and Jennifer C McElwain. A novel hypothesis for the role of photosynthetic physiology in shaping macroevolutionary patterns. Plant physiology, 181(3):1148-1162, 2019. 
We have added a few sentences to our MS to reflect the concerns and implications of Reviewers 2 and 3, and trust that this is sufficient to accept for publication in GCA. Once again, thanks very much to Reviewers 2 and 3 for these thoughtful suggestions, and encouragement.

We believe that our title is presently quite long, and perhaps also a little pedestrian. We would like whether the associate editor believes a change might be appropriate. Since our manuscript is framed in quite a general way, one possible alternative is something along the lines of:

"Differences in $\Delta^{13} \mathrm{C}$ between angiosperm and gymnosperm woody plants, and their geological significance."

Perhaps we can leave the final decision on this up to the Editors' judgement?

Please note that in the latest MS version, Fig. 5 has been re-plotted with the axes switched around (predicted as $\mathbf{x}$-axis, observed as $\mathbf{y}$-axis). This is more in line with convention. Accordingly, RMSE values have been updated in the text.

Reviewer \#2:

The authors claim here that gymnosperms are less responsive to $\mathrm{CO} 2$ than angiosperms. This appears to contradict recent work (DOI: 10.1038/s41467-017-02691-x) by the first author (Hare) that showed, "the effect of pCO2 during the last deglaciation is stronger for gymnosperms $(-1.4 \pm 1.2 \%)$ than angiosperms/fauna $(-0.5 \pm$ $1.5 \%$ )." How can these dissimilar results be reconciled? This previous study is cited within, but not in the context of showing a different result from that presented here.

Yes, this is a keen observation. We believe these dissimilar results can be reconciled, considering that the corrections used in Hare et al (2018) and this paper are fundamentally different.

Hare et al. (2018) calculated the $\mathrm{CO} 2$ sensitivities for angiosperms and gymnosperms after correction for MAP using the Kohn (2010) study. The Kohn (2010) equation assumes that angiosperms and gymnosperms respond to MAP equally. However, we have found here that angiosperms and gymnosperms respond differently to VPD (a variable which co-varies with MAP), so this assumption is incorrect - along with the correction. It follows that the $\mathrm{CO} 2$ sensitivities need to be recalculated from the paleodata in Hare et al. (2018), using a new correction derived from our updated framework.

It is interesting to note that in Hare et al. (2018), the gymnosperm and angiosperm/faunal data were biased towards different locations across the northern Hemisphere, with very different moisture availabilities (Fig $3 \mathrm{c}$ of that paper). In general, the angiosperm/faunal data were entirely biased towards continental Europe and the British Isles, whereas gymnosperm data were heavily biased towards North America, and higher latitude sites. We suspect that the $\mathrm{CO} 2$ effect for gymnosperms appeared much larger in that study because there was a strong bias in the gymnosperm dataset towards locations for which there were higher changes in VPD (see Fig 3c of that paper). This is consistent with the findings of our present study, specifically - gymnosperms are more sensitive to VPD than angiosperms.

Although an interesting observation, a more thorough investigation is arguably best suited for another publication. Re-calculation will require monthly VPD data from the latest PMIP model ensembles (for both LGM and mid-Holocene) - which is a considerable task.

I appreciate the new and revised figures, but the high scatter (Fig 4a) and lack of fit (Fig 4b) with the model remains concerning. The deviation of the observed vs predicted fit from the 1:1 line (fig. 5) is also poor. However, I still think this work represents a valued contribution and will spur additional work to test and revise the interpretations made here. These results give me pause, but the authors are clear in their approach, uncertainties, and limitations of their work, and do not overstate their conclusions.

We thank the reviewer for their comments and their helpful suggestions. Although the observed vs predicted fit is not perfect, we would like to point out that the predicted $\Delta^{*}$ a-g values explain around half of the variance in the observations $\left(R^{2}=0.51, R M S E=1.49 \%\right.$, Fig. 5), which is much more than previous models, which have held $\Delta *$ a-g to be constant. Our approach is thus a stepchange from previous studies, where $\Delta *$ a-g was assumed to be invariant with environmental conditions. This is the central point of the paper, which we have drawn attention to in the discussion. We therefore see our findings as a promising way forward for future research. We have added the following line for emphasis: 
Line 424-427 "However, it should be emphasised that although many confounding effects may potentially exist, our framework still explains over half of the variations observed in the geological record; and is thus a step-change from previous studies, where $\Delta * a-g$ was assumed to be invariant with D, [CO2], and [O2]."

One possible reason for the deviation between observed and predicted values is that we considered a $\Delta^{13} \mathrm{C}$ model which depends on changes in atmospheric $D$ through its effect on the partial pressure of $\mathrm{CO}_{2}$ in the leaf intercellular space $\left(c_{i}\right)$ and in the chloroplast $\left(c_{c}\right)$, but does not depend on changes in soil moisture. Yet, a recent study (Lavergne et al. 2020b) has shown that beta in the least-cost hypothesis, which was assumed constant here, should decrease with a reduction of soil moisture. This effect was not taken into account in our predictions mainly because we do not currently have a good understanding of how soil moisture should downscale $c_{\mathrm{i}}$ and $c_{\mathrm{c}}$ values based on first principles - but this is grounds for future research.

Because soil moisture will co-vary with atmospheric $D$, not accounting for such an effect may result in a potential underestimation of $\Delta^{13} \mathrm{C}$ values, and thus affect the predicted $\Delta *$ a-g values. Soil pH was also suggested to influence beta in several studies (Wang et al. 2017; Paillassa et al. 2020), further influencing the predicted $\Delta^{*}$ a-g values. Other controls on $c_{i}$ and $c_{c}$ (and thus $\Delta^{13} \mathrm{C}$ ) not captured by the model, such as rooting strategy, may also explain part of the discrepancies between observed and modelled $\Delta *$ a-g values. These would be worth investigating in the future.

We have added the following paragraph to clarify the lack of fit:

Line 398-405 "One possible deficiency in our ab initio model is that it assumes that $\chi_{c}$ (and thus $\triangle 13 C)$, is affected by atmospheric D, but not affected by other complex variables such as soil moisture. Because atmospheric $\mathrm{D}$ is generally expected to co-vary with soil moisture, not accounting for such additional variables might result in a potential underestimation of $\triangle^{13} C$ values, and thus affect the predicted $\Delta^{*} a-g$ values. Such co-variance might partly explain why there is an offset between the observed data and the ab initio model in Figure 4b. A recent study (Lavergne et al. 2020b) has shown that $\beta$, which was assumed constant here, should decrease with a reduction of soil moisture. This effect was not taken into account in our predictions mainly because we do not currently have a good understanding of how soil moisture should affect $\beta$ values based on first principles - but this is grounds for future research. Soil $\mathrm{pH}$ was also suggested to influence beta in several studies (Wang et al. 2017; Paillassa et al. 2020), further influencing the predicted $\Delta^{*}$ a-g values. These factors would be worth investigating in the future, although they present a challenge in paleocontexts, where variables such as soil moisture and $p H$ are often unconstrained. Further work using refined models, together with a larger observational dataset, particularly derived from plant chamber experiments, is likely to help improve the predictive skills of the ab initio model.

Perhaps the best evidence of this work's promise is the comparison shown in Fig 6 (a new figure, after Reviewer 1). I think the agreement is best for low $D$ because terrestrial organic matter records are best preserved from wet sites (preservation bias) even though many of the modern data come from sites with higher $\mathrm{D}$, and not because the model is biased towards chamber data (line 442-444).

A good observation, and of course it could be both, because the SJ2012 model is based largely on

low D experiments. We have added the following sentence:

Line 457-460 "We note that the agreement with Cui et al. (2020) at low D is perhaps unsurprising, considering that terrestrial organic matter records are generally biased towards wet sites (preservation bias), and because the Schubert \& Jahren (2018) model is predominantly based on chamber data, obtained under low D levels. "

On Fig 6, however, it is not clear why the curves for $D=0.8$ and $D=1.4$ cross in the interval around 15 to $18 \mathrm{Ma}$ ? And why the $\mathrm{D}=1.4$ gives the highest $\mathrm{CO} 2$ near $13 \mathrm{Ma}$, well after the MMCO?

Also a good observation. This has less to do with our model, and more to do with the LOWESS smoothing procedure. In order to be accurate, LOESS/LOWESS/Savitzky-Golay smoothing techniques require large, densely-sampled datasets. LOWESS relies heavily on the local data structure, and is very sensitive to outliers. At $\mathrm{D}=1.4 \mathrm{kPa}$, the model inversion produced considerably greater scatter than at $D=0.8 \mathrm{kPa}$ (see below graph of the raw output). For consistency, a common smoothing parameter (alpha=0.15) was used on both, following Cui et al. (2020). The greater scatter in the $1.4 \mathrm{kPa}$ dataset resulted in an earlier peak, due to the data 
shown in the black ellipse. The same region for $0.8 \mathrm{kPa}$ had less scatter. We have retained these curves in the manuscript as examples of the degree of uncertainty associated with the inversion + smoothing, whilst being consistent with Cui et al. (2020). However, we expect that the robustness of these curves will increase with (1) more data coverage, and (2) refinements in the smoothing technique, although this awaits another more detailed study.
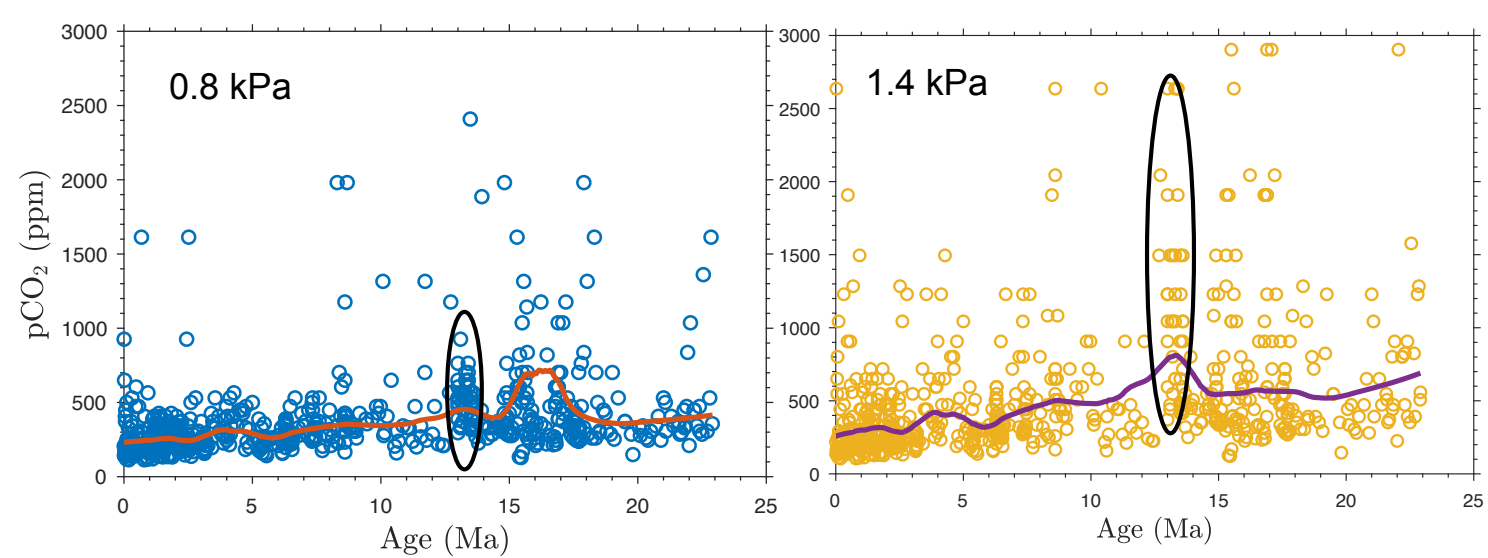

Also, it is true that $D=0.8$ and $D=1.4$ give $C O 2=550$ to 700 ppm at the MMCO (lines 448-450), but to suggest a similar $\mathrm{CO} 2$ result by lumping these two scenarios together for the MMCO is suspect given their widely different shape and timing for the $\mathrm{CO} 2$ peak in the Miocene.

As discussed in our response to the Reviewer's previous point, these scenarios are presented as a a rough visual estimate of the sensitivity of $\mathrm{CO} 2$ reconstructions, also incorporating uncertainties in smoothing procedures. They are not intended as formal error bounds, but rather as a likely range of mean/median estimates, following either model. Formal error bounds are technically complex in this case, and are arguably beyond the scope of this manuscript. A more robust curve, with formal uncertainties, will have to await future studies. However, we have included the following word of caution in our MS:

Line 466-470 "It should be noted that this range is presented as a rough estimate of the sensitivity of the terrestrial $\triangle 13 C$-based [CO2] proxy to different $\mathrm{D}$ levels - incorporating potential errors in smoothing methods - and is not a formal confidence interval. Obtaining statistically robust confidence intervals for this [CO2] proxy method is a highly technical task that will likely improve with future research, and greater data coverage."

Line 95: $f=7-16 \%$, but in Table $1=8-18 \%$.

Thank you, well spotted. We have now clarified 7-19.2 (if we include the result of Schubert \& Jahren (2018)).

Reviewer \#3:

Ln 116 - 117: these are growth chamber studies, not geologic studies. Fix to '...acknowledged in growth chamber studies'.

Thank you. We have changed this to "plant chamber studies".

Ln 320: "none of them" reads awkwardly, change to "neither relationship has been described before"

We agree. Changed.

Citations: Schlanser et al 2020a, is 'a' necessary?

The ' $a$ ' has been removed. Thank you.

\section{(New) References}

Paillassa, J., Wright, I.J., Prentice, I.C., Pepin, S., Smith, N.G., Ethier, G., Westerband, A.C., Lamarque, L.J., Wang, H., Cornwell, W.K. and Maire, V., 2020. When and where soil is important to modify the carbon and water economy of leaves. New Phytologist, 228(1), pp.121-135. 


\section{Report from Associate Editor Sarah Feakins:}

This is an intensely studied topic - whether plant $\mathrm{d} 13 \mathrm{C}$ can be used to reconstruct aspects of atmospheric chemistry and in particular pCO2, and of course this approach also faces strong criticism given all the documented ways that this can not work in the geological record, however there are certainly also studies that find ways that it can have promise. Given that publication debate, there was some reviewer fatigue on the topic, yet three reviewers volunteered their time and have offered up careful observations as they try to follow the findings and the interpretations, as well as carefully referencing the extensive work that comes before - with some of those missed references pointed out in the reviews below. I'm not sure if it is an omission in referencing or an omission in reading those studies, either way I hope you find the commentary helpful to add to the background information to surround your studies. The reviewers are all interested in the work presented, however they present a number of challenges to dimensions that are problematic. Given the extent of the concern "data does not appear to support the conclusions" and some concerns about following what is what from all reviewers, I'm not sure if this is readily fixable. However, if you find their feedback helpful and that you are able to address their major and minor concerns, any resubmission should be accompanied by details of how these concerns were addressed with a thorough response to reviews.

In light of the reviewers' concerns, and many helpful suggestions, we have re-evaluated our manuscript. We appreciate the considerable time taken by the reviewers in presenting their meticulous comments, and we now believe that we have included almost all of their suggestions.

The most significant concern was that the data did not appear to support the conclusions, as stated by Reviewer 2: "there are no apparent trends in $\Delta^{*} a-g$ observed from sedimentary records across the Cenozoic", and "the application of this to the geologic record is not convincing". Similar sentiments were echoed by Reviewer 3:" Perhaps this is why we see little to no variation in $\Delta^{*} a-g$, especially through the Paleogene?"

We agree that the manner in which this was presented in our initial contribution could have been clearer, and we have addressed this by making the following substantial changes to the manuscript (also see our detailed responses to individual reviewers), among others:

- Updates to Figure 4, including the model predictions (suggested by Reviewer 2), more robust binning, and a subfigure showing the relationship between $\Delta^{*} \mathrm{a}-\mathrm{g}$ and vapor pressure deficit $(D)$.

- New Figure 5, which shows observed vs predicted $\Delta *$ a-g across all records (suggested by Reviewer 2), including new lipid data of Schlanser et al. (2020), suggested by Reviewer 3 .

- New Figure 6, showing the effect of $\Delta^{*}$ a-g on pCO2 reconstructions at different $D$, and comparing pCO2-proxies, as well as discussion suggested by Reviewer 1.

- Table of abbreviated symbols now appears in the main text

The major change has been to the status of the proxy. Reviewer 2 best picked up on our intention: "to spark further interest in this area and to lead to additional experiments to help clarify and test the framework provided here".

After reconsideration of our data, we agree that the paper is best focussed on presenting the novel framework, as opposed to the $[\mathrm{O} 2] /[\mathrm{CO} 2]$ proxy. A proxy application is indeed premature at this stage, given the uncertainties at play (in fact, we set out to better understand the various factors behind differences in $\mathbf{\Delta 1 3 C}$, so a new proxy was never the primary aim of our paper, but seemed like a natural extension of our work at the time). Therefore, we have scaled back the claims about the proxy (as suggested by Reviewer 3), but at the same time we have included a new discussion on the implications of our findings for reconstructing $\mathrm{pCO} 2$ in general (as suggested by Reviewer 1). We believe this strikes a better balance than proposing a novel proxy and will be of better immediate use to the community.

In evaluating our revisions, we would also like to draw the attention of the Editors and Reviewers to the following: 
Note 1: After re-reading Sheldon et al. (2020), and Royer et al. (2019), there has been a change in our estimation of daytime leaf temperature $\left(T_{-} d\right)$ slightly, in light of Helliker et al. (2013), who found that most leaf daytime temperatures are remarkably constant, in the range $21.4 \pm 2.2^{\circ} \mathrm{C}$ across $50^{\circ}$ of latitude. Both Sheldon et al. (2020) and Royer et al. (2019) use the study of Helliker et al. (2013). Incorporating this finding has increased (1) the number of tree ring and leaf data included in the binning procedure, and (2) the agreement between the theoretical predictions and the data. The effect of $D$ on $\Delta * \mathrm{a}-\mathrm{g}$ is greater; and the effect of $[\mathrm{O} 2] /[\mathrm{CO}]$ on $\Delta * \mathrm{a}-\mathrm{g}$ is reduced. We also find a better fit when $h$ is varied (-10 per mil for gymnosperms, -1 for angiosperms). These new details are also presented in the text (Lines 194-197, and 209).

Note 2: Although T_d, and $h$ have been re-evaluated (Note 1), and although Figure 4 shows a more modest relationship with $[\mathrm{O} 2] /[\mathrm{CO} 2]$, the core findings of the paper have not been significantly changed. These include: (1) the sensitivity of $\Delta * \mathrm{a}-\mathrm{g}$ to $[\mathrm{O2}] /[\mathrm{CO}]$ and $D$ and (2) the different plant-specific parameter values (for Beta_c, lambda, and g_m/g_s) via the MCMC. Because this is the largest stable carbon isotope dataset ever assembled (over 9000 measurements, not including palaeo-records), Reviewer 3's suggestions of a different cutoff for canopy effect have a negligible impact on our results (more details can be found in our response below).

Note 3: Reviewer 3 stated that "There is a large body of work that focuses on the relationships between pCO2, water use efficiency, and leaf fractionation and should at least be addressed somewhere in this manuscript." We went to great lengths to incorporate water use efficiency into our manuscript at first submission (implicitly, via the theory for $C_{i} / C_{a}$, therefore it seems that Reviewer 3 has misunderstood our approach (and findings) here. We have tried to be clearer about this in the new manuscript and in our response to this Reviewer.

Note 4: Several of the papers suggested by the reviewers were known to us. Most are relevant and we have included them in the revised version of the manuscript. Schlanser et al. (2020) was not known to us - as it is a very recent paper. We have included this data, which adds more weight to our thesis.

Note 5: Based on their responses, it seems that the three Reviewers have not considered the Electronic Annexure in their reviews.

\section{Reviewer \#1:}

The authors present an in-depth study to understand the differences in carbon isotope fractionation between phylogenetically distant plant groups, the effect of this difference on paleo-CO2 reconstructions, and offer a novel way of reconstructing paleo-CO2 incorporating the novel understanding of the differences in fractionation between angiosperms and gymnosperms. The article is very well written, easy to follow, and the methods are sound. The authors use a dataset of over 7000 d13C measurements on gymnosperms and angiosperms tree-rings to identify that the ratio of mesophyll to stomatal conductance, the amount of $\mathrm{CO} 2$ released from photorespiration per oxygenation reaction, and the ratio of cost factors for carboxylation to transpiration, are all significantly different between angiosperms and gymnosperms and most likely drive the difference in carbon fractionation. In particular the amount of $\mathrm{CO} 2$ released from photorespiration per oxygenation reaction was identified as driving major differences in fractionation.

\section{Minor changes:}

- Considering the amount of different variables that the authors consider in their model that may influence carbon isotope fractionation, I'm interested to see the authors incorporate some discussion on the recent paper by Cui, Schubert \& Jahren 2020: A 23 m.y. record of low atmospheric CO2. Geology volume 48. How do the various assumptions differ, as they appear to arrive at different conclusions, at least for the middle Miocene?

After the technical points raised by Reviewers 2 and 3, we have refocussed the paper on the framework, as opposed to the [O2]/[CO2] proxy (which is arguably premature). However, following Reviewer 1's suggestion, we have retained a discussion of implications for 
discrimination-based $\mathrm{CO} 2$ proxies in general, and Cui et al. (2020) in particular. This can be found in the revised Section 5.3. Here, we have applied our model (Eqns 5-7) for angiosperms to the Cui et al. (2020) dataset, for a range of vapor pressure deficit, $D$. We applied the same LOWESS smoothing as this paper. Interestingly, at $0.4 \mathrm{kPa}$, our model agrees with the Cui et al. (2020) curve, which is perhaps not surprising (as this record is dominated by angiosperms), and gives confidence to this approach. However, at higher $D$ levels, $\mathrm{CO} 2$ is higher than the Cui et al. (2020) curve. We see our approach as complimentary to that of Cui et al. (2020) and to the model of Schubert \& Jahren (2012,2018), potentially allowing for adjustment of paleo-[CO2] proxies at variable $D$, as well as correcting gymnosperm data. Regarding assumptions, the Schubert \& Jahren (2012,2018) model implies independence of all environmental humidity (soil and atmospheric), whereas ours incorporates a measure of atmospheric humidity (vapor pressure deficit), but both are ultimately based on the similar FvCB (or Vogel) model of discrimination.

- Some other recent studies that the authors may want to incorporate, involve the improvement of $\mathrm{CO} 2$ reconstructions that address the uncertainty that arise from phylogenetically different plants: Reichgelt et al. 2020: Elevated CO2, increased leaf-level productivity, and water-use efficiency during the early Miocene. Climate of the Past. and Reichgelt \& D'Andrea 2019: Plant carbon assimilation rates in atmospheric $\mathrm{CO} 2$ reconstructions, New Phytologist. I would like to see this addressed in the discussion, particularly as the authors point out that precision and accuracy on $\mathrm{CO} 2$ reconstructions could be improved when phylogenetically different species are used.

Thank you for this suggestion. We have incorporated these references into our new Section 5.3. Reichgelt \& D'Andrea (2019), Reichgelt et al. (2020), and Royer et al (2019), regard photorespiration as negligible, and do not use these terms. Our study shows in reality that there is a lot going on with photorespiration, which can be much higher than implied by $f=-9$. This echoes findings by Schubert and Jahren (2018), and has a strong biochemical basis, recently outlined by Busch (2018) and others.

- A recent study that also goes in depth to the confounding effects of both photorespiration and leaf temperature, with differing results from the authors: Royer et al. 2019: Sensitivity of a leaf gasexchange model for estimating paleoatmospheric CO2 concentration. Climate of the Past.

And further discussion on the confounding effects of other environmental variables that the authors of the study presented here also discuss: Konrad et al. 2020: Quantitative critique of leaf-based paleoCO2 proxies: Consequences for their reliability and applicability. Geological Journal. It would be effective for the authors to discuss these papers as they can be used to highlight the sensitivity experiments that the authors include in order to more reliably reconstruct ancient atmospheric carbon dioxide.
We thank Reviewer 1 for mentioning these papers - we were aware of Konrad et al. (2020), but not of Royer et al. (2019), which was very recently published. We have included these in the discussion. The basis for small effects of temperature and photorespiration in Royer et al. (2019) appear to be chamber experiments at high and low temperature, with 6 species of woody plants - all angiosperms. Regarding temperature, our study is in agreement with Royer et al.'s findings. Regarding photorespiration, we speculate that our results are different because our dataset (over 7000 values) represents a wider range of environmental conditions within a similar range of atmospheric [CO2], and more variable $C_{3}$ plant species. Note that like Royer et al. (2019), we used the Bernacchi equation for Rubisco kinetics, but we also include in our model terms related to $D$ and [02], which might also explain the differences in interpretation. We therefore do not see our results as contradicting those of Royer; but rather as complementary (and offering a way of potentially including $\mathrm{D}$ and [O2] terms in $\mathrm{CO}_{2}$ proxies).

- Tables and figure captions: as the study incorporates many different variables that may be unfamiliar to the reader, it would be very helpful to write out in the captions what the various abbreviations stand for (e.g. gm/gs, Bc, etc). Currently, I believe that is only explained in the methods and I keep finding myself looking at the figures and thinking: "what did that stand for again...?"

We thank Reviewer 1 for this suggestion - there are indeed a lot of variables. In our first submission we presented a full table of symbols in the Electronic Annexure, but perhaps we did not make it clear in the main document that such a table was available in the document. We have 
now included a version of this table in the main text, to be retained at the discretion of the Editor. We have also now included in the captions what the abbreviations stand for.

\section{Reviewer \#2:}

Hare and Lavergne present the hypothesis that the difference in $\angle D E L T A>13 C$ value between angiosperms and gymnosperms $\left(\Delta^{\star} \mathrm{a}-\mathrm{g}\right)$ is not constant, but changes through the geologic record as a function of $02 / \mathrm{CO} 2$. Support for this is provided by first-principles theory, which they use to predict a linear, negative relationship between $\Delta^{*} \mathrm{a}-\mathrm{g}$ and $\mathrm{O} 2: \mathrm{CO} 2$. However, application might be limited given the narrow range in which their data match the prediction. Nevertheless, this is a particularly intriguing idea and has potential to augment our understanding of changes in $\angle D E L T A>13 C$ value in the geologic record. I very much enjoyed reading this manuscript, and I fully suspect this work to spark further interest in this area and to lead to additional experiments to help clarify and test the framework provided here.

We thank the Reviewer for these kind comments - this was our intention.

After re-reading Sheldon et al. (2020), and Royer et al. (2019), there has been a change in our estimation of daytime leaf temperature (T_d) slightly, in light of Helliker et al. (2013), who found that most leaf daytime temperatures are remarkably constant, in the range $21.4 \pm 2.2^{\circ} \mathrm{C}$ across $5^{\circ}$ of latitude. Both Sheldon et al. (2020) and Royer et al. (2019) use the study of Helliker et al. (2013). Incorporating this finding has increased (1) the number of tree ring and leaf data included in the binning procedure, and (2) the agreement between the theoretical predictions and the data. The effect of $D$ on $\Delta^{*} \mathrm{a}-\mathrm{g}$ is greater; and the effect of $[\mathrm{O} 2] /[\mathrm{CO}]$ on $\Delta^{*} \mathrm{a}-\mathrm{g}$ is reduced. We also find a better fit when $h$ is varied (-10 per mil for gymnosperms, -1 for angiosperms). These new details are also presented in the text ((Lines 194-197, and 209). Although T_d, and $h$ have been re-evaluated, and although Figure 4 shows a more modest relationship with $[\mathrm{O} 2] /[\mathrm{CO} 2]$, there is now greater agreement between observations and predictions, and the core findings of the paper have not been significantly changed. These include: (1) the sensitivity of $\Delta^{*}$ a-g to $[02] /[C O 2]$ and $D$ and (2) the different plant-specific parameter values (for Beta_c, lambda, and $\mathbf{g} \_\mathbf{m} / \mathbf{g} \_s$ ) via the MCMC.

I do have some substantial reservations that should be addressed before publication, including, but not limited to Figures 4 and 5, which form the heart of the proxy and application. Figure 4 represents the proxy equation that will be used to calculated $\mathrm{O} 2 / \mathrm{CO} 2$ from $\Delta^{*} \mathrm{a}-\mathrm{g}$, and is therefore critical to $\Delta^{*} \mathrm{a}-\mathrm{g}$ being used as a CO2 proxy. The choice to split the Porter (2018) data in half, and only include the two higher $\mathrm{O} 2 / \mathrm{CO} 2$ levels in the relationship (and not the two lower O2/CO2 levels) is troubling. Much of this relationship therefore leverages on the two data points representing 20th century tree rings that only cover a very narrow range of $\mathrm{O} 2 / \mathrm{CO} 2$, and on their own, would not be robust.

We agree in retrospect that our claims about the $02: \mathrm{CO} 2$ relationship were premature, and have revaluated this relationship by using values for leaf temperature $\left(\mathrm{T}_{\mathrm{g}}\right)$ following Helliker et al. (2013) (see above, and the Electronic Annexure). This has resulted in the inclusion of more data into the binning procedures, and the identification of the relationship with $D$.

As a result of this (arbitrary?) grouping, the authors suggest the relationship is valid for O2/CO2 between 400 and 650 , but the lack of clear mechanism for this is disconcerting, and extrapolation to the Paleogene and Quaternary does not work. The authors need to do a better job justifying this grouping, and reconciling these data with the first-principles theory to make this a robust proxy.

We agree that there were too few datapoints for a good test of the relationship, and that a better agreement between the theoretical predictions and observations was needed. The model predictions are now better matching the observations due to the use of the assumption from Helliker et al. (2013) regarding $\mathrm{Tg}$ (see also comparison with theoretical model in bold purple lines in the new Fig. 4ab). Note, too, that we have scaled back claims for a 02:CO2 proxy based on $\Delta^{*} \mathrm{a}-\mathrm{g}$, but nevertheless include a new discussion section (5.3) which outlines implications for existing proxies, which will be of greater interest to the community. These estimates of $\Delta^{*}$ a-g were originally obtained from a minimum of 4 gymnosperm or angiosperm datapoints. We have now also increased this minimum number to 6 datapoints. We 
have indicated the total number of datapoints used to calculate $\Delta * \mathrm{a}-\mathrm{g}$ next to each datapoint in Figure 4 a,b. Changing the bin width from 10 to 30 mol mol-1 does not significantly affect our regression. We have included details of all of this in the main text, particularly in the new Lines 232, and 300-306, as well as expanded on the caption of Figure 4ab.

Line 232 " and for D intervals of $0.5 \mathrm{kPa}$ over the range $0.4-1.0 \mathrm{kPa}$."

Lines 300-306 "Although there is more scatter in this relationship (adjusted R2 =0.51) and the trend is modest, it is in agreement with the slope predicted by Eqns. (5-7) to within 1sigma prediction bounds. Note that to ensure robust binning, a minimum number of 6 angiosperms and 6 gymnosperm $\delta 13 C$ values were used in the calculation of $\Delta^{*} a-g$. Fits are found to be somewhat insensitive to the binning procedure when a different bin width (i.e., $30 \mathrm{~mol}$ mol-1 ) is chosen; the resulting regressed coefficients are not significantly different ("epsilon $f=$ $0.0037 \pm 0.0014 \%$ mol mol-1 ). All binned data can be found in the Electronic Annexure."

Figure 5 further illustrates that the relationship suggested by Figure 4 might be spurious, as there are no apparent trends in $\Delta^{*}$ a-g observed from sedimentary records across the Cenozoic. Within the text, the authors suggest the proxy is accurate by calculating CO2 from one time point on this graph (15 $\mathrm{Ma})$, but I very much would like to see similar calculation on the other $\sim 10$ time slices shown on Figure 5.

We thank the reviewer for this helpful comment - we believe the changes to the manuscript have made this clearer. We direct the reviewer's attention to our new Figure 5 which more clearly shows the trends in $\Delta^{*}$ a-g across the Cenozoic, using more data from the Paleocene-Eocene, and assuming [CO2] levels for geological $\Delta^{13} \mathrm{C}$ data according to Foster et al. (2017) and Gehler et al. (2016).

\section{Other comments:}

Line 230. Suggest adding "decreasing" before CO2 for clarity... "The simulations show that $<$ DELTA $>13 C$ decreases strongly with decreasing [CO2] at low D, but decreases slightly with decreasing [CO2] at high D (Fig. 3a)."

Yes, this is a good suggestion- we have now rewritten the sentence accordingly (as also suggested by Reviewer 3)

Line 255-259 "The simulations show that gymnosperm $\triangle^{13} \mathrm{C}$ does not respond strongly to [O$\left.{ }_{2}\right]$ or $\left[\mathrm{CO}_{2}\right]$ levels but decreases by $\sim 6 \mathrm{per}$ mil when $\mathrm{D}$ is increased from $0.23 \mathrm{kPa}$ (solid red lines, Fig. 3a) to $1.43 \mathrm{kPa}$ (dashed red lines). For angiosperms, $\triangle^{13} \mathrm{C}$ decreases strongly with lower $\left[\mathrm{CO}_{2}\right]$ at low D (solid blue lines) but decreases slightly with lower $\left[\mathrm{CO}_{2}\right]$ at high $\mathrm{D}$ (dashed blue lines). $\Delta^{13} \mathrm{C}$ is offset between gymnosperms and angiosperms, but this offset is variable over $\left[\mathrm{CO}_{2}\right]$ levels.

Figure 3 caption. Are the curves shown in 3a drawn from Eqn 5 (with terms defined in 6 and 7)? What term(s) are primarily responsible for the different curve shapes (i.e., the gymnosperms are obviously more responsive than angiosperms for any D)? Is $3 c$ is drawn from Eqn 8 ? Including these details in the caption would be useful.

Yes, the curves are drawn from Eqn 5-7, using the best-fit parameters determined by MCMC (Table 2). We have now also indicated this on the Figure 4ab legend. Gymnosperms are generally more responsive to $D$ than angiosperms (Figure 3a). The terms responsible for this speciesspecific pattern are primarily $g_{m} / g_{s}$, and beta_c $\left(v i a \chi_{c}\right)$. Angiosperms are generally more responsive to $\mathrm{CO} 2$ (also Figure 3a) due to the term lambda. We have now included a paragraph in the discussion section to clarify the meaning of the curves from Figure 3a (Lines 324-330). We have also included the following in the caption to Figure 3:

“... as estimated from the MCMC approach applied to Eqns. (5-7). Parameters are listed in Table (2)."

Lines 324-330: "Gymnosperm ${ }_{113} C$ is more sensitive to $\mathrm{D}$ than angiosperms. This is because lower values of $g_{m}=g_{s}$ in gymnosperms amplify the response of_c ${ }_{325}$ to D, via Eqn. (6). In addition, gymnosperms are less responsive to $\left[\mathrm{CO}_{2}\right]$ because lambda/lambda_ref is generally 
much lower in this plant group than in angiosperms, reducing the photorespiratory compensation point (Eqn. 4). Our findings therefore support the recent study of Sheldon et al. (2020), who found that gymnosperm $\triangle 13 C$ values obtained from herbarium records were largely insensitive to rising levels of [CO 2 ] from $1850 \mathrm{CE}$ to present - and provide a mechanistic explanation for these authors' observations."

Figure 3c. Why show only the solution for $\mathrm{D}=0.23 \mathrm{kPa}$ and not also show $\mathrm{D}=1.54 \mathrm{kPa}$ (maybe as $3 \mathrm{~d}$ )? Both are shown in $3 b$, but only the low $D$ solution is shown in 3c.

The solution for $D=1.54 \mathrm{kPa}$ was shown in Figure $3 \mathrm{c}$, but note that the photorespiration contributions were identical in either case, so these two curves were plotted over one another. We have now included a shaded region in the figure to make this clearer.

Text on lines 267-269 is repeated on lines 271-273.

Thank you very much - we have now fixed this.

245-257. What is "low to moderate"? Why does this not work for high D?

Moderate $D$ is around $1 \mathrm{kPa}( \pm 0.3 \mathrm{kPa}$ representing $>60 \%$ of our record $)$.

Note that after our edits to Fig 4, we have now included a revised expression of the discrimination which allows calculation for $\Delta^{*} \mathrm{a}-\mathrm{g}$ at both $[\mathrm{O} 2] /[\mathrm{CO}]$ and $D$.

line 274. Something does not seem correct here. If $<$ epsilon $>f=0.017$ and $<$ epsilon $>a b=9$, then Equation 8 suggests a positive relationship between $\Delta * \mathrm{a}-\mathrm{g}$ and [O2]/[CO2], but the relationship shown in Fig 4 (and simulated in Fig 3 ) is negative. I think it is simply the sign for <epsilon>f that is wrong and should be negative 0.017 , but this should be checked.

Thank you very much for spotting this - it was a typographical error, and we have now corrected it. Note that this regression has changed in response to the new binning procedure (more datapoints), but the slope is still negative, as expected. It is lower, but in agreement with the theory.

line 280. "The linear relationship between $\Delta * \mathrm{a}-\mathrm{g}$ and [O2]/[CO2], at least over 400 to $650 \mathrm{~mol} \mathrm{~mol}-1$, is noteworthy." This is interesting, but is also across a very small change in $\mathrm{CO} 2$ (assuming $\mathrm{O} 2=21 \%$, then this represents $\mathrm{CO} 2=350-525 \mathrm{ppm}$ ). The fact that the trend does not continue to lower $\mathrm{O} 2 / \mathrm{CO} 2$ is troubling.

Please see our comments above, and our revised interpretation.

Likewise, the implied $\Delta * \mathrm{a}-\mathrm{g}$ for O2/CO2 of the latest Pleistocene (very high O2/CO2, 1200 mol mol1) from Fig 4 is extremely low (on the order of $-10 \%$ ). Are there any data to support such a large implied offset between angiosperms and gymnosperms during the last glacial maximum, for example?

This is a very good idea, LGM data would indeed be an excellent test of our framework. In the two years leading up to this article, we performed an extensive search of the literature for colocated data from the LGM but could not find any. When undertaking these revisions and following Reviewer 2's suggestion, we contacted Prof Takeshi Nakagawa (Ritsumeikan University, Kyoto) and Dr Richard Staff (Glasgow) regarding their unpublished Lake Suigetsu leaf macrofossil $\delta 13 \mathrm{C}$ record. They kindly looked through it but found only two needles from the LGM (both at about -27 per mil), so it is impossible to discern any statistically-meaningful trends (or lack thereof) here, given the challenges with the binning procedures for low sample numbers (see comments above). This will have to await research in years to come.

Note, it would be easier to compare the simulations (Fig 3) to the results (Fig 4) if both figures were on the same scales. Or, perhaps the model (expected) relationship can be drawn on Fig 4 ?

Thank you very much for this excellent suggestion. We have included the expected relationship on Figure 4 (heavy purple line). It is in agreement with our updated regression, to within uncertainties. Note that the expected relationship did not agree with the regression in the initial version of this manuscript, but after our changes in binning and estimation of $\mathrm{Tg}$, we believe the two are now in better agreement (with more modest slopes). Changing the bin width does not significantly affect the result (as discussed in the text). 
ppm assuming $\mathrm{O} 2=21 \%$, and according to Fig 4 represents a substantial portion of the Neogene and all the Paleogene. The above is really my biggest concern for this work. I appreciate the observation that first-principles theory suggests a linear, negative relationship between $\Delta^{*} \mathrm{a}-\mathrm{g}$ and O2:CO2, but the application of this to the geologic record is not convincing. The authors report a strong linear correlation between $\Delta * \mathrm{a}-\mathrm{g}$ and $\mathrm{O} 2 / \mathrm{CO} 2$, but only for a very small window of $\mathrm{O} 2 / \mathrm{CO} 2$ space, and the meaning of this is not clear. The way the authors grouped the data appears very arbitrary: there are 6 O2/CO2 levels represented, 4 from Porter (2018) and 2 from tree ring data. The authors chose to group the two higher O2/CO2 experiments from Porter with the tree ring data, and leave the two lower O2/CO2 experiments separate. Why? Instead, if the grouping changed and only the Porter (2018) data are plotted, then the relationship changes completely. Much of this interpretation therefore hinges on the two data points represented by the 20th century tree rings. Yet, these two points would be entirely unconvincing on their own (only two data points, both with large overlapping errors, and an extremely narrow range of O2/CO2: $\sim 590$ to $630 \mathrm{~mol} / \mathrm{mol}$ ). Does the relationship shown in Fig 4 match the predicted trend? Is this why the authors believe this grouping of the data is best?

Please see our comments above, and our revised interpretation. Thank you for drawing attention to this. The relationship shown in Fig 4 now matches the predicted trend, to within errors. Although the errors are quite large, they are conservative formal error bounds for $\Delta^{*}$ a-g, i.e. they represent the $95 \%$ CI for the difference between two means. Therefore, one can say, for instance, that the (chamber) values for $\Delta^{*}$ a-g at 90 and 400 are higher than those at 520 and 570 (which is significant at alpha $=\mathbf{0 . 0 5}$ ). The datapoint at 110 seems a bit low (but has larger error bounds). In Fig 4, we have now also indicated the total number of angiosperm+gymnosperm datapoints above each data point.

318/328. To suggest this works for the Paleogene (and PETM in particular) is troubling given what is shown in Figure 4.

We agree with the reviewer, and have reconsidered our interpretation, as well as scaled back the claims for a proxy throughout the new manuscript.

325-326. I disagree. What support is there for this working at $\mathrm{CO} 2<325 \mathrm{ppm}(\mathrm{O} 2 / \mathrm{CO} 2>650$ $\mathrm{mol} / \mathrm{mol})$ ?

We agree with the reviewer, and have reconsidered our interpretation, as well as scaled back the claims for a proxy.

Figure 5 shows the measured $\Delta * a-g$, but the predicted values are not shown. It would be much more convincing to the reader that " $\Delta * a-g$ calculated from the paleo-data generally support our novel interpretation" (line 327) if the authors showed the predicted values on this plot (could use open symbols), or show an additional plot of measured versus predicted ( $x-y$ plot). As of now, this plot looks like $\Delta * a-g$ stays constant at $\sim 2-3 \%$ for all of the Neogene and Paleogene, with tree ring records showing somewhat lower values (1-2\%). As currently shown, this figure does little to convince the reader of the utility of this proxy.

This is an excellent suggestion, thank you. We have now included a new Figure 5 of measured versus predicted $\Delta^{*}$ a-g.

360. Same potential sign issue for <epsilon>f. Should this be -0.017 ?

See response above - corrected.

358-361. This would be much more powerful if the authors did the same calculation for the other 10 time slices represented on Fig 5 , and not only picking one point. However, it seems to me that the other Betchel data (Betchel et al 2007a, 2007b) would give similar (or slightly higher) values to this one, yet these are not at the MCO. It also appears that many of the other data points also have much higher uncertainty than the one chosen at $15 \mathrm{Ma}$. I do not follow why the authors chose this one time slice to illustrate. It appears that this single point is critical to verifying the proxy (see also final sentence of abstract), but why only this point?

Since we have scaled back our proxy approach, this comment is no longer relevant, but for interest's sake, we chose this dataset because of the precision available at a single location ( $n=83$ diterpenoids, $n=113$ triterpenoids), which propagated into small uncertainties in $\Delta^{*} \mathrm{a}-\mathrm{g}$, and thus $[\mathrm{O} 2] /[\mathrm{CO} 2]$. 
371-374. Yes, this proxy benefits from its independence from < delta $>13 \mathrm{CO}$. However, it has its own requirements/inputs (namely $\mathrm{O} 2$, and also $\mathrm{T}$ and $\mathrm{D}$ ?), as do all proxies. What is the evidence that uncertainty in <delta> $13 \mathrm{CO} 2$ yields greater uncertainty in $\mathrm{CO} 2$ for these other proxies than do the uncertainties in $\mathrm{O} 2, \mathrm{~T}$, and $\mathrm{D}$ do here?

We are not aware of any systematic published study into the uncertainties of $813 \mathrm{CO} 2 \mathrm{on}$ palaeoatmosphere reconstruction, and although it is mentioned briefly in Hollis et al. (2019), it awaits further investigation. We have therefore left this out of the new manuscript, to make way for the new Section 5.3. $813 \mathrm{CO} 2$ is generally estimated using the method of Tipple et al. (2010) on foraminifers (input into this model are T, via the equilibrium fractionation factor between DIC and $\mathrm{CO}_{2}$ ). However, this method sometimes disagrees with measurements from Antarctic ice cores (Eggleston et al., 2016), by up to 1 per mil, at periods (perhaps related to DIC disequilibrium effects - see graph below from ongoing study by VJH). This is yet to be published, but one might expect it to propagate strongly into estimates of $\mathrm{CO} 2$, on the order of uncertainties of $\mathrm{D}$, and possibly of $\mathrm{O}_{2}$.

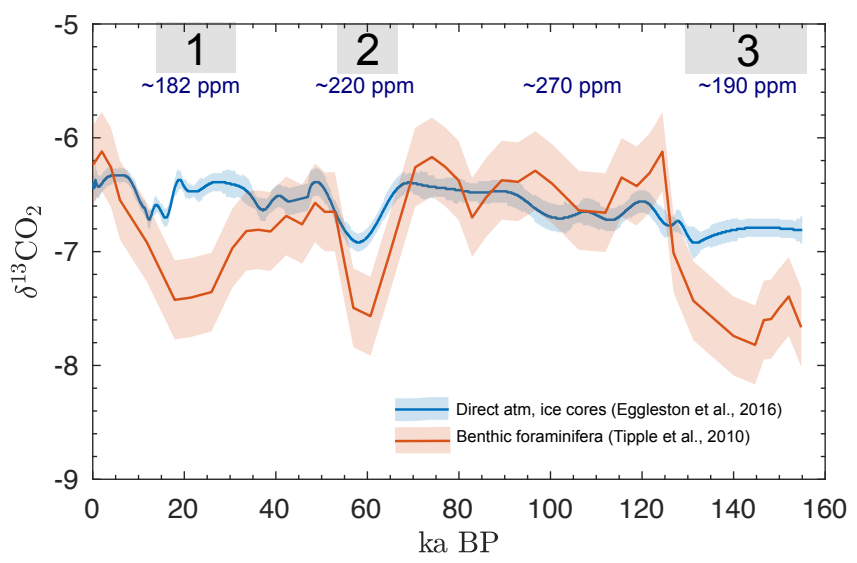

Reviewer \#3:

This manuscript uses a modern dataset to train a plant physiology model to explain the relationship between the offset of angiosperms and gymnosperms leaf fractionation and the $\mathrm{O} 2: \mathrm{CO} 2$ ratio that can then be applied to the geologic record as a $\mathrm{CO} 2$ proxy. The O2:CO2 level on plant fractionation merits investigating. However, I have a number of major concerns about the project design and these need be addressed before this could be considered for publication. I have outlined my major concerns below and also include some minor comments.

\section{Major Comments}

1. The data does not appear to support the conclusions.

* The model is based on a large compilation of modern datasets. Comparatively little data is used to then validate the Dleaf-O2:CO2 model; 2 datapoints from field data in the last century, and 5 datapoints from growth chamber studies, two of which, do not match the model. Going forward, this study should either validate the model with more data or scale back the assertive claims about the proxy (i.e., lines 289 - 292).

Following the comments of Reviewer 2, and changes to our binning procedure and estimation of $\mathrm{Tg}$, we have scaled back the assertive claims about the proxy. We also identify a strong relationship to vapor pressure deficit. Both the relationship to $\mathrm{D}$ and to [O2]:[CO2] are now in broad agreement with the predicted relationship (Eqns. 5-7). Note that the parameters responsible for this predicted relationship (lambda, gm/gs, beta_c) are inferred from the largest compilation of stable carbon isotopes yet assembled $(n>7000)$, with great care and attention to numerical procedures. Comparatively few data are indeed used in the testing dataset - but nevertheless, our binning procedures are now robust (new lines 300-306, as well as expanded on the caption of Figure $4 \mathrm{ab}$ ), and $\Delta^{*} \mathrm{a}-\mathrm{g}$ represents the community average.

Lines 300-306 "Although there is more scatter in this relationship (adjusted $R 2=0.51$ ) and the trend is modest, it is in agreement with the slope predicted by Eqns. (5-7) to within 1sigma 
prediction bounds. Note that to ensure robust binning, a minimum number of 6 angiosperms and 6 gymnosperm $\delta 13 C$ values were used in the calculation of $\Delta * a-g$. Fits are found to be somewhat insensitive to the binning procedure when a different bin width (i.e., $30 \mathrm{~mol} \mathrm{~mol}-1$ ) is chosen; the resulting regressed coefficients are not significantly different ("epsilon_f = . $0.0037 \pm 0.0014 \%$ mol mol-1 ). All binned data can be found in the Electronic Annexure."

* Looking at the geologic data (Figure 5), <DELTA>a-g largely reflect a 2-3 per mil offsets with little to no variation, especially through the Paleogene despite large fluctuations in $\mathrm{pCO} 2$ during this span of time (see: Foster, G. L., Royer, D. L., \& Lunt, D. J. (2017). Future climate forcing potentially without precedent in the last 420 million years. Nature Communications, 8, 14845 and references therein). Does this mean the proxy is not as sensitive on geologic timescales and different phylogenies have offsets that remain fairly consistent through time? Also, to consider, the samples used here are derived from sediment, and thus represent time and community averages rather than individual plant specimens, such as those used to calibrate the model. Could this add an extra level of error? Perhaps this paper could benefit from a section in the discussion specifically addressing assumptions and caveats that would help future studies using this model.

We have now included a new Figure 5 which more clearly shows variations in $\Delta^{*}$ a-g, along with new data from Schlanser et al. (2020). We use the Foster et al. (2017) spline to predict $\Delta^{*} \mathrm{a}-\mathrm{g}$, and compare it with observed values. Note that according to some of the data from Schlanser et al. (2020) incorporated in Figure 4, $\Delta^{*} \mathrm{a}-\mathrm{g}$ is negative for modern contexts. Our Figure shows this is common for early $20^{\text {th }}$ century trees growing under conditions of low $D$, in agreement with our predictions.

Although we have scaled back the assertive claims about the proxy, we have included a new section in the discussion (5.3) which addresses implications for other leaf-based proxies.

* The most important product of this paper is to establish a new Da-g - pCO2:O2 proxy. However, only one example value from the Miocene was calculated. Why not reconstruct $\mathrm{pCO} 2$ from all the samples pulled from the geological record in Figure 5 and compare it to the most up-to date pCO2 curves? What do the results look like? This would be a stronger approach.

Please see our new figures 5 and 6 , where we have done something equivalent, using all available data, and the pCO2 curves of Foster et al. (2017) and Cui et al. (2020). Note that pCO2 curves are highly uncertain. For that reason, we deliberately chose to train our core model with data for which $\mathrm{pCO} 2$, pO2, and D are much more precise (i.e., over the $20^{\text {th }}-21$ st centuries), avoiding uncertainties associated with data from chamber experiments. We have now clarified this in

Lines 225-228: "Note that for various reasons, we excluded these data from the training dataset to estimate the plant-specific parameters. These included potential uncertainties in chamber design (Porter et al. , 2015 ), and estimation of chamber $\delta_{13} \mathrm{CO}_{2}$ values (Leavitt, 2001), which occasionally result in high variability of $\triangle 13 C$ "

In lines 266-267 a notable point is made that the model spans O2:CO2 values from 400 to 650 , however the 02:CO2 geologic range, as stated, spans 150 to 1150. Could assuming a linear model be problematic, especially if plants are not behaving linearly at low $02: \mathrm{CO} 2$ values as documented in the growth chamber study? Is it possible that values derived for ef and eab should only be used for this smaller range? What about geologic values outside of this range, such as the Shouten PETM samples? Can calculating pCO2 for locations with low $\mathrm{O} 2: \mathrm{CO} 2$ values be justified?

We have proposed a linear model, not only based on functional form implied by the discrimination model, but also because for its simplicity (Occam's Razor). We do not know yet whether calculating pCO2 for the Schouten PETM samples will work, and so we have not presented the pCO2 proxy in this paper. It might be complicated by uncertainties in vapor pressure deficit (see new section 5.3).

2. From the abstract and intro, it is not immediately clear what is being done in this study. A new framework is mentioned, but is this a model? Is this a framework based on data? Date generated in this project? Growth chamber data? Data from the geologic record? This should be clarified.

We have edited the abstract to add greater clarity. We use framework and simple empirical model interchangeably, but we are more careful to refer to the full model (Eqns. 5-7) as the comprehensive ab initio model of discrimination (see response to minor comment \#1). Throughout the manuscript, we have been specific when we are referring to particular datasets (including "training" and "testing" - new terms). 
Lines 35-40: It was also unclear how the O2:CO2 ratios were determined through geologic time. How were the large errors in $\mathrm{O} 2$ proxies handled? How was $\mathrm{pCO} 2$ derived (what proxies were used)? Add citations. Would it be useful to plot this into a figure?

This is not a formal inference; it was a back-of-the-envelope calculation. We do not know much about $\mathrm{O} 2$ during the Cenozoic (the assumption is usually $21 \%$ ), so we have to use this value. As this currently stands in the introduction, it is merely to frame the questions, so more formal calculations are arguably not required.

3. This study should consider the implications of water use efficiency (WUE) on leaf fractionation. Many of the studies cited within the manuscript highlight WUE as an important factor influencing $<$ DELTA>leaf values in both modern and geologic studies (i.e., Shouten et al., 2007; Pedentchouk et al., 2008; Diefendorf et al., 2010; Franks et al., 2014; Diefendorf et al., 2015). There is a large body of work that focuses on the relationships between $\mathrm{pCO} 2$, water use efficiency, and leaf fractionation and should at least be addressed somewhere in this manuscript. Perhaps this is why we see little to no variation in $\angle D E L T A>a-g$, especially through the Paleogene? For additional references, see:

* Seibt, U., Rajabi, A., Griffiths, H., \& Berry, J. A. (2008). Carbon isotopes and water use efficiency: sense and sensitivity. Oecologia, 155(3), 441.

* Franks, P. J., \& Beerling, D. J. (2009). CO2-forced evolution of plant gas exchange capacity and water-use efficiency over the Phanerozoic. Geobiology, 7(2), 227-236.

* Soh, W. K., Yiotis, C., Murray, M., Parnell, A., Wright, I. J., Spicer, R. A., ... \& McElwain, J. C. (2019). Rising CO2 drives divergence in water use efficiency of evergreen and deciduous plants. Science advances, 5(12), eaax7906.

The reviewer might not be aware that we went to great lengths to consider the effects of water use efficiency in our paper, albeit implicitly. One of the first formulations for WUE was proposed by Ehleringer et al. (1993). According to Eqn. (4) of Soh et al. (2019), iWUE $=\mathrm{Ca}(1-\mathrm{Ci} / \mathrm{Ca}) / 1.6$, or in our notation iWUE $=\mathrm{Ca}\left(1-\chi_{\mathrm{c}}\right) / 1.6 \cdot \chi_{\mathrm{c}}($ our study) and iWUE are intrinsically linked. There are several models for $\chi_{c}$. In this paper we used an explicit form (Wang et al., 2017) derived from least-cost optimality theory (Prentice et al., 2014), which predicts the response of $\chi_{c}$ (thus iWUE) to different environmental conditions.

Note that Eqn (5) of Seibt et al. (2008) corresponds closely to our Eqn. 5 derived from Wang et al. (2017). All these models are more or less functionally equivalent. We have now drawn greater attention to this in the Theory section, the Methods section, and in the Abstract. E.g. in the Theory section:

Lines 149-151: "Note that Eqn. (6) implicitly ties plant WUE to $\mathrm{D}$ and $\mathrm{C}$ a via the relationship between $\chi_{\mathrm{c}}$ and intrinsic WUE, i.e. $i W U E=$ theta_m/ $/(1+$ theta_m $) \mathrm{Ca}\left(1-\chi_{\mathrm{c}}\right) 1.6$ (Ehleringer et al., 1993, Soh et al, 2019, Lavergne et al., 2019)."

4. Throughout, the manuscript is not consistent about what data comes from growth chambers and what data is derived from the geologic record. These may not be compatible and be aware of the possible caveats of comparing across these different timescales. For example, see lines $104-106$. All studies cited here are growth chamber studies, not geological studies, as stated in text. Growth chamber studies test the plant's short-term plasticity and not necessarily its evolutionary capacity to evolves over many plant lifespans and should be used with some amount of caution when directly comparing results to geologic records. See:

* Reichgelt, T., D'Andrea, W. J., \& Fox, B. R. (2016). Abrupt plant physiological changes in southern New Zealand at the termination of the Mi-1 event reflect shifts in hydroclimate and pCO2. Earth and Planetary Science Letters, 455, 115-124.

${ }^{*}$ Reich, P. B., Hobbie, S. E., Lee, T. D., \& Pastore, M. A. (2018). Unexpected reversal of C3 versus C4 grass response to elevated CO2 during a 20-year field experiment. Science, 360(6386), 317-320"

We have edited the manuscript throughout to draw attention to the distinction between the training dataset $\left(20^{\text {th }}\right.$ century leaves and tree rings), and the testing dataset (all other data, including chambers and geological data). We decided to separate them for the fairly simple reason that modern data are thought to be less sensitive to diagenesis (and other effects) than geological data. 
We thank the Reviewer for these references, we were aware of them. We have now included Reich et al. (2018) in our caution about change over evolutionary scales and plant lifetimes (Line 466). It is indeed possible that growth chamber studies might partially reflect short-term plasticity. This is partly why we included these data in the "testing" dataset, instead of the "training" dataset (see comments above).

The interpretation of Reichgelt et al (2016) rests on the assumption of negligible relationships between $C_{a}$ and $\Delta^{13} C$, based on earlier studies, i.e. Diefendorf et al. (2015) and Kohn (2016) (Section 4.2 of that paper). However, recent and emerging studies suggest otherwise. Based on a compilation of higher resolution data over the deglaciation, the more recent papers of Hare et al. (2018) and Schlanser et al. (2020b) highlight the significant relationship between $\mathrm{Ca}$ and $\Delta^{13} \mathrm{C}$, after accounting for hydrological changes (a relationship is also expected on theoretical grounds, following from the full $\Delta^{13} \mathrm{C}$ theory, including photorespiration terms - see Schubert and Jahren (2018)). Considering this, Reichgelt et al (2016)'s interpretation that secular trends in $\Delta 13 C$ imply changes in carbon assimilation might not be the most appropriate example of plasticity on longer timescales.

\section{Minor Comments}

Abstract: Does "first principles theory" imply basic proposition or assumption that cannot be deduced from any other proposition or assumption? If so, the relationship between Dleaf, pCO2, temperature, and vapor pressure, etc., are still debated and vary based on timescales and phylogeny, etc. Therefore, the statement "according to first-principles theory..." in the abstract seems like an unnecessary overstatement and detracts away from the objectives of this study and the model that is being proposed here. The terminology 'first principles theory' should be omitted throughout the manuscript.

We do not use "first principles" in the sense of Philosophy, which according to Wikipedia: "is a law or assumption that cannot be deduced from any other assumption". We use "first principles" here in the conventional scientific sense: to imply that it is deduced from the physics and biochemistry of isotope fractionation. Wikipedia (same page) also state that:

"in physics and other sciences, theoretical work is said to be from first principles, or ab initio, if it starts directly at the level of established science and does not make assumptions such as empirical model and parameter fitting."

The full model of $\Delta^{13} \mathrm{C}$ was derived $a b$ initio (from theory), as also stated in Wikipedia: (https://en.wikipedia.org/wiki/Fractionation of carbon isotopes in oxygenic photosynthesis) So too are the values of $a_{\mathrm{b}}, a_{\mathrm{s}}, a_{\mathrm{m}}$, and $f$, as well as the model for $\chi_{\mathrm{c}}$.

Therefore, we do not share the reviewer's view that it is an overstatement to call this a first principles approach (or $a b$ initio). As mentioned in the manuscript, the full model is almost never used in the geological literature because it is un-tractable. But the model potentially contains several important terms which are expected to be relevant to paleo-data. We placed this approach at the heart of this paper, calibrating the $a b$ initio model with the modern dataset, because we believe it will help to bridge several knowledge gaps between geological and modern eco-physiological studies. However, we do appreciate the reviewer's frustration that the terms "theory", and "model" were sometimes used interchangeably. Therefore, we have tightened up the language, where possible, with respect to "model" vs "theory", and included "comprehensive $a b$ initio model of discrimination" instead of 'first-principles theory', where appropriate, to avoid any potential ambiguity in meaning, e.g. in our Abstract we now write:

"Here, we combine a comprehensive ab initio model of discrimination, with a recent model of plant eco-physiology based on least-cost optimality theory, to show how differences between angiosperm and gymnosperm $\Delta^{13}$ C arise."

Line 41: This is not correct. See: "Sheldon, N. D., Smith, S. Y., Stein, R., \& Ng, M. (2020). Carbon isotope ecology of gymnosperms and implications for paleoclimatic and paleoecological studies. Global and Planetary Change, 184, 103060." 
We have now amended this for greater clarity, and included this reference, and Schlanser et al (2020) in the paragraph:

Lines 41-45 "In geological contexts, it is generally assumed that isotope discrimination in $C_{3}$ plants is independent of phylogeny. This implies that the offset in $\triangle 13 C$ between angiosperms and gymnosperms is more or less constant over time. As a result, offsets of 2-3 per mil between ancient tissues from each plant group are sometimes regarded as indicators of fossil integrity, i.e. resistance to diagenesis (Diefendorf et al., 2015, Schlanser et al., 2020).

However, emerging evidence suggests that isotope discrimination might vary between different C3 plant groups (Sheldon et al., 2020), and substantial changes in the difference ..."

Lines 45-47: There is a more recent paper looking at terpenoids derived from angiosperms and gymnosperms in the geologic record. See "Schlanser, K. M., Diefendorf, A. F., West, C. K., Greenwood, D. R., Basinger, J. F., Meyer, H. W., ... \& Naake, H. H. (2020). Conifers are a major source of sedimentary leaf wax n-alkanes when dominant in the landscape: Case studies from the Paleogene. Organic Geochemistry, 147, 104069."

We thank the reviewer for this excellent suggestion - since it has only very recently been published, we did not have the chance to read it thoroughly before submitting this paper. We have now included the dataset provided by this study in the new Figure 5.

51-52: This statement may be seen as somewhat misleading. Schouten et al., 2007 does explore the differences between angiosperm and gymnosperms d13C values, citing differences in the ci/ca ratio, which is negatively related to WUE. This study suggests WUE for angiosperms decreased relative to conifers, see Eq 2.

Please see our comment above regarding WUE. We do not see changes in WUE as inconsistent with our framework. The purpose of this paragraph was to introduce the concept of changes in the offset of $\triangle 13 \mathrm{C}$ in the geological record, and the current uncertainties regarding their drivers (eco-physiological, environmental and climatic). Both eco-physiological (via changes in ci/ca ratio or WUE) and climatic ([O2]/[CO2]) drivers have an effect, and we have tried to make this clearer in the revised manuscript. We have added the following lines:

Lines 49-51: "Some of these changes have been explained by differences in plant water-use efficiency (WUE), i.e. the ratio of carbon uptake to water transpired, which is intrinsically coupled to leaf-level discrimination (Soh et al. 2019, Lavergne et al., 2019). On the other hand, they could also be explained by..."

53-59: This paragraph is extremely vague for framing the rest of the manuscript. Using what dataset? Modern, geological, growth chamber, natural environment? Regional, global? Remove first principles. Just state what the three factors are (line 56). What is meant by framework, a model? How is it novel? Briefly explain how it is novel, not just that it is unique.

We disagree with the reviewer that this paragraph is extremely vague. But we have tried to make it clearer.

60: What is meant by secular?

We use the word secular in the standard geophysical sense, i.e., time-varying. We see no issue with this.

65: Still unclear what the approach is and what is meant by paleo(climate) sensitivity?

We are unsure of what was unclear about paleo(climate) sensitivity, as this is a fairly standard concept in the literature, but we have restructured this section a bit to highlight its relevance for the paper.

Theory: For a manuscript such as this with so many abbreviated variables, would it be helpful to compile into table?

With our first submission we presented an extensive table of abbreviated variables in the Electronic Annexure, which we mentioned in the text. We have now included this in the main text, to be retained at the discretion of the Editor. 
Fixed.

105: Schubert and Jahren 2018, date not correct in text

Thank you very much. We have now fixed this.

164: Where is this cut off value from? Citation needed. Often cited is Kohn 2010, who use a cutoff of 31.5 per mil. see "Kohn, M. J. (2010). Carbon isotope compositions of terrestrial C3 plants as indicators of (paleo) ecology and (paleo) climate. Proceedings of the National Academy of Sciences, 107(46), 19691-19695."

The Kohn (2010) compilation presented 570 data (both angiosperms and gymnosperms) from $1970 \mathrm{CE}$ onwards $(>80 \%$ postdating the 1990 s) when $\delta 13 \mathrm{CO} 2$ was -7.32 per mil, whereas our compilation comprised $>7000$ data from as early as $1901 \mathrm{CE}$, when $\delta 13 \mathrm{CO} 2$ was $\mathbf{- 6 . 7 3}$ per mil. Due to the Suess effect, the $\delta 13 C O 2$ values in 1901 is 1.1 per mil higher than the 1990 values (i.e., $\mathbf{- 7 . 8 6}$ per mil). So the Kohn values would imply a cutoff of around $\mathbf{- 3 0 . 4}$ per mil for our older sites. Most of our record is derived from tree ring data pre-1990, therefore we do not see the Kohn cutoff as incompatible with our nominal level of $\mathbf{- 3 0 . 0}$ permil and therefore have retained it. Note that in Lavergne et al. (2020), we used a cutoff threshold of $\mathrm{c}_{\mathrm{i}} / \mathrm{c}_{\mathrm{a}}\left(\chi_{\mathrm{c}}\right)=\mathbf{0 . 9 5}$, implying $\delta 13 C$ values $<-29$ per mil under a $340 \mathrm{ppm}$ atmosphere. Therefore, in this study we chose -30 per mil as a compromise. When we apply a cutoff of $\mathbf{- 3 1 . 5}$ per mil to our dataset it results in the inclusion of only 230 more datapoints (all angiosperms), which has a marginal effect on our parameter estimation using the MCMC (e.g. $\beta_{\mathrm{c}}=209.79 \mathrm{vs} 209.53, \mathrm{~g}_{\mathrm{m}} / \mathrm{g}_{\mathrm{s}}=2.55 \mathrm{vs} 2.53, \lambda \lambda_{\text {ref }}=$ 5.2 vs 4.4), and does not change any of our conclusions. For consistency, we have therefore decided to retain the cutoff of $\mathbf{- 3 0}$ per mil, and inserted the following into the methods:

Line 177-178 "(i.e. we adjusted the Kohn (2010) cutoff value of $-31.5 \%$ by $\sim 1.1 \%$ o to account for the Suess effect)"

230: Is <DELTA>leaf decreasing strongly with increasing or decreasing pCO2? Unclear here. We have added "lower [CO2]" to both instances.

291-292: Delete, unnecessary.

This part has been removed, to make way for more discussion of Figure 4 (see above).

319: Clarify that these studies are geologic studies. Also, Schlanser et al., 2020 also measured the offset of co-located angiosperm and gymnosperm through the early Cenozoic, and generally finds a fairly constant 2 to 3 mil offset.

We have included the reference of Schlanser et al. (2020). Interestingly, the modern terpenoid data of Schlanser show a reversal of the $\Delta *$ a-g trend, in agreement with our predictions (see comment above).

327-330: Precipitation was also very high during this time, and D would have been high in the Arctic during this time. How does this affect your results? A recent study just came out showing that Dleaf varies across two different regions in China during the PETM and is attributed to differences in precipitation. See: Chen, Z., Dong, X., Wang, X., Tang, Z., Yang, S., Zhu, M., \& Ding, Z. (2020). Spatial change of precipitation in response to the Paleocene-Eocene thermal Maximum warming in China. Global and Planetary Change, 103313.

Thank you for drawing our attention to this very recent publication - and an interesting finding. We do not see it as incompatible; on the contrary, the effect of $D$ on $\Delta^{13} C$ is expected to show strong regional variation, at any given atmospheric composition.

354 - 357: Unless this is referring to leaf scraping techniques, oftentimes fossil plant materials are derived from sediment and represent some amount of time and community averaging. For example, most of the geologic plant biomarkers used in this study (Diefendorf, Shouten) are derived from sediment, specifically terpenoids, and represent a community averages, not individual leaves. Are averaged individuals from a single fossil bearing zone versus community averaged sediment directly comparable?

We assume that they are comparable, after correction for lipid post-photosynthetic fractionation. 
Likewise, this part has been removed, to make way for the new discussion. However, please note our comments above regarding uncertainties in $\mathrm{O}_{2}$.

389-393: Calling the model in this manuscript a theory may be a stretch?

We see the reviewer's point, regarding the linear approximation model (epsilon_f, and epsilon_ab). We have now been more consistent throughout the revised manuscript (but please see our comments above regarding the model derived ab initio - which was one of the key aspects of the paper).

398-401: Is diagenesis discussed anywhere else in the manuscript?

Yes, at several places (Lines 44, 51-52, 488). And it is implicitly behind our choice of training dataset.

Line 44 "regarded as indications offossil integrity, i.e. resistance to diagenesis (Diefendorf et al. , 2015 ; Schlanser et al. , 2020a)"

Lines 51-52 "On the other hand, they could also be explained by diagenesis, or variability in post-photosynthetic fractionations, particularly in the case of plant lipids (Diefendorf et al. , 2019)."

Line 48 "if diagenesis can be ruled out, and D levels can be independently constrained."

518: Fix citation, I think there is another author on this study.

Indeed there is, thank you. We have now fixed this.

540: Fix citation, wrong year.

Thank you. We have now fixed this.

\section{References}

Ehleringer, J. R., Hall, A. E., \& Farquhar, G. D. (1993). Water use in relation to productivity. In J. R. Ehleringer, A. Hall, \& G. D. Farquhar (Eds.), Stable isotopes and plant carbon-water relations (pp. 155172). San Diego, CA: Academic Press Inc.

Foster, G.L., Royer, D.L. and Lunt, D.J., 2017. Future climate forcing potentially without precedent in the last 420 million years. Nature Communications, 8, p.14845.

Gehler, A., Gingerich, P.D. and Pack, A., 2016. Temperature and atmospheric CO2 concentration estimates through the PETM using triple oxygen isotope analysis of mammalian bioapatite. Proceedings of the National Academy of Sciences, 113(28), pp.7739-7744.

Helliker, B.R. and Richter, S.L., 2008. Subtropical to boreal convergence of tree-leaf temperatures. Nature, 454(7203), pp.511-514.

Lavergne, A., Sandoval, D., Hare, V.J., Graven, H. and Prentice, I.C. (2020) Impacts of soil water stress on the stomatal limitation of photosynthesis: insights from stable carbon isotope data, Global Change Biology 26, 7158-7172, doi:10.1111/gcb.15364

Schlanser, K., Diefendorf, A.F., Greenwood, D.R., Mueller, K.E., West, C.K., Lowe, A.J., Basinger, J.F., Currano, E.D., Flynn, A.G., Fricke, H.C. and Geng, J., 2020b. On geologic timescales, plant carbon isotope fractionation responds to precipitation similarly to modern plants and has a small negative correlation with pCO2. Geochimica et Cosmochimica Acta, 270, pp.264-281. 